\title{
Analysis of Haul Truck- Related Fatalities and Injuries in Surface Coal Mining in West Virginia
}

Meng Zhang

Follow this and additional works at: https://researchrepository.wvu.edu/etd

\section{Recommended Citation}

Zhang, Meng, "Analysis of Haul Truck- Related Fatalities and Injuries in Surface Coal Mining in West Virginia" (2014). Graduate Theses, Dissertations, and Problem Reports. 7031.

https://researchrepository.wvu.edu/etd/7031

This Thesis is protected by copyright and/or related rights. It has been brought to you by the The Research Repository @ WVU with permission from the rights-holder(s). You are free to use this Thesis in any way that is permitted by the copyright and related rights legislation that applies to your use. For other uses you must obtain permission from the rights-holder(s) directly, unless additional rights are indicated by a Creative Commons license in the record and/ or on the work itself. This Thesis has been accepted for inclusion in WVU Graduate Theses, Dissertations, and Problem Reports collection by an authorized administrator of The Research Repository @ WVU. For more information, please contact researchrepository@mail.wvu.edu. 
Analysis of Haul Truck- Related Fatalities and Injuries in Surface Coal Mining in West Virginia

Meng Zhang

Thesis submitted to the

Benjamin M. Statler College of Engineering and Mineral Resources

at West Virginia University

in partial fulfillment of the requirements for the degree of

\author{
Master of Science \\ In \\ Mining Engineering \\ Vladislav Kecojevic, Ph.D., Chair \\ Christopher J. Bise, Ph.D. \\ Aaron Noble, Ph.D. \\ Department of Mining Engineering \\ Morgantown, West Virginia \\ 2014
}

Keywords: haul truck; fatalities; root causes; Fault Tree Analysis; intervention strategies.

Copyright 2014 Meng Zhang 


\title{
ABSTRACT \\ Analysis of Haul Truck- Related Fatalities and Injuries in Surface Coal Mining in West Virginia
}

\begin{abstract}
Meng Zhang
Trucks are the primary means of haulage in surface coal, metal, and nonmetal mining operations. The number of fatal accidents involving trucks is higher when compared to all other mining equipment. The Mine Safety and Health Administration (MSHA) reports that 137 fatalities were haul truck- related in the United States between 1995 and 2011. A total of 12 truck-related accidents, including 13 fatalities, were recorded in surface coal mining operations in West Virginia (WV) during this period. The objectives of this research were to (i) analyze the root causes of these accidents, and (ii) develop effective intervention strategies to eliminate these fatalities. The Fault Tree Analysis (FTA) technique was used to systematically analyze truck related fatalities. Data on truck-related injury accidents in West Virginia surface coal mines during 2012 and 2013 were also analyzed in this study. Results of the study indicate that inadequate or improper pre-operational check and poor maintenance of trucks were the two most common root causes of these accidents. A total of eight accidents occurred on haul roads, while 10 accidents occurred while the trucks were moving forward. The two most violated provisions of Code of Federal Regulations were 30 CFR\$77.404 - Machinery and equipment; operation and maintenance (six times), and 30 CFR\$77.1606 - Loading and haulage equipment; inspection and maintenance (five times).
\end{abstract}

A total of 223 reported injuries were recorded at West Virginia surface coal mines. With the exception of two missing data, a total of 178 accidents were equipment-related and 43 accidents occurred without equipment being involved. The equipment categories accounting for the most number of injuries were: truck (57 times) and bulldozer/dozer/crawler tractor (43 times). The majority of the truck-related injuries occurred within the worker's first five years at the mine and within the first five years at their current job title. Workers between ages 25 and 39 had the greatest percentage of injuries. Most injuries were recorded during "Section I" (6:00 a.m. - 2:00 p.m.), and the fall season has the greatest number of truck-related injuries of all four seasons. Regarding the nature of injury, "sprains and strains" made up about 32\%, topping all other types of injuries. The most commonly injured body part in truck-related injuries was the "Multiple parts."

A two-pronged approach to accident prevention was used: one that is fundamental and traditional (safety regulations, training and education, and engineering of the work environment); and one that is innovative and creative (e.g., applying technological advances to better control and eliminate the root causes of accidents). Suggestions for improving current training and education system were proposed, and recommendations were provided on improving the safety of mine working conditions, specifically safety conditions on haul roads, dump sites, and loading areas. Currently available technologies that can help prevent haul truck-related fatal accidents were also discussed. The results of this research may be used by mine personnel to help create safer working conditions and decrease truck-related fatalities and injuries in surface coal mining. 
Analysis of Haul Truck- Related Fatalities and Injuries in Surface Coal Mining In West Virginia

Meng Zhang

Thesis submitted to the

Benjamin M. Statler College of Engineering and Mineral Resources at West Virginia University in partial fulfillment of the requirements for the degree of

Master of Science

In

Mining Engineering

Department of Mining Engineering

APPROVAL OF THE EXAMNING COMMITTEE

Vladislav Kecojevic, Ph.D., Chair

Christopher J. Bise, Ph.D.

Date

Aaron Noble, Ph.D. 


\section{ACKNOWLEDGEMENT}

I would like to express my very great appreciation to my advisor, Dr. Vladislav Kecojevic, for his patient guidance, tremendous support, enthusiastic encouragement and useful critiques in the past two years.

I wish to extend my thanks to my committee members, Dr. Christopher J. Bise and Dr. Aaron Noble, for their valuable time spent for reviewing my humble thesis.

I would like to thank all my colleagues and friends here at WVU for their help and support during the past two years.

I would like to thank my parents, Zhang Wenlin and Zhang Bin; my brother Zhang Huan, for their ceaseless and selfless support and caring, from where I sensed the importance and power of family.

This study was sponsored by the West Virginia Coal and Energy Research Bureau (CERB). The views, opinions and recommendations expressed herein are solely those of the authors and do not imply any endorsement by CERB. Their financial contribution is gratefully acknowledged. 


\section{TABLE OF CONTENTS}

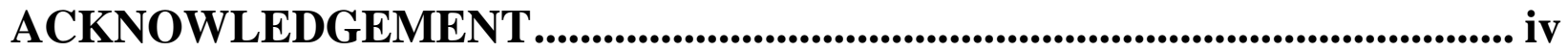

LIST OF TABLES .......................................................................................... vii

LIST OF FIGURES .................................................................................... viii

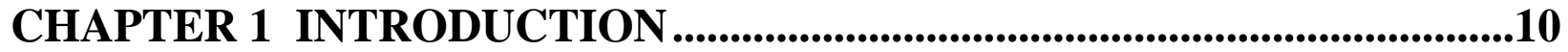

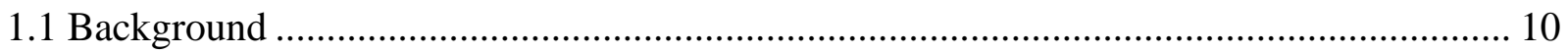

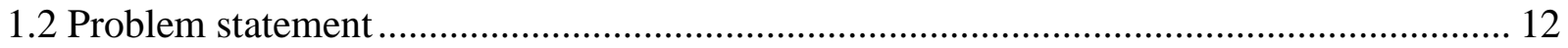

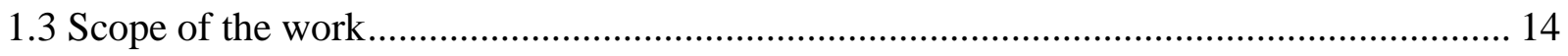

CHAPTER 2 LITERATURE REVIEW ....................................................15

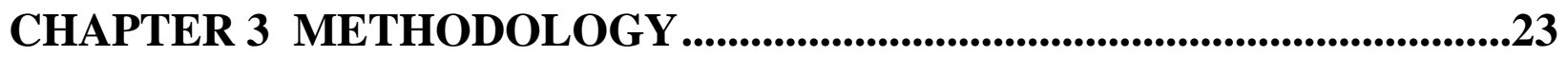

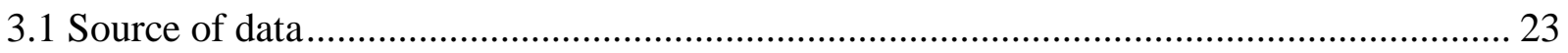

3.2 Analysis of truck-related fatalities by the Fault Tree Analysis (FTA) method................... 23

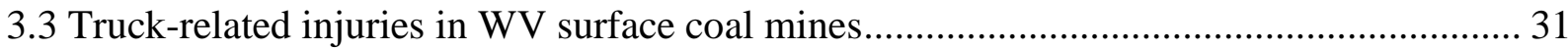

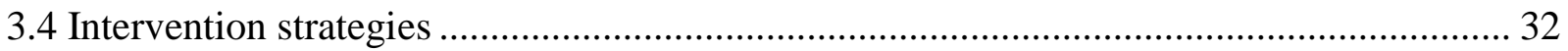

\section{CHAPTER 4 RESULTS AND DISCUSSION ......................................................34}

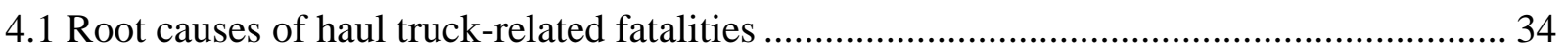

4.2 Analysis of truck-related injuries in WV surface coal mines.............................................. 51

4.3 Intervention strategies for haul truck-related fatal accidents ............................................. 60 


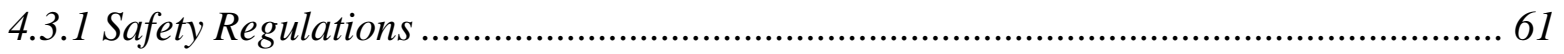

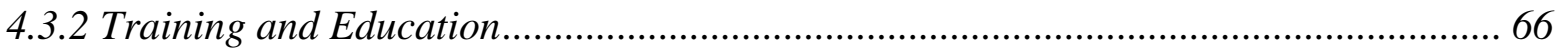

4.3.3 Conditions of Haul Trucks Working Environment ................................................. 77

4.3.4 Truck-related Safety Technologies ...................................................................... 92

\section{CHAPTER 5 CONCLUSIONS AND RECOMMENDATIONS FOR}

FUTURE RESEARCH ...........................................................................98

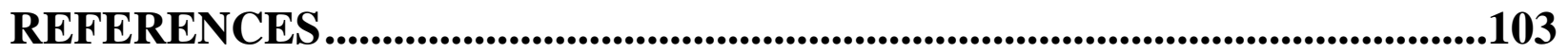

APPENDIX A 


\section{LIST OF TABLES}

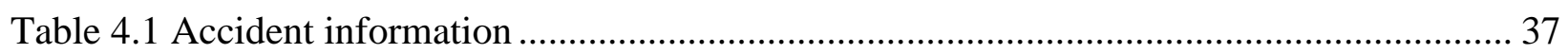

Table 4.2 Calculation and results of minimal cut sets ...................................................... 43

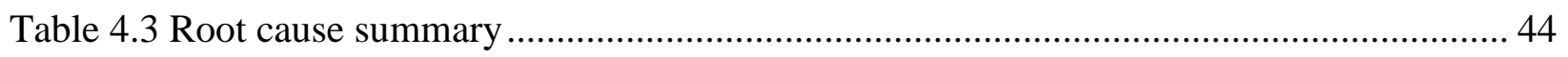

Table 4.4 Conclusion of Accident \#1, \#2, \#3, \#4 ............................................................... 45

Table 4.5 Summary of data corresponding to use of seat belt ........................................... 46

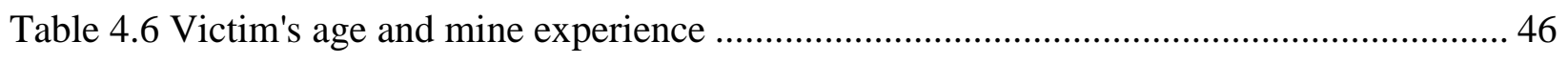

Table 4.7 Distribution of accidents by location of accident ........................................... 47

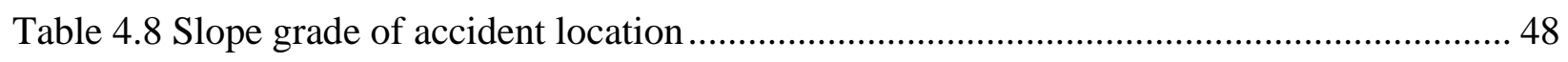

Table 4.9 Distribution of accidents by truck activity .................................................. 48

Table 4.10 Weather conditions and characteristics of haul roads, dump site, and access road... 49

Table 4.11 Violations of Federal Code of Regulations..................................................... 50

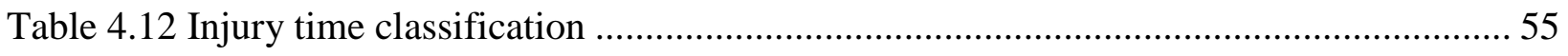

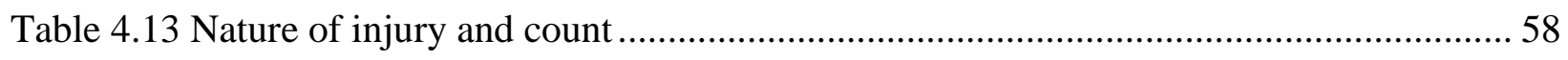

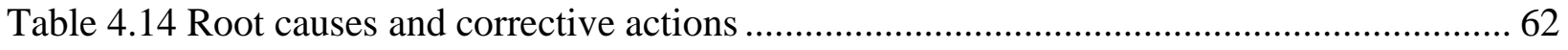

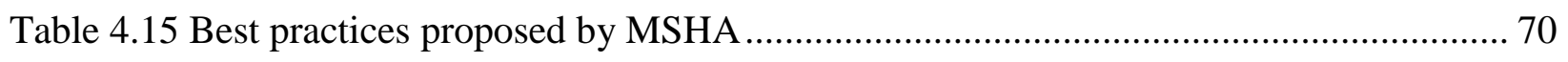

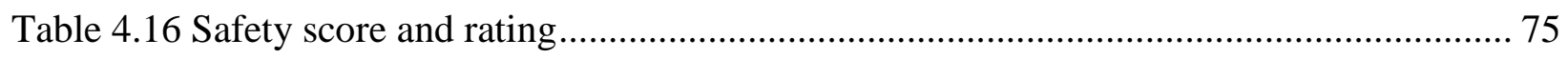

Table 4.17 Truck's stopping distance (ft) when the slope grade is 10\% (MSHA, 1999)........... 83 


\section{LIST OF FIGURES}

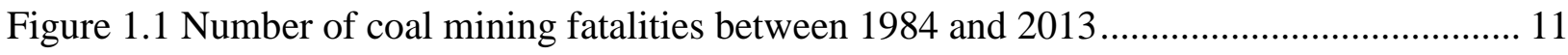

Figure 1.2 Total numbers of coal mining fatalities and equipment-related fatalities between 1995

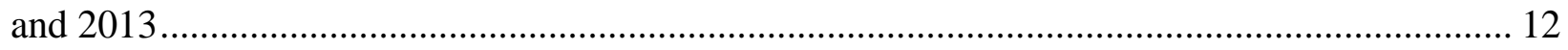

Figure 2.1 Initial patterns for haul truck accidents (Drury et al, 2012) .................................... 18

Figure 3.1 Inductive and deductive analysis model (Vesely et al, 2002) ................................ 24

Figure 3.2 Main Symbols used in Fault Tree........................................................................ 28

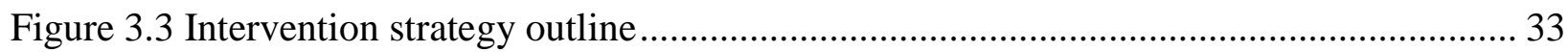

Figure 4.1 Haul truck-related fatal accidents in surface coal mining in West Virginia (source of

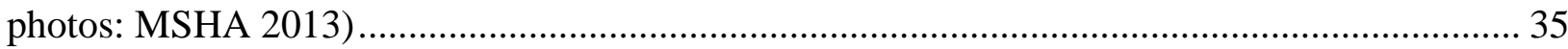

Figure 4.2 Distribution of haul truck-related fatal accidents between 1995 and 2011 .............. 36

Figure 4.3 Fault Tree \#1 for Accident \#5 ........................................................................... 38

Figure 4.4 Fault Tree \#2 for Accident \#6 ....................................................................... 38

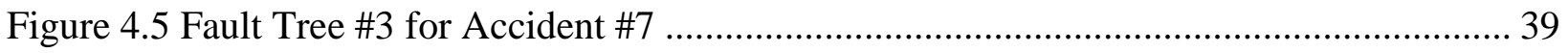

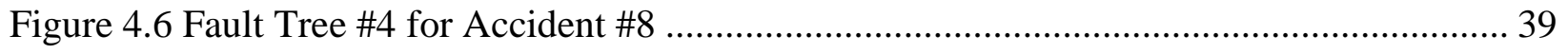

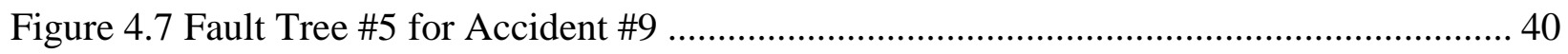

Figure 4.8 Fault Tree \#6 for Accident \#10 .................................................................... 41

Figure 4.9 Fault Tree \#7 for Accident \#11 .................................................................... 42

Figure 4.10 Fault Tree \#8 for Accident \#12 …...................................................................... 42

Figure 4.11 Surface mining injury categories and frequency …...................................... 52

Figure 4.12 Distribution of injuries by mining equipment involved ................................... 52

Figure 4.13 Distribution of injuries by age categories.................................................... 53 
Figure 4.14 The relationship between truck-related injury frequency and years at current job title

Figure 4.15 The relationship between truck-related injury frequency and years at current mine 55

Figure 4.16 Distribution of truck-related injuries by injury time ...................................... 56

Figure 4.17 Distribution of injury frequency by day of the week ...................................... 57

Figure 4.18 Distribution of truck-related injuries by seasons .......................................... 58

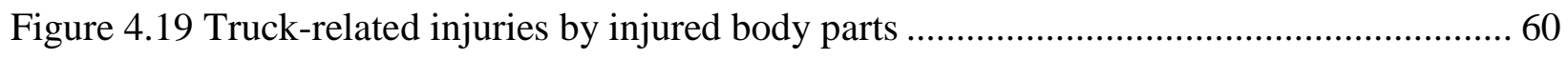

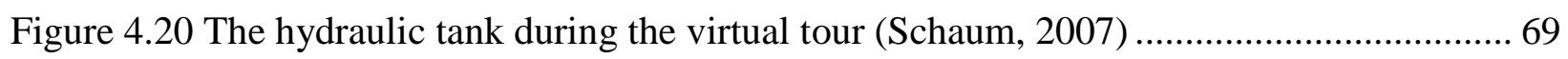

Figure 4.21 Steep grade slope warning sign (MSHA, 2004) .............................................. 79

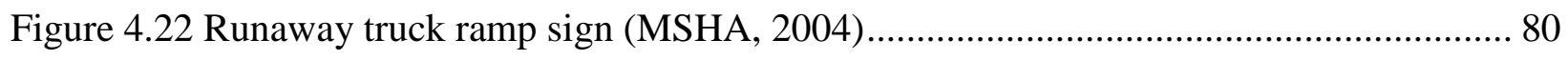

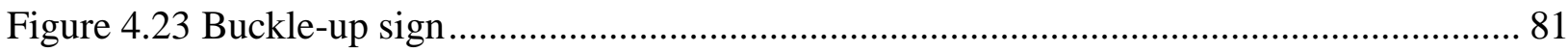

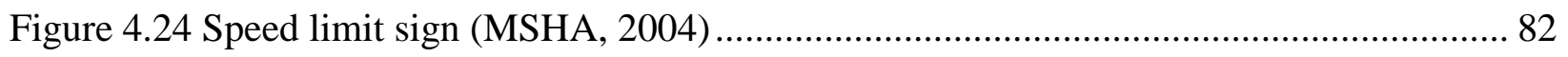

Figure 4.25 Relationship between truck speed and slope grade (MSHA, 1999) ...................... 84

Figure 4.26 Recommended minimum road width (Holman, 2006) ..................................... 86

Figure 4.27 Safety berms along haul road and dump area (MSHA, 2014) ............................ 90

Figure 4.28 Minimum safety berm height (Holman, 2006).............................................. 91 


\section{CHAPTER 1}

\section{INTRODUCTION}

\subsection{Background}

The mining industry is a vital economic sector for many countries including the U.S. and comprises the utilization of coal, metal, and nonmetal minerals. According to the Mine Safety and Health Administration (MSHA 2014), there were 12,060 metal/nonmetal mines, 1,701 surface and underground coal mines in the U.S. in 2013. Almost 375,000 miners were engaged in mining operations in every aspect of mining operations, including production, preparation, processing, development, maintenance, repair and shop or yard work.

Mining has been one of the hazardous industries with injuries and deaths reported every year. The deadliest year in the U.S. coal mining history was 1907, when 3,242 fatalities occurred. The annual coal mining fatalities decreased to from 451 in the 1950 s to 141 in the 1970s (MSHA, 2014).

Figure 1.1 presents the trend of number of coal mining fatalities over the past 30 years. It can be noted that the total number of fatalities trended downward during the past 30 years, from 1984 to 2013.

In spite of the fact that there are a decreasing number of fatal accidents, the proportion of these accidents involving mine equipment has consistently been significant (Kecojevic et al, 2007, Ruff, 2011). According to MSHA records (2014), the highest number of fatalities in U.S. mining is 
attributed to the general category of Equipment which can be further classified to subcategories including: belt conveyors, haul trucks, front-end loaders, continuous miners, longwalls, doers, drills, forklifts, shuttle cars, hoisting equipment, load-haul-dump (LHD), roof bolters, and miscellaneous equipment (shovel, crane/dredge, tractor, scraper, bucket truck ,bunker car, locomotive, water truck, dragline, crusher, various types of cranes (Md- Nor, 2008).

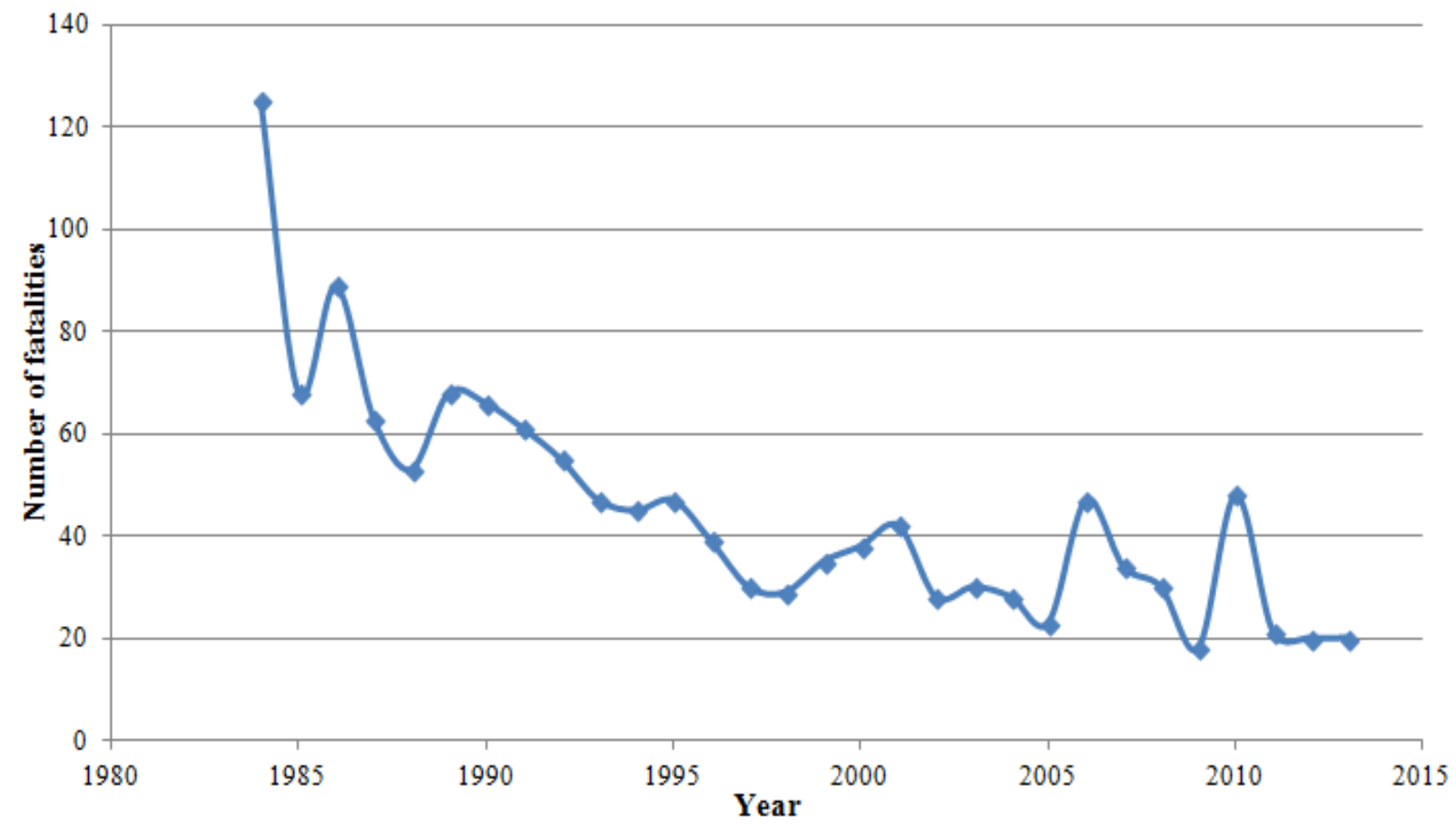

Figure 1.1 Number of coal mining fatalities between 1984 and 2013

Figure 1.2 shows a comparison of total number of equipment-related fatalities against total number of coal mining fatalities between 1995 and 2013. It is clear that equipment-related fatalities still account for a significant proportion of the total number of coal mining fatalities regardless of the improvement that has been achieved in reducing the number of these fatalities. 


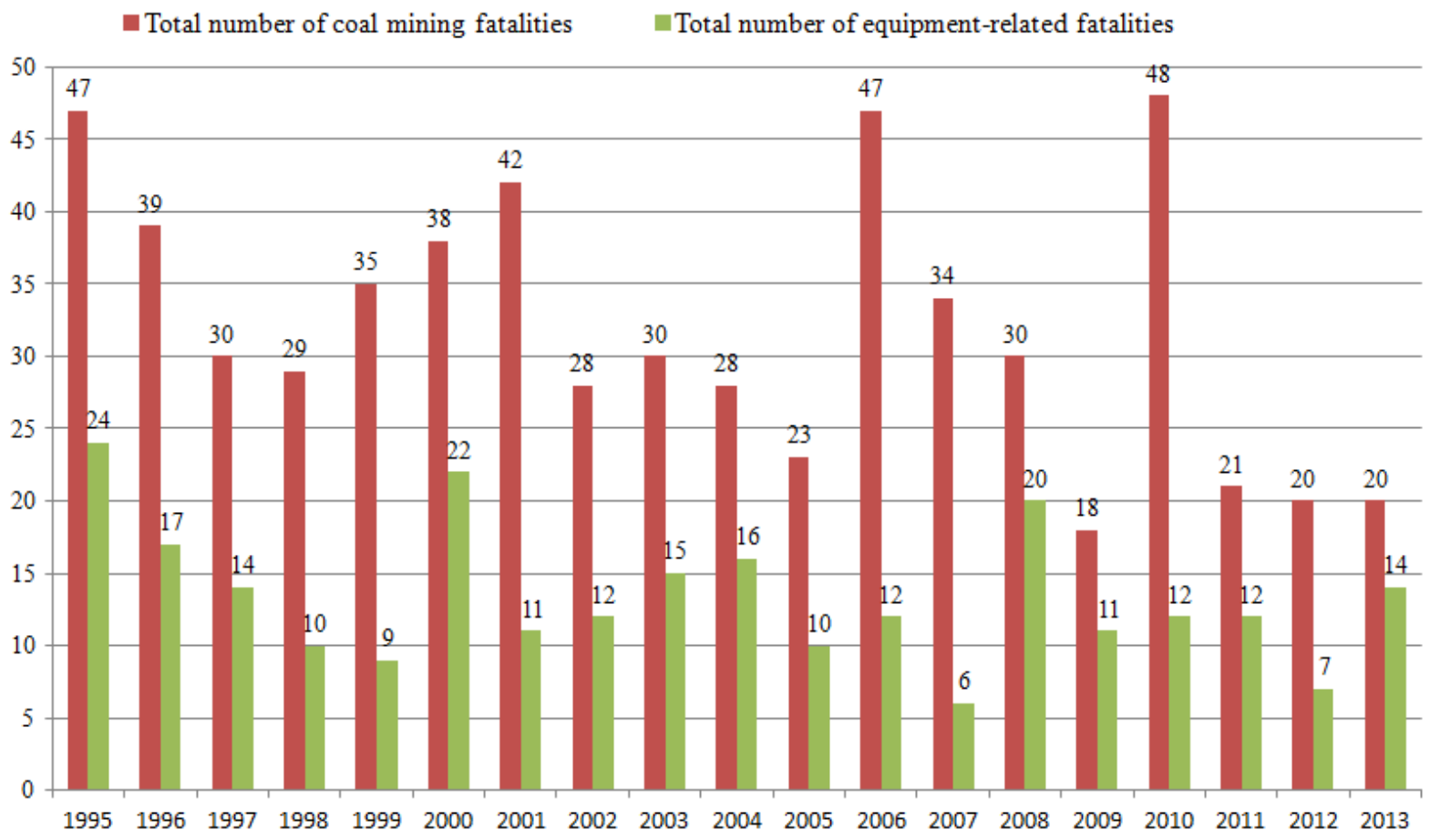

Figure 1.2 Total numbers of coal mining fatalities and equipment-related fatalities between 1995 and 2013

According to Mine Safety and Health Administration records (MSHA, 2013), there were 643 mining fatalities in the United States between 1995 and 2011 attributed to the general category of Equipment. A total of 137 fatalities or 21.9 percent were haul truck-related. The highest number (47) of these fatalities occurred in surface coal mining. A total of 12 accidents, resulting in 13 fatalities, were recorded in surface coal mining operations in West Virginia.

\subsection{Problem statement}

There have been several studies analyzing truck-related fatalities (Kecojevic and Radomsky, 2004;

Kecojevic et al, 2007; Ruff et al, 2011). Md-Nor et al. (2008) conducted a risk assessment of truck- 
related fatalities in surface mining in the United States. The hazards were established, and risks were quantified and evaluated.

Kecojevic and Radomsky (2004) proposed that three types of training (i.e. skill training, management training, and motivational training) should be applied in the mining industry. Kecojevic et al (2007) analyzed equipment-related fatal accidents in U.S. mining operations between 1995 and 2005, and recommended that traditional task training be combined with computer-based simulation training and retraining of employees. The same authors also stated that effective monitoring and control of equipment, particularly maintenance, is essential. Ruff et al (2011) discussed machine-related fatalities at U.S. mines from 2000 to 2007, and suggested that improved operator training should continue to be pursued and emphasized in mine safety programs. Ruff et al (2011) also stated that improvements in edge detection and collision warning technology, with an emphasis on combining technologies, may improve safety performance.

Do (2012) suggested that mining companies should consider applying a Normal Accident Theorybased (NAT-based) risk management approach to mine safety as opposed to the "regulatory" approach that is typically practiced in the U.S. mining industry. A NAT-based risk management approach views risk from a system-complexity perspective, and not as independent accident events; while a regulatory approach prescribes ways to mitigate risks through compliance. MdNor et al (2008) performed risk assessment for haul trucks-related fatalities, and suggested that "failure of mechanical/electrical/hydraulic component" should be given highest priority since it was defined as "very high risk." 
Sun et al (2010) presented a conceptual model and framework of Assisted Driving System (ADS) to help improve haul truck-related safety. This system include Google-Earth graphics engine to display roads and objects in close proximity, a truck driver fatigue detection system and an enhanced visibility display that can be used when low visibility is encountered.

Despite the progress that has been achieved in reducing truck-related fatalities and injuries, the number and severity of accidents which occur are still unacceptable. Therefore, there is a need to analyze the root causes of these accidents and propose intervention strategies to eliminate them.

\subsection{Scope of the work}

The specific scope and aims of this research are as follows:

Analyze the root causes of haul truck-related fatal accidents in surface coal mines in West Virginia.

$>$ Examine the relationship of the number of fatalities with truck activities and locations.

Analyze the frequency of violation of 30 CFR (Code of Federal Regulations).

$>$ Analyze the road conditions of accident scenes.

Analyze the truck-related injury accidents happened in West Virginia surface coal mines in 2012 and 2013.

$>$ Propose intervention strategies to eliminate the truck-related fatalities in surface coal mines in West Virginia. 


\section{CHAPTER 2}

\section{LITERATURE REVIEW}

Many attempts have been made to analyze accidents related to mining equipment. The hazards related to equipment in underground coal mines were identified in studies carried out by Krohn et al (1983), Helander and Krohn (1983), Grayson et al. (1992). Special emphasis was placed on analyzing the activities being performed at the time of the injuries and the mechanism by which the injuries occurred. Sanders and Shaw (1989) and Klishis et al. (1993) studied the nature and mechanism of injuries in underground coal mines. Radolph and Boldt (2005) carried out safety analysis of surface haulage accidents, and determined accident causes. Burgess and Steiner (2007) found out the five top priority hazards associated with underground coal mining equipment, as well as potential contributing factors. Research conducted by Zheng and Jiang (2012) focused on surface mining safety and mining equipment safety issues. Armour (2003) conducted research on the effectiveness of current methods to control sprain and strain injuries in the coal industry.

Groves et al (2007) used MSHA and Current Population Survey (CPS) data to examine equipmentrelated injuries over the period 1995 - 2004. Injuries were reviewed to determine which types of mining equipment were most often involved and to identify and characterize trends. It was found that off-road ore haulage was the most common source of fatalities. In addition, younger employees had an elevated risk of injury while workers with more than 55 years had an elevated risk for fatality. A large majority of injuries involved workers with less than 5 years' experience. 
Md-Nor (2008) conducted risk assessment of fatalities related to haul trucks, belt conveyors, frontend loaders, dozers, continuous miner, drilling machines, shuttle cars, and miscellaneous equipment. For haul trucks specifically, a total of 16 hazards were identified and the Hazard Inventory Table was created. Md-Nor (2008) determined that the hazards "Failure of mechanical/electrical/hydraulic components", "Failure of victim to respect equipment working area" and "Failure to provide adequate berm at dump sites or haul roads" fall into the category of "very high" risk.

Wiehagen et al (2001) reported a total of 875 serious injuries related to dozers between 1988 and 1997. A decrease was observed in the number of serious injuries to dozer operators. The reduction in serious injuries was accompanied by a decrease in days lost due to injury. The authors also suggested various ways to reduce the likelihood of dozer-related injuries.

A study was conducted by Komljenovic et al (2007) to analyze mining injuries for a 10-year period between 1995 and 2004. A preliminary risk matrix was developed after analyzing the fatalities, non-fatal days-lost (NFDL) injuries, and no-days-lost (NDL) injuries.

Moore et al (2009) undertook a research to investigate equipment-related mining injuries in the U.S. It was found that the majority of injuries occurred in relation to large trucks, wheel loaders, dozers, and conveyors belts. Another conclusion was that the severity of injury is independent of age. 
Saleh and Cummings (2011) summarized and analyzed safety and accident statistics in the U.S. mining industry. The authors also discussed safety issues regarding technical, organizational, and regulatory aspects in the mining industry. They also recommended control strategies and guiding safety principles that could be used to improve safety performance in mining.

Kecojevic and Radomsky (2004) conducted a study on loader and truck-related fatalities in surface mines. They revealed that accidents involving 'rollovers' from the elevated edge of the pit, waste dump or elevated haul roads were the most common representing $47 \%$ of the total fatalities. Kecojevic and Radomsky (2004) also classified the root cause into nine categories: 1) failure of mechanical components; 2), lack of and/or failure to obey warning signals; 3) failure to maintain adequate berms; 4) failure to recognize adverse geological conditions; 5) inadequate hazard training; 6) inadequate maintenance procedures; 7) failure to respect the truck's working area; 8) failure to set the parking brake; and 9) operator's health condition. The "Failure of mechanical components" was the most common root cause which accounted for $28 \%$ of the haul truck-related fatalities.

Santos et al (2010) made an attempt to profile injuries sustained during haul truck operations, and to identify priorities for further investigation as well as potential injury prevention strategies. Data for a 5-year period (2004 - 2008) from MSHA annual administrative database was sorted and reviewed. The majority of the records for injuries were classified as "struck against moving object". Almost two-thirds of the injuries occurred while the operator was driving (either in forward or backward direction). 
Drury et al (2012) analyzed 40 detailed fatal accident reports for haul truck accidents in an attempt to develop repeating patterns of accidents (Figure 2.1). The initial patterns were refined subsequently and detailed classification for mechanical failure and non-mechanical failure were proposed. Specifically, mechanical failure involved transmission failure, steering failure, multiple failures, door failure and brake failure. Non-mechanical failure consists of speed, hit guardrail/berm or berm not sufficient, failed turn, misuse of brakes, alcohol/drugs, backed over edge/ too close to dump, and overloaded.

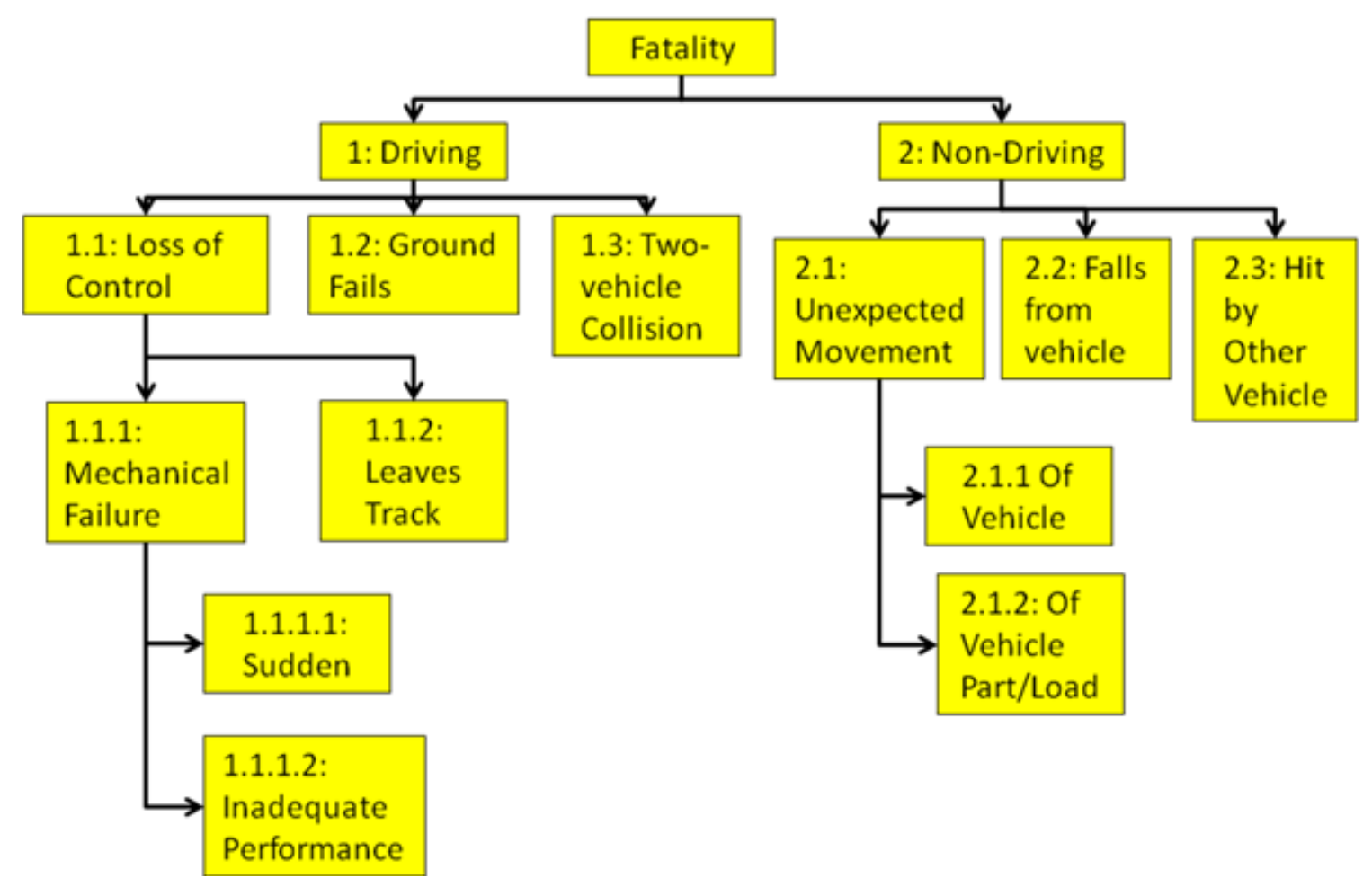

Figure 2.1 Initial patterns for haul truck accidents (Drury et al, 2012)

MSHA (2008) analyzed surface haulage accidents that occurred between January 1990 and July 1996 including haul trucks and other surface mining equipment. It was suggested that continued proper construction and maintenance of road berms are required, and berm maintenance programs which include routine berm inspections and appropriate maintenance should be established. In 
addition, it was proposed that a general industry guideline for construction of ore and waste dumps should be developed. Communications, seat belt use, and exercise of safe work practices were also areas of concern that should be addressed by the mining industry.

Kecojevic and Md-Nor (2009) studied the data from the period 1995 through 2007 to identify major hazards for underground mining equipment-related fatal accidents. The study reveals that the major hazard for continuous mining equipment-related fatal incidents is "Failure of victim to respect equipment working area", while the highest number of fatalities for shuttle car is attributed to the hazard "Failure of mechanical components." Kecojevic and Md-Nor (2009) recommended that constant vigilance regarding the identification and control of mining hazards is the most judicious approach to accident prevention. Compliance with rules and regulations must be complemented with education and training (safety, skills, supervisory, etc.), and specific programs and activities addressing employee hiring and selection, inspections, engineering controls, maintenance, job analysis, group meetings, planned observations, behavioral reinforcement, incident analysis, and investigations.

Ruff et al (2011) studied mining accidents that are involving machinery or equipment in motion. It was found that equipment related accidents accounted for $41 \%$ of all severe accidents in the mining industry during 2000-2007. To decrease these accidents further, they stated that emphasis should be placed on tasks associated with machine maintenance, repair and clean up. Innovative sensors to detect the presence of workers near hazardous components should be studied further. 
MSHA (2004a) stated that common factors in accidents for haul trucks were: steep grades, defective brakes, overloading, and driver error. Keys to prevent truck-related accidents include: systematic preventive maintenance on equipment, effective driver training and supervision, and good haul road layout and road maintenance.

Coleman and Kerkering (2007) analyzed distributions and summary statistics regarding lost workdays of all the injuries reported to MSHA from 1983 to 2004. A beta distribution was used to measure mining safety by analyzing lost workdays as an indicator. The results showed the probability of an injury having 10 or more lost workdays was 0.52 for coal mine cases versus 0.35 for metal/nonmetal mine cases. A comparison of injuries involving continuous mining machines in 2001-2002 versus 2003-2004 showed that there are increased risks for such operations.

Technologies have also been playing a role in enhancing truck operators' safety performance. Goodbody (2013) reported that fatigue is implicated in approximately $69 \%$ of mining accidents involving haul trucks. Understandably, fatigue management has been recognized by mining companies as a critical part of ensuring safe operations. Workers who sleep less than 7-9 hours in a 24-hour period are at high risk of fatigue-related accidents. Monotonous and repetitive activities that provide no or little variance in mental stimulation will leave workers highly susceptible to fatigue. The RIGEL VZ-4000 Laser Scanner was developed by RIEGL (2014), and it has been used for eyesafe scan and data acquisition. Circadian (2014) provides fatigue risk management and predictive modeling solutions for many industries, including mining. Comprehensive fatigue management programs map out the course of activities to provide high safety standards while reducing the cost associated with fatigue-related errors and incidents. The Circadian Alertness 
Simulator (CAS) Driver Fatigue Model generates a fatigue score for every operator every seven days. The score indicates the driver who is most likely to have incidents related to fatigue in the next week. Circadian also offers provides like shift schedule optimization, programs to help shift worker with their health.

The SmartCap is developed by CRC Mining (SmartCap, 2013), and it provides real-time measurements of fatigue for vehicle drivers or operators of heavy equipment. The system includes a baseball cap with sensors in its lining. Brainwave information is measured by using eletroencephalography (EEG) to calculate a measure of drowsiness and the data is transmitted wirelessly to a display in-cab. The SmartCap determines the wearer's level of alertness every second. Confirmed alertness or fatigue information is displayed on a Bluetooth enabled device such as a mobile phone. If the level of fatigue is not identified within any two-minute period, the display lets the operator know that his/her fatigue level is unknown (SmartCap, 2013).

SAFEmine's Safety Center System (SCS) is designed to combine SAFEmine CAS, radar, and cameras into a single interface. The CAS in SCS is used to detect vehicles and plant equipment that are fitted with SAFEmine systems. Radar is used to detect untagged personnel and obstacles, and cameras are able to provide visual awareness for operators (Smith, 2013).

Modular Mining System, Inc. developed the DISPATCH system for fleet management solutions. It offers proximity detection with visual and audible warnings. The SpeedAlert Module in the system continuously measures the GPS velocity of mobile equipment. If operators exceed the limit, 
they are alerted by a message and audible warning on their onboard mobile device, and the dispatcher and foreman can also be notified (Modular Mining, 2014).

Readiband, developed by Fatigue Science (2013), is a wrist-worn device that automatically detects a driver's sleep and wake periods. It is composed of three components: first, it uses actigraphy to measure sleep cycles, measuring wrist motion and then converting the movement data into sleep/wake cycles. Second, the system measures fatigue by using the Sleep, Activity, Fatigue, and Task Effectiveness (SAFTE) model, which was developed and used by U.S. military and validated by the U.S. Department of Transportation. It directly shows the levels of fatigue at any point the person is awake (Goodbody, 2013). 


\section{CHAPTER 3}

\section{METHODOLOGY}

\subsection{Source of data}

Data on truck-related accidents for the period from 1995 through 2011 were obtained from investigation reports, which are publicly accessible from the MSHA web site (MSHA, 2013). A typical report is approximately ten pages long and contains the date of accident, age, and work experience of the victim; a description of the accident; discussion; root cause analysis; conclusions; and enforcement actions. However, four out of 12 investigation reports were incomplete and did not specifically address the root causes of accidents, and they were excluded from the detailed analysis. Based on a review of the MSHA investigation reports, a database containing the following information was developed: ordinal number of the fatality; date of the fatal accident; a short narration of the accident; location and haul truck activity during the accident; and age and mining experience of the victim. Information about "location" and "activity" during the accident was classified according to previous studies by McCann (2006), Burgess (2006), and Md-Nor (2008).

\subsection{Analysis of truck-related fatalities by the Fault Tree Analysis (FTA) method}

System analysis methods could be classified into two categories: inductive methods and deductive methods. Inductive methods involves reasoning from a specific event to a general conclusion, which means inductive methods are applied to identify what the possible outcomes are if certain event happens. Example of inductive system analysis include failure mode and effective analysis 
(FMEA), preliminary hazards analysis (PHA), fault hazard analysis (FHA), double failure matrix (DFM), failure mode effect AND criticality analysis (FMECA), and event tree analysis (ETA). In a deductive system, analysis is carried out in an attempt to find out the root causes resulted in the system failure. In other words, deductive analysis is conducted to determine in what way the system may fail. FTA is an example of deductive methods. The fundamental difference between the two models is inductive models forwardly induce the consequences of an event, whereas deductive models backwardly deduce the cause of an event (Vesely et al, 2002). Figure 3.1 shows the two basic types of system analysis model.
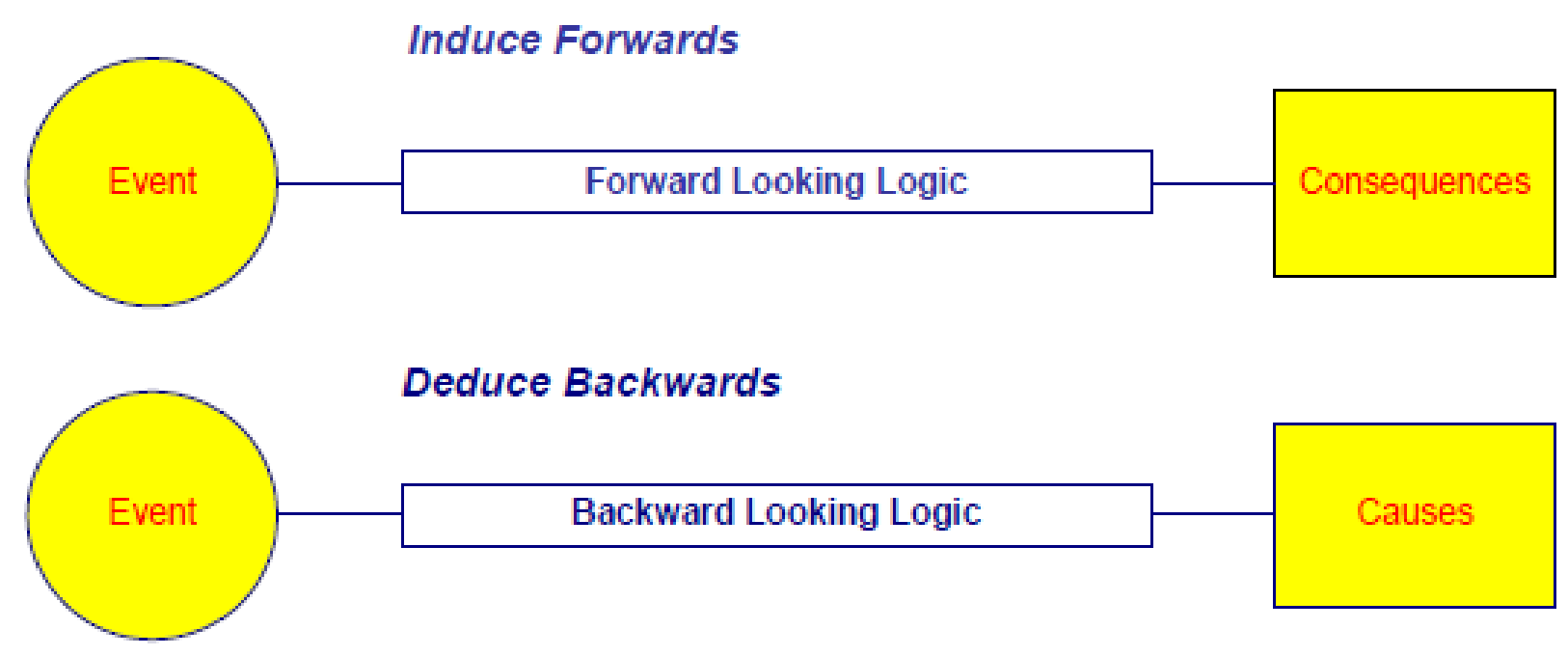

Figure 3.1 Inductive and deductive analysis model (Vesely et al, 2002)

The FTA technique was first developed by $\mathrm{H}$. Watson at bell Telephone Laboratories to facilitate analysis of the launch control system of the intercontinental Minuteman missile (Watson, 1961). It marked the very beginning of the worldwide interest in FTA in 1965 when Boeing Company and the University of Washington sponsored the first System Safety Conference (Ericson, 1999). 
Later FTA was performed after Apollo 1 launch pad fire accident and space shuttle Challenger accident.

FTA was applied in nuclear power industry after Chernobyl disaster in 1986. Following the lead of aerospace industry, the nuclear power industry found the benefits of FTA, and began applying the approach in designing and developing nuclear power plants (Ericson, 1999). FTA now has become one of the most widely used techniques for system reliability and safety studies. (Xing and Amari, 2008). FTA starts to gain its popularity in mining industry as well. Chao (1995) adopted FTA to study spontaneous combustion of sulphide ores. Zhou (2013) made an attempt to analyze the coal mine fires using FTA method. Beamish et al (2010) applied FTA to analyze coal spontaneous combustion. Other industries at risk, such as off-shore (Lavasani et al, 2011; Cooke et al, 2011), chemical (Chang et al, 2002; Dong and Yu, 2005), transportation (Xia et al, 2012), and mining (Iverson et al, 2011; Beamish et al, 2010), construction (Burhan, 2010, Venkatakrishnaiah and Swarna, 2014) have also started to apply this analysis technique in recent years.

Fault Trees can be broadly classified into coherent and non-coherent categories. Coherent Fault Trees do not use inverse gates, that is to say, the inclusion of inversion may lead to a non-coherent fault tree. Coherent trees can be further classified as static or dynamic trees depending on the sequence relationship between the input events (Xing and Amari, 2008). In this study, FTA is referring to Static Fault Trees. 
The FTA involves development of a graphic model of the pathways within a system that can lead to a foreseeable, undesirable loss event, which is referred to as the "Top Event," as it is located at the top of the Fault Tree (FT). It is not a model of all possible causes for system failure, but rather includes those faults that contributed to the undesired "Top Event" (NASA, 2002). The pathways interconnect contributory events and conditions using a set of standard logic symbols. The paths are so defined that all possible events or actions leading to the occurrence of the "Top Event" are sufficiently described. Such definition allows understanding of how accidents occurred, the functional relationships between failures, and identification of cause-and-effect relationships (Joshua and Garber, 1991).

NASA (2002) suggests eight steps to be considered in the FTA:

(i) Identify the objective for the FTA;

(ii) Define the top event of the FT;

(iii) Define the scope of the FTA;

(iv) Define the resolution of the FTA;

(v) Define ground rules for the FTA;

(vi) Construct the FT;

(vii) Evaluate the FT;

(viii) Interpret and present the results.

The first step in conducting FTA is to define the objective. In this study, FTA was carried out with the objective of analyzing the root causes of the accidents. 
In the second step, the top event needs to be defined. This study considered the haul truck-related accidents, so all the top events for all constructed FT were defined as "fatal accidents."

In the third step, the scope of FTA should be defined. According to NASA (2002), the scope of FTA should indicate which of the failures and contributors will be included and which will not. In this study, the failures to be analyzed were generated from MSHA investigation reports and included, for example, brake failure, communication failure, failure to control the truck, failure to wear seat belt, etc.

In the fourth step, the resolution of FTA needs to be defined. The resolution represents the level of detail to which the basic event causes of the top event will be developed. In this study, all the basic events of FT were grounded on the root cause analysis in MSHA investigation reports.

The fifth step involves the definition of ground rules for the FTA. Generally, the ground rules include nomenclature by which the events are named in the FT. In order to make clear what exactly happened, names of the events are fairly verbose and similar to those words stated in the MSHA investigation reports.

In the sixth step, the actual construction of FT is conducted. The main symbols of events and logic gates that are used in the FT to represent the relationship between events are shown in Figure 3.2. 


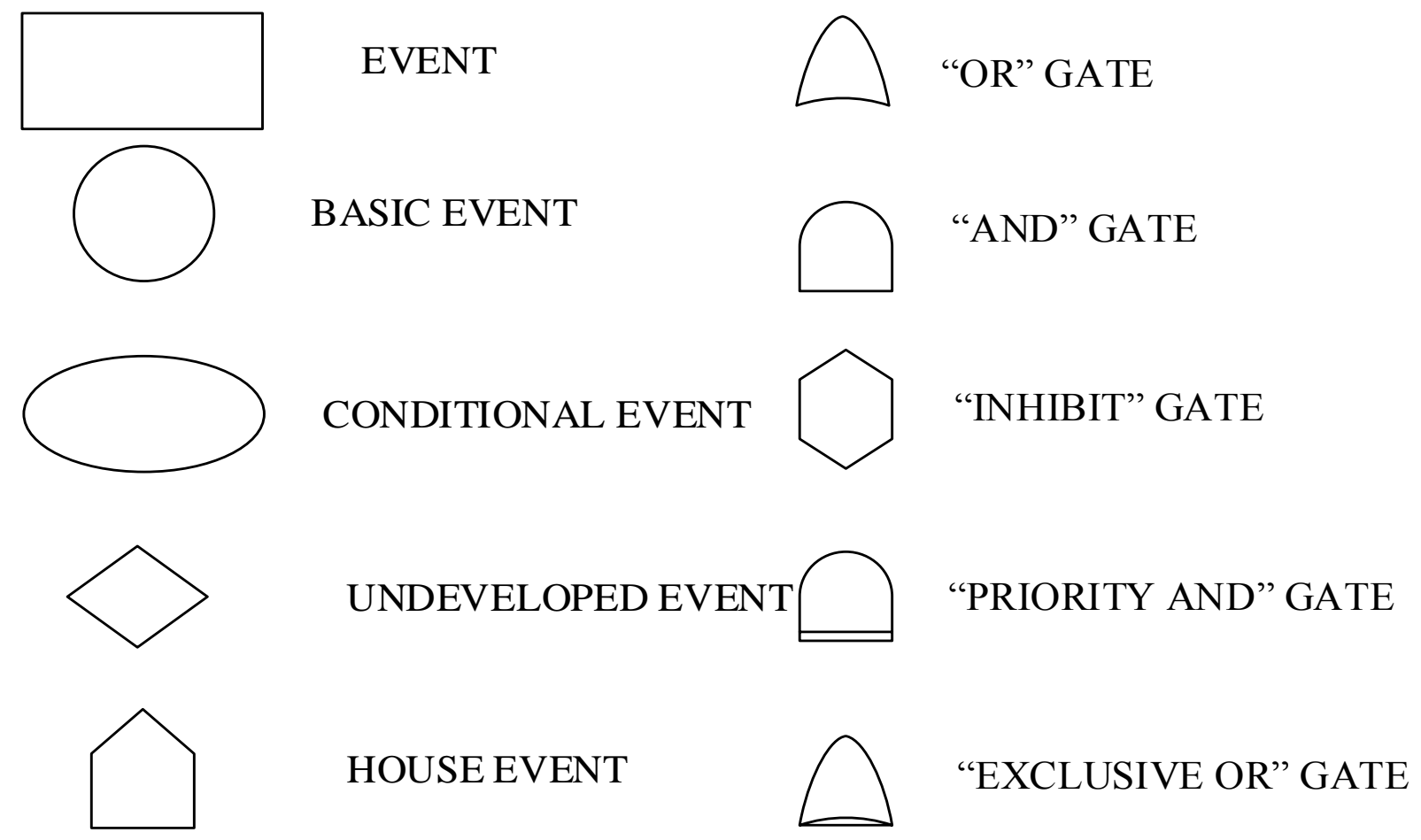

Figure 3.2 Main Symbols used in Fault Tree

In the FTA, the event symbol, signified by a rectangle, can be either top event or intermediate event. Top event is an undesirable event, toward which all the paths flow. In this study, all the top events are defined as "fatal accident." Intermediate event is the output event of its upper level event and the input event of its lower level event, i.e., intermediate event is the result of its lower level event and the reason for its upper level event. Basic event is a basic initiating fault requiring no further development. Root causes stated in every investigation report were applied as basic events in this study. Conditional event is an indispensable event which, in some cases, causes the top event, and it will be discussed along with "INHIBIT" gate. The undeveloped event, which is represented by a diamond, is a fault event that is not further developed, either because the event is 
of insufficient consequence or the related information is not available. The house event is the event that is expected to occur, such as a phase change in a dynamic system.

Logic gates are used to show the relationship between the lower level event and the upper level event. Specifically, "OR" gate is used to depict the occurrence of output fault if at least one of the input faults occurs. Any input must be (1) necessary and (2) sufficient to cause the output. The "AND" gate describes the situation when an output fault occurs if all the input faults occur, therefore, all inputs must be (1) necessary and (2) sufficient to cause the output. "INHIBIT" gate states that in addition to the causes stated in the basic events, the conditional event has to be true to trigger the top event (Ortmeier and Schellhorn, 2006). The "INHIBIT" gate, represented by a hexagon, is a special case of an "AND" gate where the condition does not have to be a fault. The output is caused by a single input, but some qualifying condition must be satisfied before the input can produce the output, and the condition that must exist is the conditional event (NASA, 2002). "PRIORITY AND" gate is a special case of an "AND" gate, and it is used to signify a situation in which the output event occurs only if the input event occurs in an ordered sequence. "EXCLUSIVE OR" gate is used in a situation in which the output event occurs only if one of the input events occurs but not two or more.

The evaluation of FT, which is used in seventh step, can be conducted qualitatively quantitatively, or both (Joshua and Garber, 1991). Generally, qualitative evaluation includes the calculation of minimal cut set for the top event and structural importance, and quantitative evaluation is carried out to work out the possibility of the top event given the probability of basic events. In this study, only qualitative evaluation was conducted. 
A cut set is any group of FT initiators which, if all occur, will lead to the occurrence of the top event. A minimal cut set is a least group of basic events which will cause the top event to occur, if they occur. Generally, the more minimal cut sets there are in FT, the more dangerous the whole system is, because every cut set would be a path in which the top event may occur. Based on the minimal cut sets, corresponding countermeasures can be proposed. Following is one of many approaches to find minimal cut sets. The upper level event would be either the sum or product of the lower level events. It is the logic gates that decide whether "plus" or "times" should be used. When it comes to an "OR" gate, "plus" is selected, and when it comes to an "AND" gate, "times" is selected. Finally, there will be the sum of the product of the basic events, and the product would be the minimal cut set of the FT. A more detailed description on how to perform an FT qualitative analysis may be found in specialized literature (NRC, 1981; NASA, 2002).

The final step in FTA (Step viii) involves the interpretation and presentation of the results. The results are shown and interpreted in Chapter 4.

It is common practice to use one unique FT in analysis of accidents. In this study, it was decided to construct FT for every accident, as opposed to one unique FT, in order to show adequate and relatively detailed information on truck-related accidents. Such an approach helps to provide a way to analyze how the root causes caused each fatal accident to occur. In addition, constructing FT for every accident helps summarize the frequency of root causes. 
A unique FT will be eventually developed in a subsequent phase of the study, and is desirable for conducting an overall impact study of contributing factors of fatalities, and determining their importance measures such as Fussel-Vesely (FV) or Risk Achievement Worth (RAW) as described in NASA (2002).

Although there was no root cause analysis of four accident reports (\#1, \#2, \#3, and \#4), conclusions of MSHA reports indicated contributing factors. These contributing factors were used with root causes of the eight accidents to list all factors involved in twelve accidents. The number of fatalities was later used to examine the relationship among other elements, such accident location and truck activity before the accident happened.

\subsection{Truck-related injuries in WV surface coal mines}

Data on truck-related injury accidents for the period from 2012 to 2013 were retrieved from the West Virginia Board of Coal Mine Health and Safety (2014). The data were classified into 61 fields, including variables such as the MSHA mine ID assigned to an operation, the month, day, year, and time of injury, the mine machine involved, accident classification, accident type, age of employee, experience, injury type, total days lost, and job title.

Worker's ages were classified into four categories: 18-24 years, 25-39 years, 40-54 years, and $\geqslant$ 55 years, in an attempt to identify their relationship with distribution of truck-related injuries. Years at current job title and years at current mine were two data categories used to analyze the

relationship between experience and injury frequency. Worker's experience (years at current job 
title and years at current mine) were classified into different categories by years, i.e. 0-5, 6-10, 11$15,16-20,21-25$, and $\geq 26$. Time is divided into three eight-hour sections, which are 6:00 a.m.2:00 p.m., 2:00 p.m.-10:00 p.m., and 10:00 p.m.-6:00 a.m., and they are designated as "Section I", "Section II", and "Section III", respectively. Analysis was conducted to identify which time interval accounted for the largest number of injuries. The date of injury occurrence for each injury was analyzed to find out their relationship with injury frequency. Dates are sorted from Monday through Sunday with the purpose of identifying which day has more injury frequency. In addition, injury dates are also sorted by seasons, i.e., spring, summer, fall, and winter. Months were classified into four categories: March $1^{\text {st }}-$ May $31^{\text {st }}$ (Spring), June $1^{\text {st }}$-August $31^{\text {st }}$ (Summer), September $1^{\text {st }}-$ November $30^{\text {th }}$ (Fall) and December $1^{\text {st }}-$ February $28^{\text {th }}$ (Winter). Nature of injury was summarized to identify the common type of truck-related injuries.

\subsection{Intervention strategies}

Intervention strategies were proposed on the basis of findings of FTA. After analyzing the fatal accident reports, and constructing the FTs for the accidents, root causes of the haul truck-related fatalities were identified. Intervention strategies were proposed to prevent the root causes from happening again.

A two-pronged approach to accident prevention was used: one that is fundamental and traditional (safety regulations, training and education, and engineering of the work environment); and one that is innovative and creative (e.g., applying technological advances to better control and eliminate the root causes of accidents). The intervention strategies are outlined in Figure 3.3. 


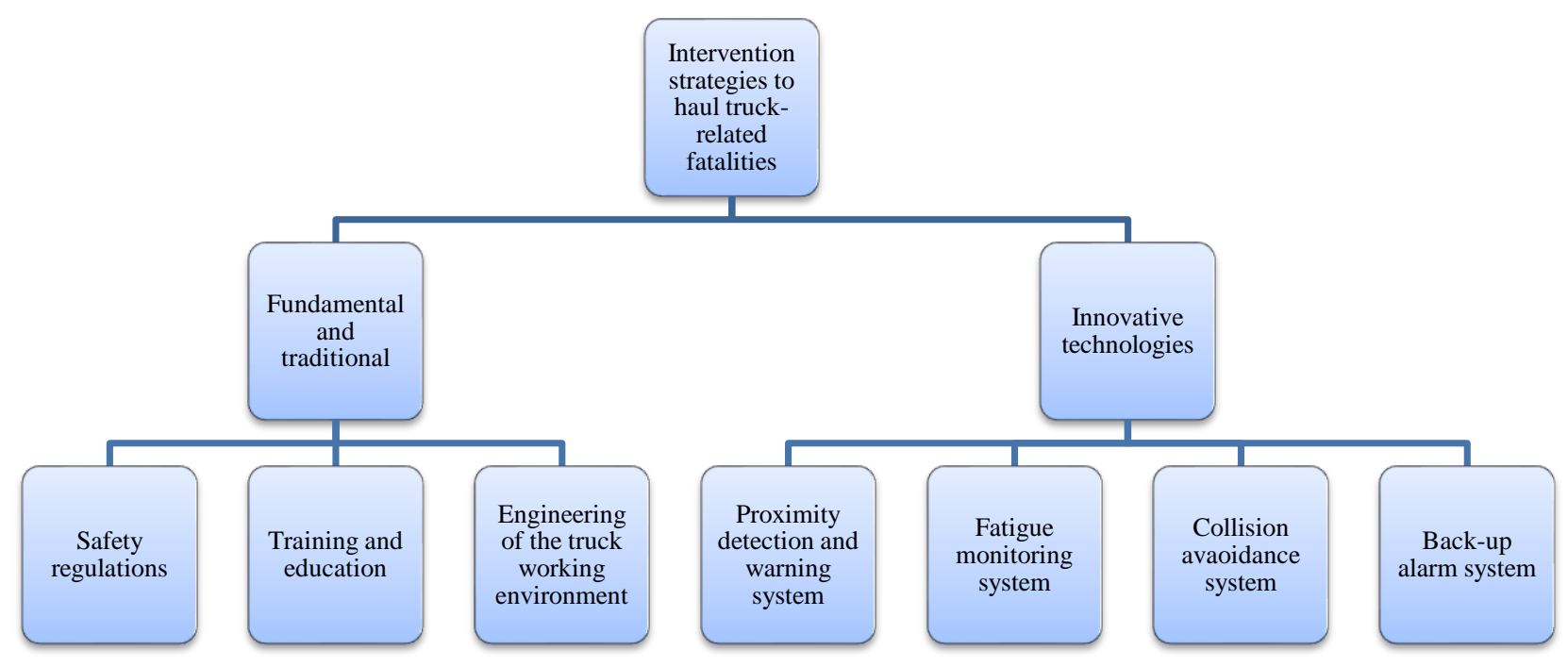

Figure 3.3 Intervention strategy outline

Suggestions for improving current training and education system were proposed, and recommendations were provided on improving the safety of mine working conditions, specifically safety conditions on haul roads, dump sites, and loading areas. Currently available technologies that can help prevent haul truck-related fatal accidents were also discussed. 


\section{CHAPTER 4}

\section{RESULTS AND DISCUSSION}

\subsection{Root causes of haul truck-related fatalities}

A pictorial representation of 12 haul truck-related accidents in surface coal mining in West Virginia is presented in Figure 4.1, while Figure 4.2 shows the distribution of haul truck-related fatalities for the study period. Table 4.1 shows the detailed information on fatal accidents: date of accidents, a short narration, location and truck activity, victim's age, and mining experience.

In order to show adequate and detailed information of every accident and how the basic events caused the upper level and top event to occur, FTs were constructed for every accident. Figures from 4.3 to 4.10 show the constructed FT for eight accidents. Fault Tree \#1 was constructed based on the report of Accident \#5, FT \#2 was based on Accident \#6, FT \#3 was based on Accident \#7, and so forth. The root causes (i.e. the basic events in the FT) are available in Root Cause Analysis section in MSHA investigation reports. According to MSHA, root cause was defined that, if eliminated, would have either prevented the accident or mitigated its consequences. 


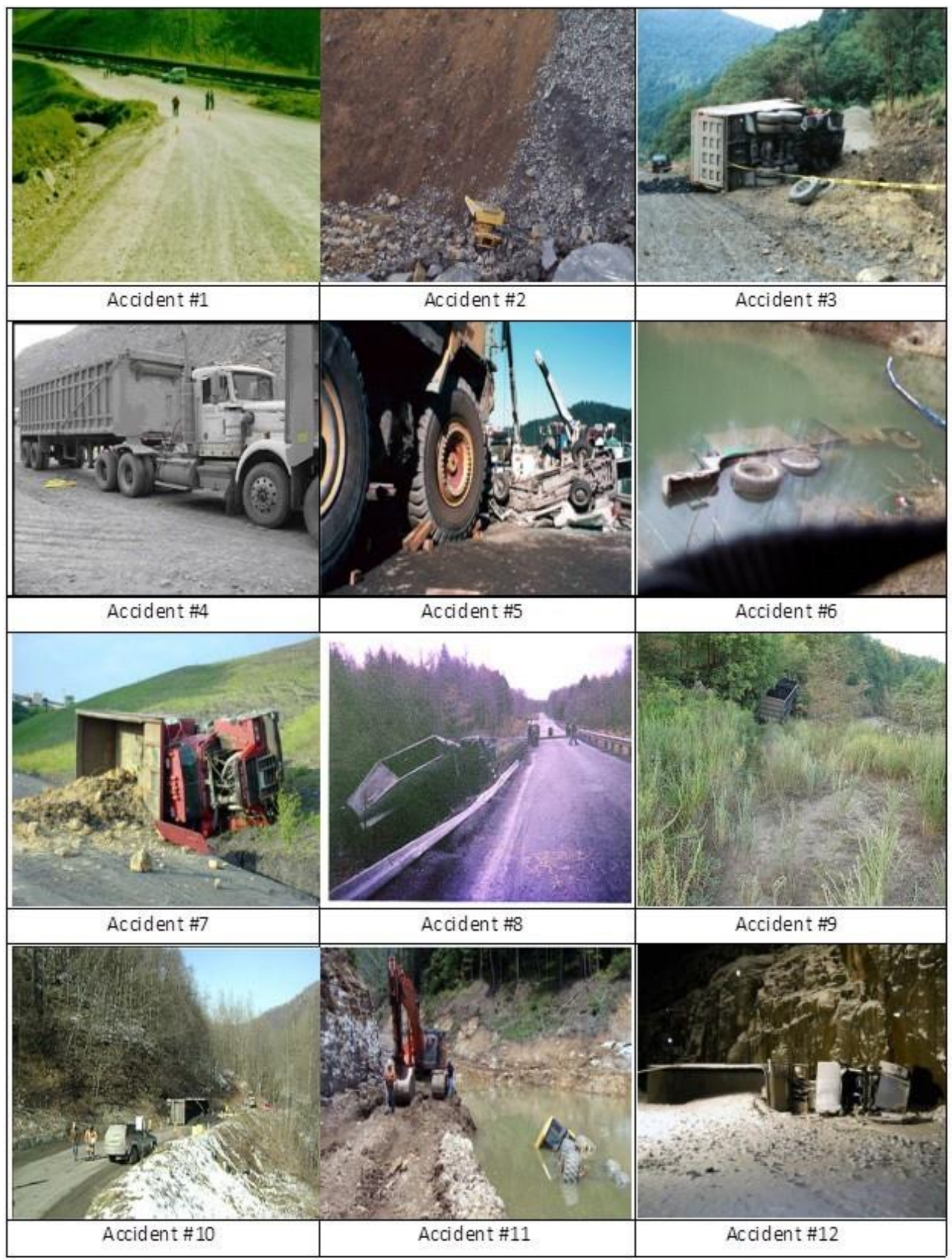

Figure 4.1 Haul truck-related fatal accidents in surface coal mining in West Virginia (source of photos: MSHA 2013) 


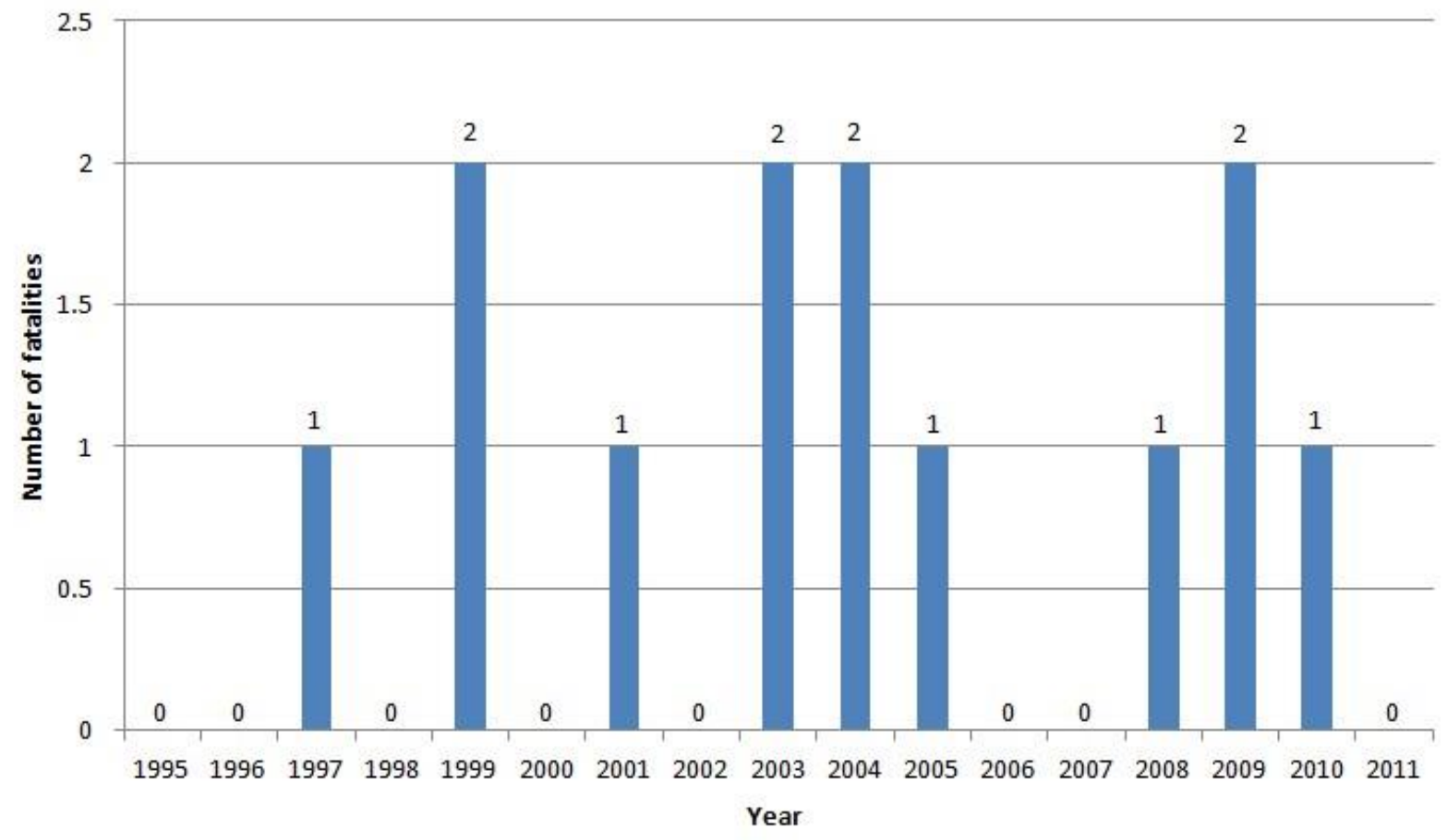

Figure 4.2 Distribution of haul truck-related fatal accidents between 1995 and 2011 
Table 4.1 Accident information

\begin{tabular}{|c|c|c|c|c|c|c|}
\hline \multirow{2}{*}{$\begin{array}{l}\text { Accident } \\
\quad \text { No }\end{array}$} & \multirow{2}{*}{ Date } & \multirow{2}{*}{ Narration } & \multicolumn{2}{|c|}{$\begin{array}{c}\text { Location and Truck } \\
\text { Activity }\end{array}$} & \multicolumn{2}{|c|}{ Victim } \\
\hline & & & Location & Activity & Age & Experience. \\
\hline $1^{*)}$ & 4/2/1997 & $\begin{array}{l}\text { A telephone technician was driving a } \\
\text { service truck down a mine access road } \\
\text { when the truck overturned. }\end{array}$ & $\begin{array}{l}\text { Mine } \\
\text { access road }\end{array}$ & $\begin{array}{l}\text { Moving } \\
\text { forward }\end{array}$ & $\mathrm{n} / \mathrm{a}$ & $\mathrm{n} / \mathrm{a}$ \\
\hline $\left.2^{*}\right)$ & $1 / 20 / 1999$ & $\begin{array}{l}\text { A truck driver was dumping a load at a } \\
\text { spoil dump when the berm and spoil pile } \\
\text { collapsed. }\end{array}$ & Dump site & Dumping & 39 & $18 \mathrm{y}$ \\
\hline $\left.3^{*}\right)$ & $6 / 28 / 1999$ & $\begin{array}{l}\text { A truck driver apparently lost control of } \\
\text { his loaded coal truck while traveling } \\
\text { down a haul road. The truck struck the } \\
\text { right side berm near an escape ramp and } \\
\text { flipped over on its side. }\end{array}$ & Haul road & $\begin{array}{l}\text { Moving } \\
\text { forward }\end{array}$ & $\mathrm{n} / \mathrm{a}$ & $1 d$ \\
\hline $\left.4^{*}\right)$ & $11 / 1 / 2001$ & $\begin{array}{l}\text { The operator failed to set the parking } \\
\text { brake while parking. The truck rolled } \\
\text { back and ran over another truck } \\
\text { operator. }\end{array}$ & $\begin{array}{l}\text { Loading } \\
\text { area }\end{array}$ & Parking & 25 & $4 d$ \\
\hline 5 & $9 / 17 / 2003$ & $\begin{array}{l}\text { Truck driver failed to give warning } \\
\text { signal before moving; crushed a van } \\
\text { parked at the blind side, killing another } \\
\text { driver and a driller. }\end{array}$ & Haul road & $\begin{array}{l}\text { Moving } \\
\text { forward }\end{array}$ & 47 & $10 y$ \\
\hline 6 & $2 / 10 / 2004$ & $\begin{array}{l}\text { The truck hit a } 24 \text {-inch pipe and berm, } \\
\text { travelling an additional } 75 \text { feet up the } \\
\text { pond access road and sliding into the } \\
\text { pond. }\end{array}$ & $\begin{array}{l}\text { Pond access } \\
\text { road }\end{array}$ & $\begin{array}{l}\text { Moving } \\
\text { forward }\end{array}$ & 54 & $22 y$ \\
\hline 7 & $6 / 10 / 2004$ & $\begin{array}{l}\text { A truck driver lost control of the truck } \\
\text { while descending a hill. The truck left } \\
\text { the roadway, traveled across a deep } \\
\text { ditch, and overturned. }\end{array}$ & Haul road & $\begin{array}{l}\text { Moving } \\
\text { forward }\end{array}$ & 52 & $10 y$ \\
\hline 8 & $11 / 8 / 2005$ & $\begin{array}{l}\text { The truck driver left the mine haul road, } \\
\text { ran through a guard rail and overturned. }\end{array}$ & Haul road & $\begin{array}{l}\text { Moving } \\
\text { forward }\end{array}$ & 26 & $2 y$ \\
\hline 9 & $8 / 22 / 2008$ & $\begin{array}{l}\text { The victim either fell or jumped from } \\
\text { the defective haul truck he was } \\
\text { operating as it struck a berm, left the } \\
\text { roadway, and ran over him with the rear } \\
\text { tandem wheels. }\end{array}$ & Haul road & $\begin{array}{l}\text { Moving } \\
\text { forward }\end{array}$ & 38 & $3 d$ \\
\hline 10 & $2 / 6 / 2009$ & $\begin{array}{l}\text { The truck ran up the embankment at } \\
\text { approximately a } 45 \text { degree angle for } \\
\text { approximately } 87 \text { feet. The truck then } \\
\text { rolled over to the right onto the haul } \\
\text { road, trapping the victim beneath the } \\
\text { cab's right side. }\end{array}$ & Haul road & $\begin{array}{l}\text { Moving } \\
\text { forward }\end{array}$ & 70 & $56 \mathrm{~d}$ \\
\hline 11 & $7 / 28 / 2009$ & $\begin{array}{l}\text { The driver was traveling in reverse } \\
\text { along a narrow road adjacent to a pond. } \\
\text { The truck rolled onto its top, trapping } \\
\text { the driver under water. }\end{array}$ & Haul road & $\begin{array}{l}\text { Moving } \\
\text { forward }\end{array}$ & 27 & $6 y$ \\
\hline 12 & $12 / 4 / 2010$ & $\begin{array}{l}\text { A truck driver missed the berm when he } \\
\text { lost control of the truck and ran the left } \\
\text { side tires up onto the berm for a distance } \\
\text { of } 93 \text { feet before the truck overturned. }\end{array}$ & Haul road & $\begin{array}{l}\text { Moving } \\
\text { forward }\end{array}$ & 32 & $10 \mathrm{y}$ \\
\hline
\end{tabular}

$\left.{ }^{*}\right)$ - no FT constructed for those accidents 


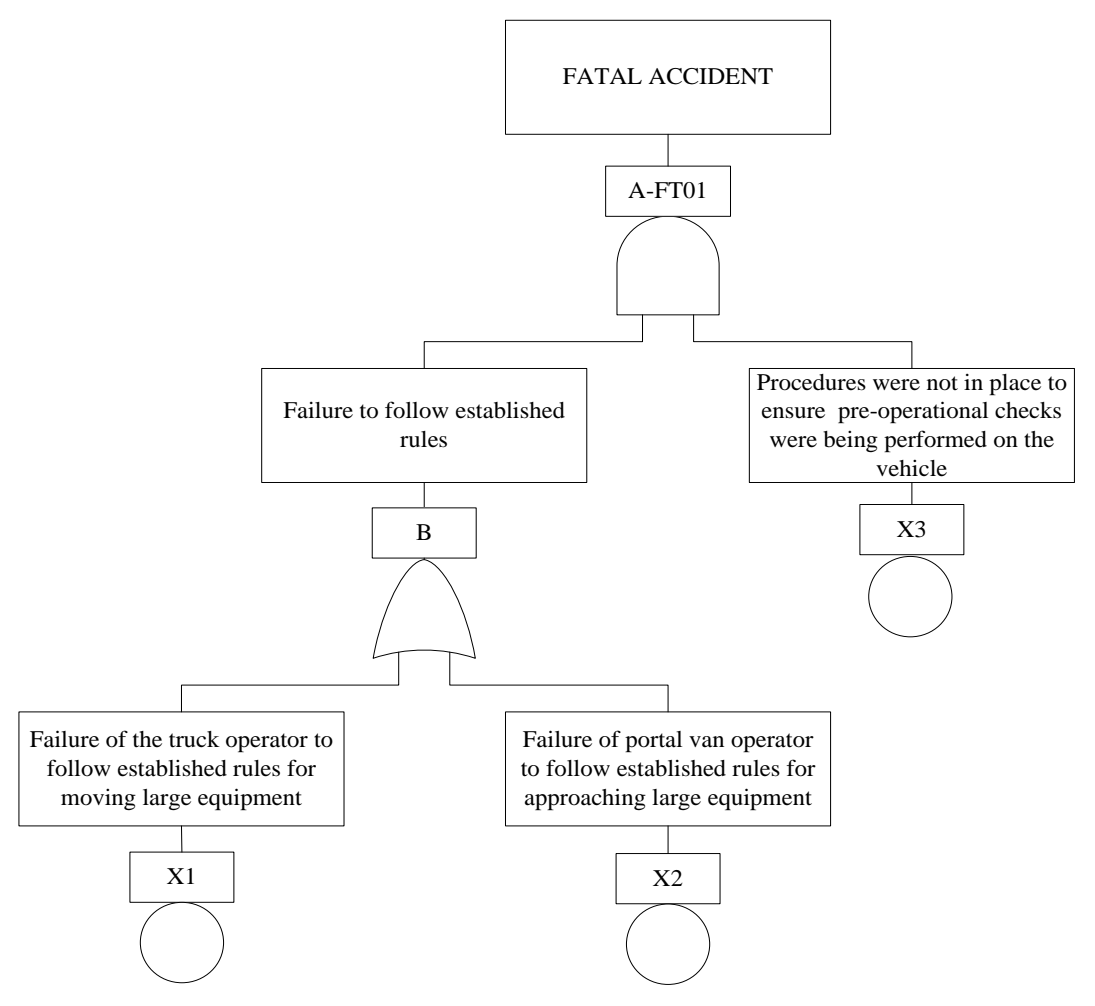

Figure 4.3 Fault Tree \#1 for Accident \#5

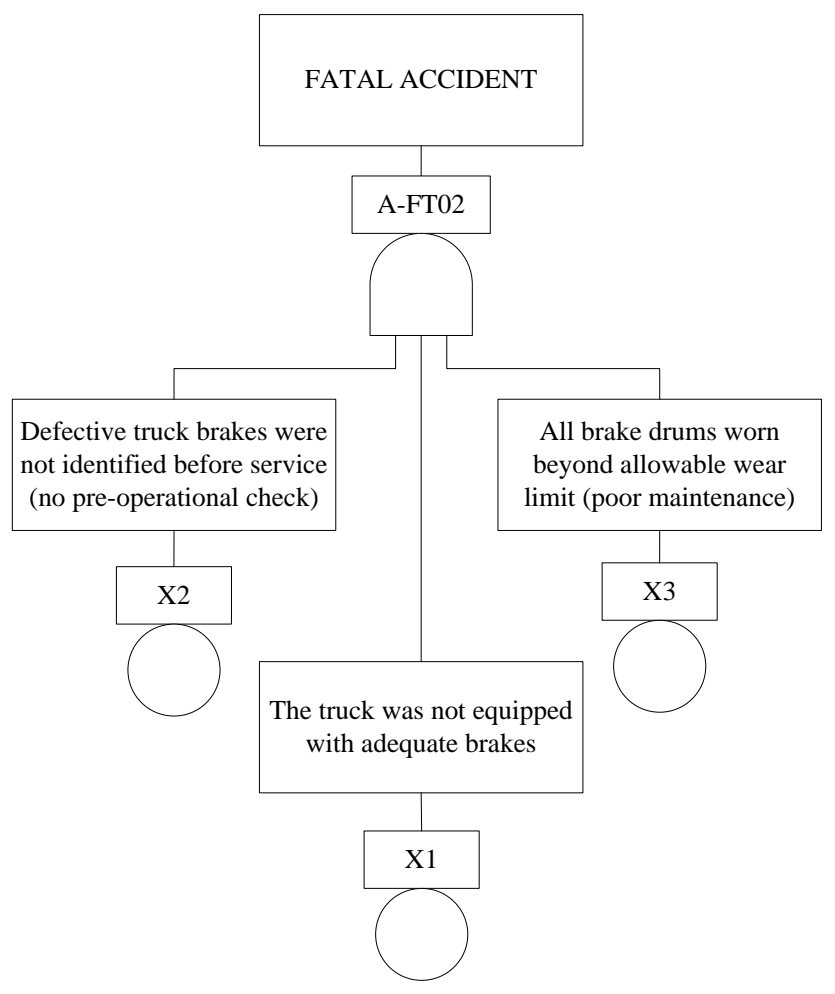

Figure 4.4 Fault Tree \#2 for Accident \#6 


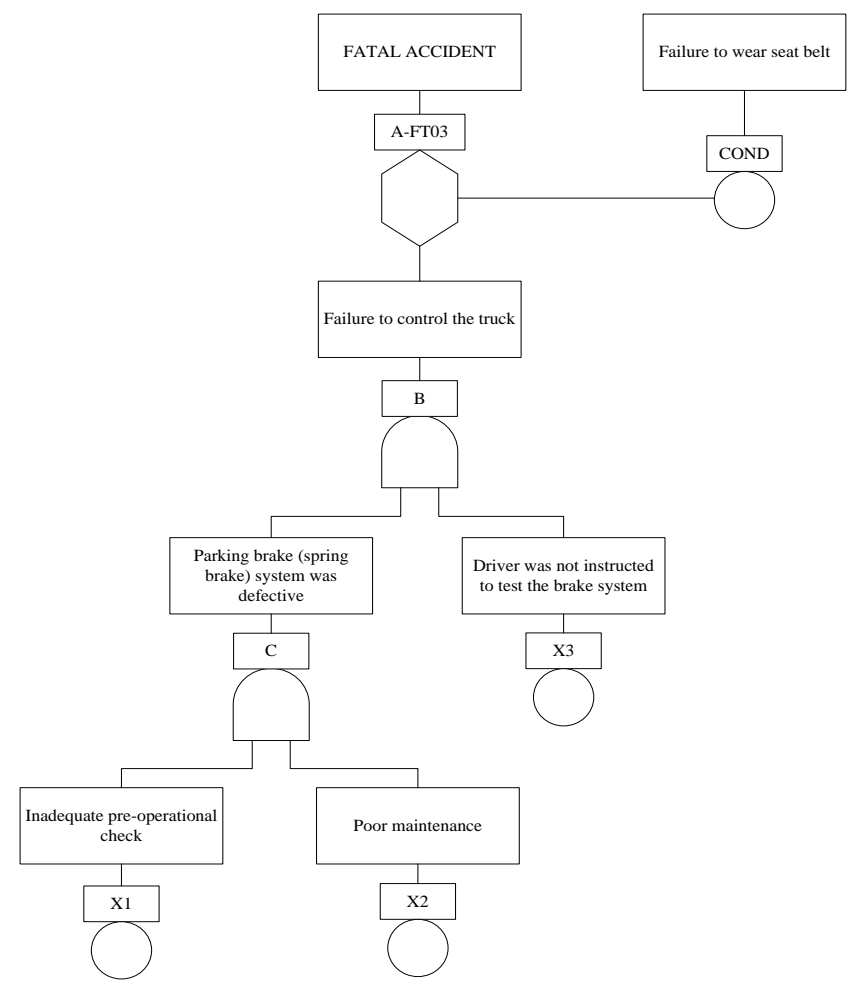

Figure 4.5 Fault Tree \#3 for Accident \#7

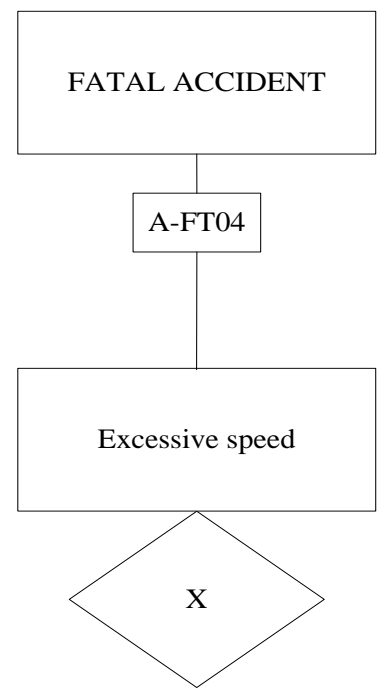

Figure 4.6 Fault Tree \#4 for Accident \#8 


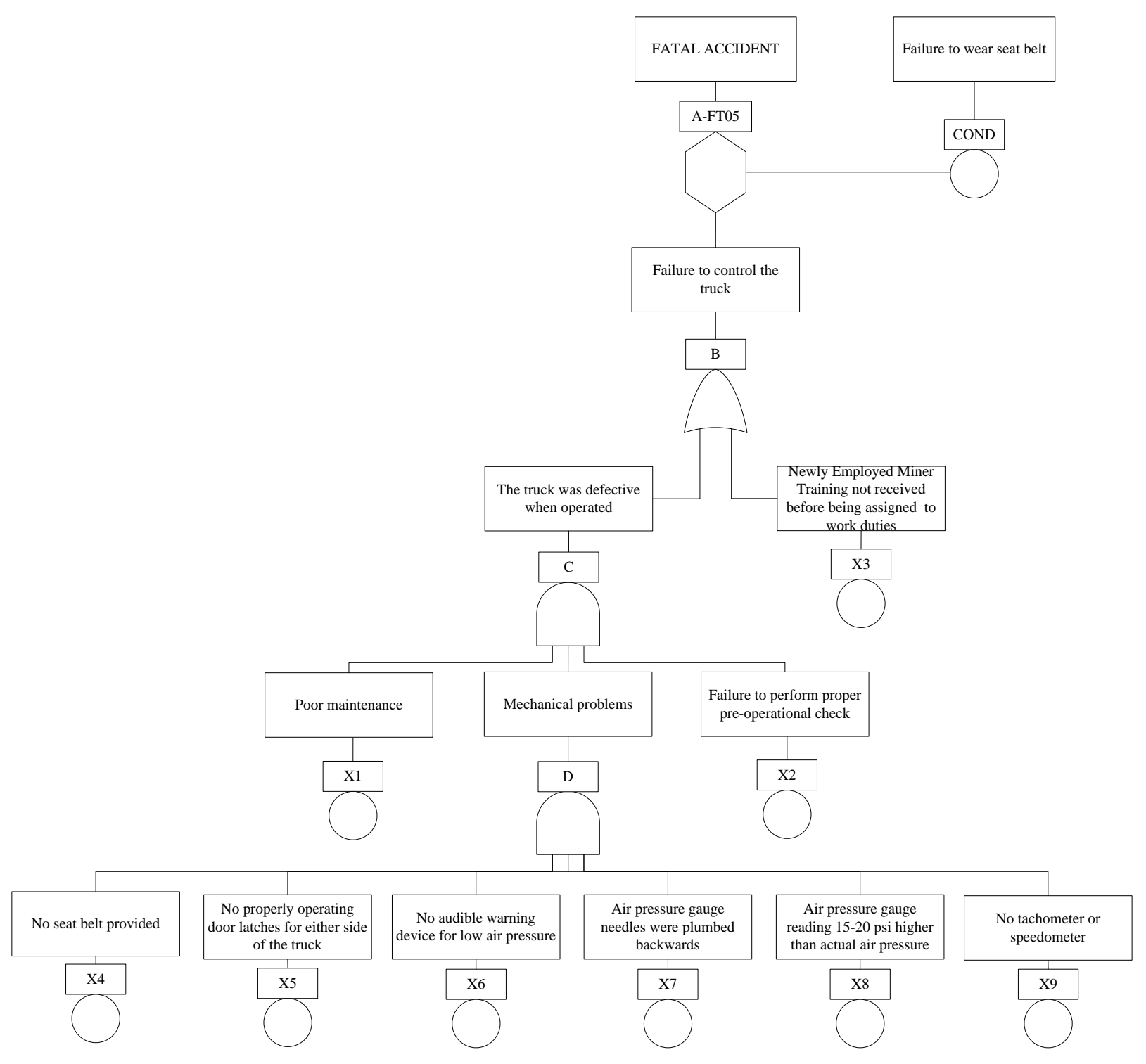

Figure 4.7 Fault Tree \#5 for Accident \#9 


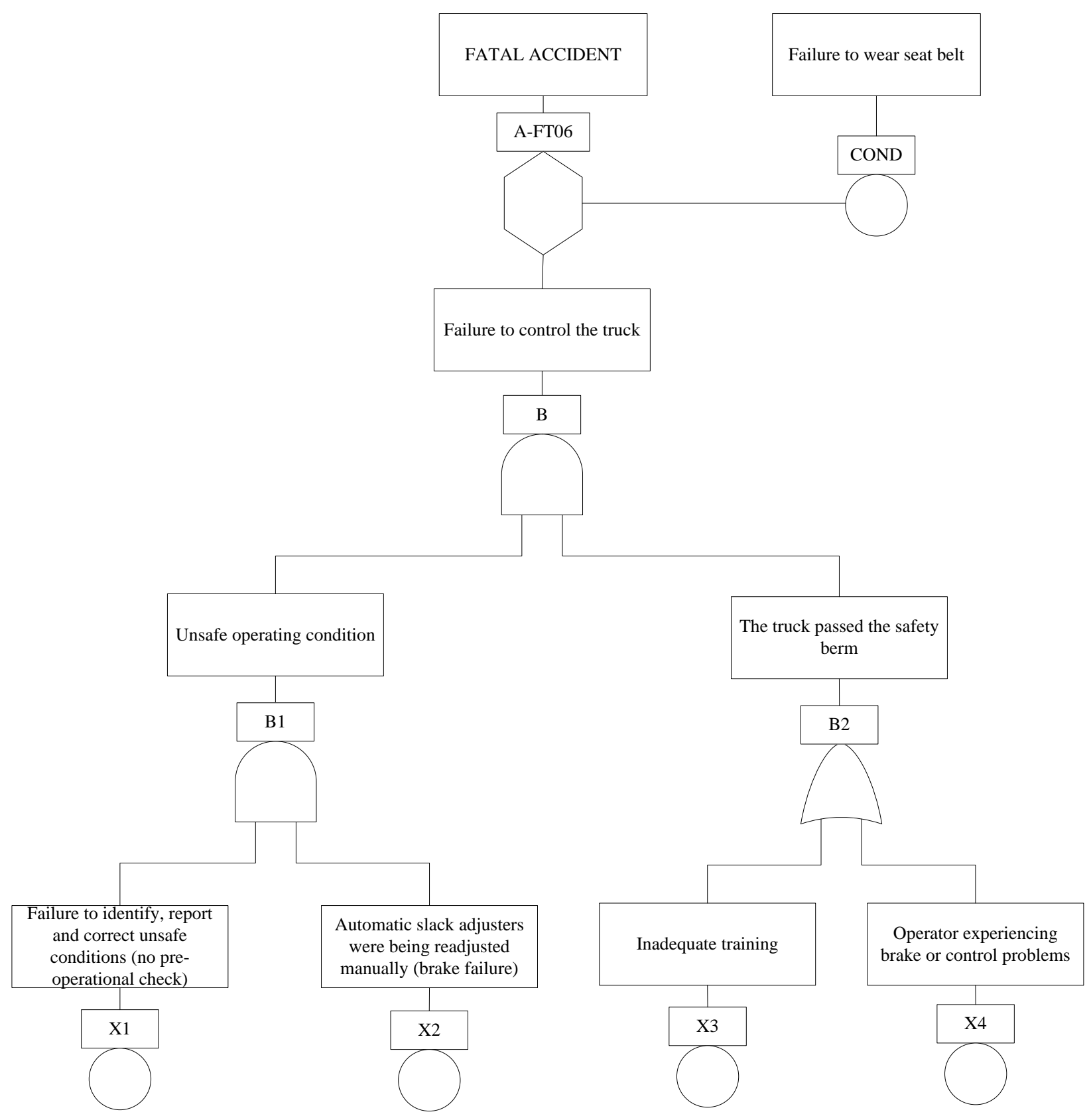

Figure 4.8 Fault Tree \#6 for Accident \#10 


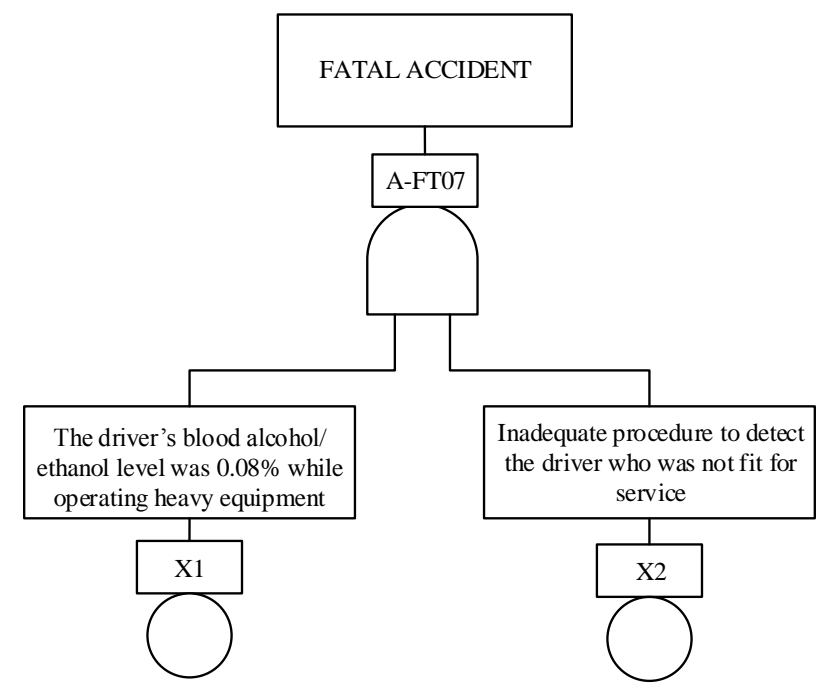

Figure 4.9 Fault Tree \#7 for Accident \#11

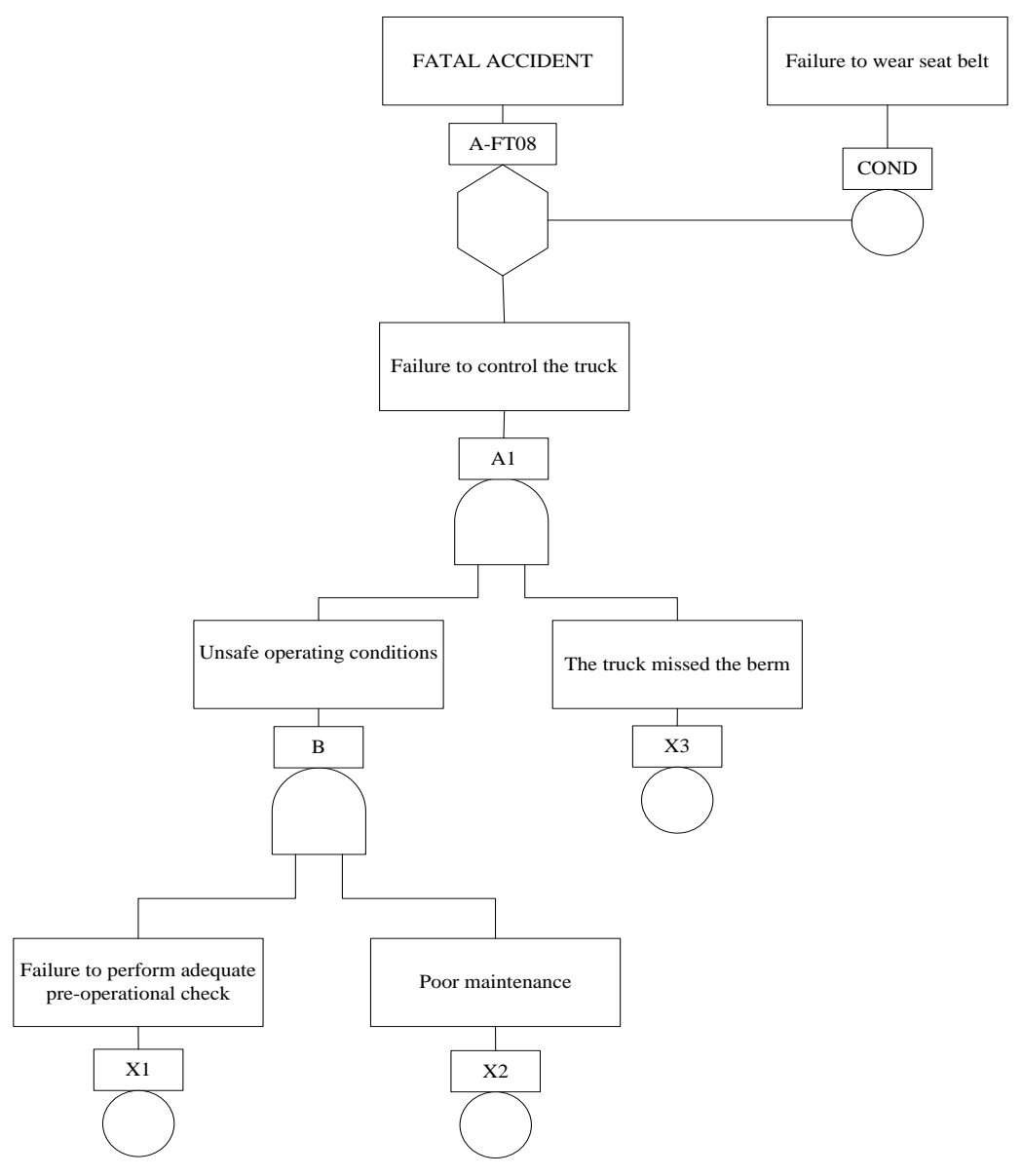

Figure 4.10 Fault Tree \#8 for Accident \#12 
Table 4.2 shows the calculation and results of the minimal cut sets of the FTs. The frequency of the root causes involved in the accidents, based on the Fault Trees in Figures 4.3 to 4.10, is shown in Table 4.3. Two most common root causes are inadequate or improper pre-operational check, and poor maintenance. The former was a root cause of six accidents (\#5, \#6, \#7, \#9, \#10, and \#12), while the latter was the root cause of four accidents (\#6, \#7, \#9, and \#12). Inadequate training was a root cause of two accidents (\#9 and \#10). It was noted in MSHA investigation reports that accidents were associated with multiple root causes, which supports Randolph and Boldt's (1997) observation that attempting to identify a single cause for accidents is usually an oversimplification. Kecojevic and Md-Nor (2009) also stated that, generally, an incident resulting in or fatality is multi-causal.

Table 4.2 Calculation and results of minimal cut sets

\begin{tabular}{|c|c|c|}
\hline $\begin{array}{l}\text { Fault } \\
\text { Tree }\end{array}$ & Calculation & Minimal Cut Sets \\
\hline 1 & $\mathrm{~A}=\mathrm{B} \times \mathrm{X} 3=(\mathrm{X} 1+\mathrm{X} 2) \times \mathrm{X} 3=\mathrm{X} 1 \times \mathrm{X} 3+\mathrm{X} 2 \times \mathrm{X} 3$ & $(\mathrm{X} 1, \mathrm{X} 3),(\mathrm{X} 2, \mathrm{X} 3)$ \\
\hline 2 & $\mathrm{~A}=\mathrm{X} 1 \times \mathrm{B} 1 \times \mathrm{B} 2=\mathrm{X} 1 \times \mathrm{X} 2 \times \mathrm{X} 3$ & $(\mathrm{X} 1, \mathrm{X} 2, \mathrm{X} 3)$ \\
\hline 3 & $\begin{array}{l}\mathrm{A}=\mathrm{B} \times \mathrm{COND}=\mathrm{C} \times \mathrm{X} 3 \times \mathrm{COND}=\mathrm{X} 1 \times \mathrm{X} 2 \times \mathrm{X} 3 \times \\
\mathrm{COND}\end{array}$ & $(\mathrm{X} 1, \mathrm{X} 2, \mathrm{X} 3, \mathrm{COND})$ \\
\hline 4 & $A=X 1$ & $(\mathrm{X} 1)$ \\
\hline 5 & $\begin{array}{l}\mathrm{A}=\mathrm{B} \times \mathrm{COND}=(\mathrm{C}+\mathrm{X} 3) \times \mathrm{COND} \\
=(\mathrm{X} 1 \times \mathrm{X} 2 \times \mathrm{D}+\mathrm{X} 3) \times \mathrm{COND}=\mathrm{X} 1 \times \mathrm{X} 2 \times \\
\mathrm{X} 4 \times \mathrm{X} 5 \times \mathrm{X} 6 \times \mathrm{X} 7 \times \mathrm{X} 8 \times \mathrm{X} 9 \times \mathrm{COND}+\mathrm{X} 3 \times \mathrm{COND}\end{array}$ & $(\mathrm{X} 1, \mathrm{X} 2, \mathrm{X} 4, \mathrm{X} 5, \mathrm{X} 6, \mathrm{X} 7, \mathrm{X} 8, \mathrm{X} 9, \mathrm{COND}),(\mathrm{X} 3, \mathrm{COND})$ \\
\hline 6 & $\begin{array}{l}\mathrm{A}=\mathrm{B} \times \mathrm{COND}=(\mathrm{B} 1 \times \mathrm{B} 2) \times \mathrm{COND}= \\
{[(\mathrm{X} 1 \times \mathrm{X} 2) \times(\mathrm{X} 3+\mathrm{X} 4)] \times \mathrm{COND}}\end{array}$ & $(\mathrm{X} 1, \mathrm{X} 2, \mathrm{X} 3, \mathrm{COND}),(\mathrm{X} 1, \mathrm{X} 2, \mathrm{X} 4, \mathrm{COND})$ \\
\hline 7 & $\mathrm{~A}=\mathrm{X} 1 \times \mathrm{X} 2$ & $(\mathrm{X} 1, \mathrm{X} 2)$ \\
\hline 8 & $\mathrm{~A}=\mathrm{B} \times \mathrm{X} 3 \times \mathrm{a}=\mathrm{C} \times \mathrm{COND}=\mathrm{X} 1 \times \mathrm{X} 2 \times \mathrm{X} 3 \times \mathrm{COND}$ & $(\mathrm{X} 1, \mathrm{X} 2, \mathrm{X} 3, \mathrm{COND})$ \\
\hline
\end{tabular}


Table 4.3 Root cause summary

\begin{tabular}{|c|c|c|}
\hline No. & Root Cause & Frequency \\
\hline 1 & Inadequate or improper pre-operational check & 6 \\
\hline 2 & Poor maintenance & 4 \\
\hline 3 & Inadequate training & 2 \\
\hline 4 & Excessive speed & 1 \\
\hline 5 & $\begin{array}{l}\text { Established rule, policies for moving/approaching large mobile equipment was not } \\
\text { followed }\end{array}$ & 1 \\
\hline 6 & Operator experiencing brake or control problems & 1 \\
\hline 7 & Automatic slack adjusters were readjusted manually & 1 \\
\hline 8 & Inadequate procedure to detect the driver who was not fit for service & 1 \\
\hline 9 & The driver's blood alcohol/ethanol level was $0.08 \%$ while operating heavy equipment & 1 \\
\hline 10 & No seat belts provided & 1 \\
\hline 11 & No properly operating door latches for either side of the truck & 1 \\
\hline 12 & No audible warning device for low air pressure & 1 \\
\hline 13 & $\begin{array}{l}\text { Air pressure gauge needles (green and orange) that measure the primary and } \\
\text { secondary air braking system pressure were plumbed backwards }\end{array}$ & 1 \\
\hline 14 & $\begin{array}{l}\text { Air pressure gauge that measures the primary and secondary air braking system was } \\
\text { reading } 15 \text { to } 20 \text { psi higher than actual pressure }\end{array}$ & 1 \\
\hline 15 & No tachometer or speedometer & 1 \\
\hline 16 & The truck was not equipped with adequate brakes & 1 \\
\hline 17 & The driver was not instructed to test the brake system & 1 \\
\hline 18 & The truck missed the berm & 1 \\
\hline
\end{tabular}

Despite the fact that no root causes were specified in MSHA investigation reports of Accidents \#1, $\# 2$, \#3, and \#4, the conclusion of each report indicates the contributing factors of these accidents (Table 4.4).

Many mechanical failures that occurred during operation were related to poor maintenance, and to defective trucks being placed into service due to inadequate or improper pre-operational check. Mechanical failure is often the result of a combination of inadequate or improper pre-operational check and poor maintenance. As McMahan et al. (2010) reported, problems not detected during maintenance and pre-operational checks can result in costly mechanical failures and operator 
injuries. As Fesak et al. (1996) reported, the failure of vehicles' braking systems is generally directly related to poor inspection and maintenance.

Table 4.4 Conclusion of Accident \#1, \#2, \#3, \#4

\begin{tabular}{cl}
\hline Accident No. & \multicolumn{1}{c}{ Conclusion } \\
\hline 1 & $\begin{array}{l}\text { The victim lost control of the vehicle for some unknown reason, throwing him out and pinning } \\
\text { him underneath the truck. }\end{array}$ \\
& The unconsolidated, randomly dumped earth failed to support the weight of the loaded truck \\
and collapsed and the collapse caused the truck to fall into the valley. \\
The victim failed to slow or stop the vehicle because of: 1.This was the victim's first day on \\
the job and his second trip down the mountain. 2 . The victim was not familiar with the vehicle \\
and did not receive task training on the vehicle he was operating. 3. The victim was not familiar \\
with the terrain on which he was required to haul. 4. The brake system for the truck contained \\
several defects. 5. The payload capacity for the truck was routinely exceeded from 100\% to \\
125\%. 6 . The gravity of these conditions was greatly increased due to the adverse slope, with \\
a grade ranging from 10.6\% to 17.4\%. \\
The accident was caused by failure to set the parking brake, inadequate training, and air leaks \\
on the truck.
\end{tabular}

In Accident \#2, the unstable ground failed to support the truck. Accident \#11 was caused as a result of operator being affected by alcohol. Accident \#1 was caused by failure of the operator to control the truck because of some unknown reason. Accident \#4 was caused by failure to set the parking brake when the operator exited the truck. Failure of the victims to follow the rules for approaching large equipment caused the Accident \#5. Excessive speed resulted in Accident \#8.

There were only six accident reports indicating whether the seat belt was used at the time of the accident (Table 4.5). There were four accidents in which the contributing factors included a failure to use the seat belt, and two accidents in which seat belt were worn. In Accident \#9, no seat belts were provided in the truck. Four accidents' $(\# 3, \# 4, \# 5$, and \#6) reports did not mention the use of seat belts. Whether the seat belts were used or not cannot be determined in Accident \#1 and \#11. 
Table 4.5 Summary of data corresponding to use of seat belt

\begin{tabular}{ccc}
\hline Seat belts & Accident involved & Number of accidents \\
\hline Worn & Accident \#2, \#8 & 2 \\
Not worn & Accident \#7, \#9, \#10, \#12 & 4 \\
Not mentioned & Accident \#3, \#4, \#5, \#6 & 4 \\
Cannot be determined & Accident \#1, \#11 & 2 \\
\hline
\end{tabular}

Table 4.6 shows data on age and mine experience for all victims in haul truck-related fatalities in surface mines in WV. There are two victims with no records on age, and one victim without data on mine experience. It can be noted that five victims had less than five years of mine experience. Seven victims lost their lives despite the fact that they had mine experience of more than five years, even 10 or 20 years.

Table 4.6 Victim's age and mine experience

\begin{tabular}{ccc}
\hline No & $\begin{array}{c}\text { Age } \\
\text { (years) }\end{array}$ & $\begin{array}{c}\text { Victim } \\
\text { Mine Experience } \\
\text { (y-year; d-days) }\end{array}$ \\
\hline 1 & n/a & n/a \\
2 & 39 & $18 \mathrm{y}$ \\
3 & $\mathrm{n} / \mathrm{a}$ & $1 \mathrm{~d}$ \\
4 & 25 & $4 \mathrm{~d}$ \\
5 & 47 & $7 \mathrm{y}$ \\
6 & 37 & $10 \mathrm{y}$ \\
7 & 54 & $22 \mathrm{y}$ \\
8 & 52 & $10 \mathrm{y}$ \\
9 & 26 & $2 \mathrm{y}$ \\
10 & 38 & $3 \mathrm{~d}$ \\
11 & 70 & $56 \mathrm{~d}$ \\
12 & 27 & $6 \mathrm{y}$ \\
13 & 32 & $10 \mathrm{y}$ \\
\hline
\end{tabular}

Studies have been conducted on the effect of work experience on the injury rate in mining industry. Bennett and Passmore (1986) reported that severity of injury was not related to worker's total mining experience. A study conducted by the U.S. Bureau of Mines (USBM) found that injuries 
in the coal industry vary more by experience at present company than by age (Butani, 1988). Younger employees had an elevated risk of injury while workers $>55$ years had an elevated risk for fatality. A large majority of incidents involve workers with $<5$ years experience (Groves et al, 2007). Md-Nor (2008) reported that while younger workers were a risk group for occupational injuries, these injuries were less often fatal than those of older workers.

The association between the number of accidents and accident location is shown in Table 4.7. Eight out of 12 accidents occurred on haul roads, two were on access roads, one was on a dump site, and one was at a loading area. The accidents on haul roads account were the most numerous, which is consistent with Md-Nor's findings (2008).

Table 4.7 Distribution of accidents by location of accident

\begin{tabular}{ccccc}
\hline Location of accident & Haul road & Dump site & Access road & Loading area \\
\hline Number of accidents & 8 & 1 & 2 & 1 \\
\hline
\end{tabular}

With the exception of a few investigation reports that did not specify the slope grade of the accident location, most of the slope grades of the locations were recorded. The grades and their average value are displayed in Table 4.8. It appears that the most of these accidents happened on a slope and the slope was relatively steep. The average grade of the slopes was $9.83 \%$.

The relationship between the number of fatal accidents and haul truck activity just before the accident happened was also examined (Table 4.9). The activity "moving forward" was involved in 10 accidents. The activities "parking" and "dumping" only occurred two times. The results are also consistent with the finding of Md Nor et al (2008). 
Table 4.8 Slope grade of accident location

\begin{tabular}{|c|c|c|c|c|c|c|c|c|c|c|c|c|}
\hline Accident & 1 & 2 & 3 & 4 & 5 & 6 & 7 & 8 & 9 & 10 & 11 & 12 \\
\hline $\begin{array}{l}\text { Grade of } \\
\text { slope }\end{array}$ & $12.2 \%$ & $\mathrm{n} / \mathrm{a}$ & $14.0 \%$ & $9.4 \%$ & $\mathrm{n} / \mathrm{a}$ & $10.0 \%$ & $9.4 \%$ & $\mathrm{n} / \mathrm{a}$ & $5.0 \%$ & $9.5 \%$ & $\mathrm{n} / \mathrm{a}$ & $9.1 \%$ \\
\hline $\begin{array}{l}\text { Average } \\
\text { grade }\end{array}$ & \multicolumn{12}{|c|}{$9.83 \%$} \\
\hline
\end{tabular}

Table 4.9 Distribution of accidents by truck activity

\begin{tabular}{cccc}
\hline Haul truck activity & Moving forward & Parking & Dumping \\
\hline Number of accidents & 10 & 1 & 1 \\
\hline
\end{tabular}

Table 4.10 shows descriptive data on weather conditions, and characteristics of haul roads, dump site material and access road at the time of accidents. It can be noted that only four descriptive values for weather conditions were recorded, and no data on width of the haul roads were available in investigation reports. 
Table 4.10 Weather conditions and characteristics of haul roads, dump site, and access road.

Accident

\begin{tabular}{|c|c|c|c|c|c|}
\hline No. & Weather & & Haul road & Dump site & Access road \\
\hline & & width & material & material & \\
\hline 1 & clear and cool & $\mathrm{n} / \mathrm{a}$ & $\mathrm{n} / \mathrm{a}$ & $\mathrm{n} / \mathrm{a}$ & $\begin{array}{l}79 \mathrm{ft} \text { wide mine } \\
\text { access road }\end{array}$ \\
\hline 2 & clear and dry & $\mathrm{n} / \mathrm{a}$ & $\mathrm{n} / \mathrm{a}$ & $\begin{array}{l}\text { unconsolidated } \\
\text { rock }\end{array}$ & $\mathrm{n} / \mathrm{a}$ \\
\hline 3 & clear and dry & no data & $\begin{array}{c}\text { crushed gravel } \\
\text { surface over a rock } \\
\text { base. }\end{array}$ & $\mathrm{n} / \mathrm{a}$ & $\mathrm{n} / \mathrm{a}$ \\
\hline 4 & no data & $\mathrm{n} / \mathrm{a}$ & $\mathrm{n} / \mathrm{a}$ & $\mathrm{n} / \mathrm{a}$ & $\mathrm{n} / \mathrm{a}$ \\
\hline 5 & Clear & no data & no data & $\mathrm{n} / \mathrm{a}$ & $\mathrm{n} / \mathrm{a}$ \\
\hline 6 & no data & $\mathrm{n} / \mathrm{a}$ & $\mathrm{n} / \mathrm{a}$ & $\mathrm{n} / \mathrm{a}$ & $\begin{array}{l}12-15 \mathrm{~m} \text { wide } \\
\text { pond access road; } \\
\text { rock and dirt } \\
\text { construction }\end{array}$ \\
\hline 7 & no data & no data & no data & $\mathrm{n} / \mathrm{a}$ & $\mathrm{n} / \mathrm{a}$ \\
\hline 8 & no data & no data & no data & $\mathrm{n} / \mathrm{a}$ & $\mathrm{n} / \mathrm{a}$ \\
\hline 9 & $\begin{array}{l}\text { dry with good } \\
\text { visibility }\end{array}$ & no data & no data & $\mathrm{n} / \mathrm{a}$ & $\mathrm{n} / \mathrm{a}$ \\
\hline 10 & no data & no data & no data & $\mathrm{n} / \mathrm{a}$ & $\mathrm{n} / \mathrm{a}$ \\
\hline 11 & no data & no data & no data & $\mathrm{n} / \mathrm{a}$ & $\mathrm{n} / \mathrm{a}$ \\
\hline 12 & no data & no data & no data & $\mathrm{n} / \mathrm{a}$ & $\mathrm{n} / \mathrm{a}$ \\
\hline
\end{tabular}

Citations to the companies were also recorded in the MSHA investigation reports. Based on the citations stated in these reports, Table 4.11 was developed to show the provisions of $30 \mathrm{CFR}$ that were violated, aiming at summarizing the frequently violated provisions and testing the relationship between violations and the root causes of the accidents. A similar study has also been conducted by Orsulak et al (2010). Table 4.11 shows that the most frequently violated provision is 30 CFR§77.404 - Machinery and equipment; operation and maintenance (six times), followed by 30 CFR $\$ 7.1606$ - Loading and haulage equipment; inspection and maintenance (five times). 
Table 4.11 Violations of Federal Code of Regulations

\begin{tabular}{|c|c|c|}
\hline Accident \#. & Violation & Notes \\
\hline 1 & $\mathrm{n} / \mathrm{a}$ & $\mathrm{n} / \mathrm{a}$ \\
\hline 2 & $30 \mathrm{CFR} \S 77.1608$ & Dumping facilities \\
\hline \multirow{4}{*}{3} & $30 \mathrm{CFR} \$ 48.26$ & $\begin{array}{l}\text { Training of newly employed experienced miners; minimum courses of } \\
\text { instruction }\end{array}$ \\
\hline & $30 \mathrm{CFR} \$ 48.27$ & $\begin{array}{l}\text { Training of miners assigned to a task in which they have had no previous } \\
\text { experience; minimum courses of instruction }\end{array}$ \\
\hline & $30 \mathrm{CFR} \$ 77.404$ & Machinery and equipment; operation and maintenance \\
\hline & $30 \mathrm{CFR} \$ 77.1607$ & Loading and haulage equipment; operation \\
\hline \multirow[t]{2}{*}{4} & $30 \mathrm{CFR} \$ 77.404$ & Machinery and equipment; operation and maintenance \\
\hline & $30 \mathrm{CFR} \$ 48.27$ & $\begin{array}{l}\text { Training of miners assigned to a task in which they have had no previous } \\
\text { experience; minimum courses of instruction }\end{array}$ \\
\hline \multirow{2}{*}{5} & $30 \mathrm{CFR} \$ 77.1607$ & Loading and haulage equipment; operation \\
\hline & $30 \mathrm{CFR} \$ 77.404$ & Machinery and equipment; operation and maintenance \\
\hline \multirow{2}{*}{6} & $30 \mathrm{CFR} \$ 77.1605$ & Loading and haulage equipment; installations \\
\hline & $30 \mathrm{CFR} \$ 77.1606$ & Loading and haulage equipment; inspection and maintenance \\
\hline \multirow{2}{*}{7} & $30 \mathrm{CFR} \$ 77.404$ & Machinery and equipment; operation and maintenance \\
\hline & $30 \mathrm{CFR} \$ 77.1606$ & Loading and haulage equipment; inspection and maintenance \\
\hline \multirow[t]{2}{*}{8} & $\mathrm{n} / \mathrm{a}$ & $\mathrm{n} / \mathrm{a}$ \\
\hline & $30 \mathrm{CFR} \$ 77.1606$ & Loading and haulage equipment; inspection and maintenance \\
\hline \multirow{5}{*}{9} & $30 \mathrm{CFR} \$ 48.25$ & Training of new miners; minimum courses of instruction; hours of instruction \\
\hline & $30 \mathrm{CFR} \$ 48.27$ & $\begin{array}{l}\text { Training of miners assigned to a task in which they have had no previous } \\
\text { experience; minimum courses of instruction }\end{array}$ \\
\hline & $30 \mathrm{CFR} \S 48.31$ & Hazard training \\
\hline & $30 \mathrm{CFR} \$ 77.404$ & Machinery and equipment; operation and maintenance \\
\hline & $30 \mathrm{CFR} \$ 77.1708$ & Safety program, instruction of persons employed at the mine \\
\hline \multirow{2}{*}{10} & $30 \mathrm{CFR} \$ 48.25$ & Training of new miners; minimum courses of instruction; hours of instruction \\
\hline & $30 \mathrm{CFR} \$ 77.1606$ & Loading and haulage equipment; inspection and maintenance \\
\hline \multirow[t]{2}{*}{11} & $30 \mathrm{CFR} \$ 77.1607$ & Loading and haulage equipment; operation \\
\hline & $30 \mathrm{CFR} \$ 77.1606$ & Loading and haulage equipment; inspection and maintenance \\
\hline \multirow[t]{2}{*}{12} & $30 \mathrm{CFR} \$ 77.404$ & Machinery and equipment; operation and maintenance \\
\hline & 30 CFR $\$ 77.1710$ & Protective clothing; requirements \\
\hline
\end{tabular}




\subsection{Analysis of truck-related injuries in WV surface coal mines}

In this section, an attempt was made to analyze truck-related injuries that happened in 2012 and 2013 in surface coal mines in West Virginia. A total number of 1,967 reported injuries were recorded in both underground and surface mines in West Virginia. Among all the injuries, there were 223 reported injuries at surface mines.

With the exception of two missing data, a sum of 178 injuries was related to equipment, and 43 accidents happened with no equipment involved, as shown in Figure 4.11. Obviously, equipmentrelated safety issues are still of concern with respect to surface mines. The two equipment categories accounting for the greatest number of injuries are: truck ( 57 times) and bulldozer, dozer, crawler tractor (43 times). A detailed distribution of injuries by mine machines is presented in Figure 4.12. It should be noted that category "Machine" was not clearly defined in the original injury data, therefore it is unknown which type of equipment is classified as "Machine".

Adequate attention should be given to truck-related injuries since they occurred most frequently. An attempt was made to identify the worker's age distribution. The injured worker's ages were classified into four categories (18-24 years, 25-39 years, 40-54 years, and $\geqslant 55$ years) as shown in Figure 4.13. 


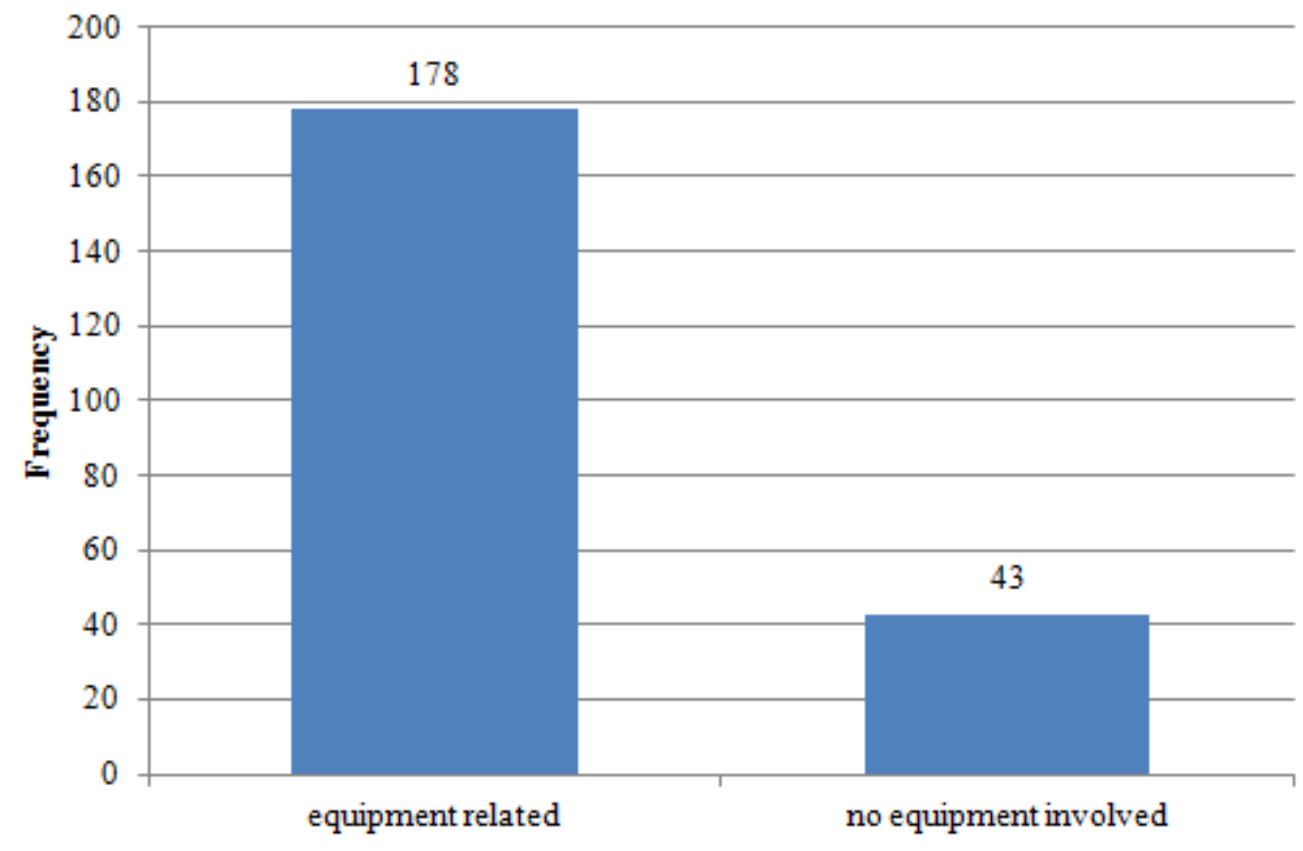

Figure 4.11 Surface mining injury categories and frequency

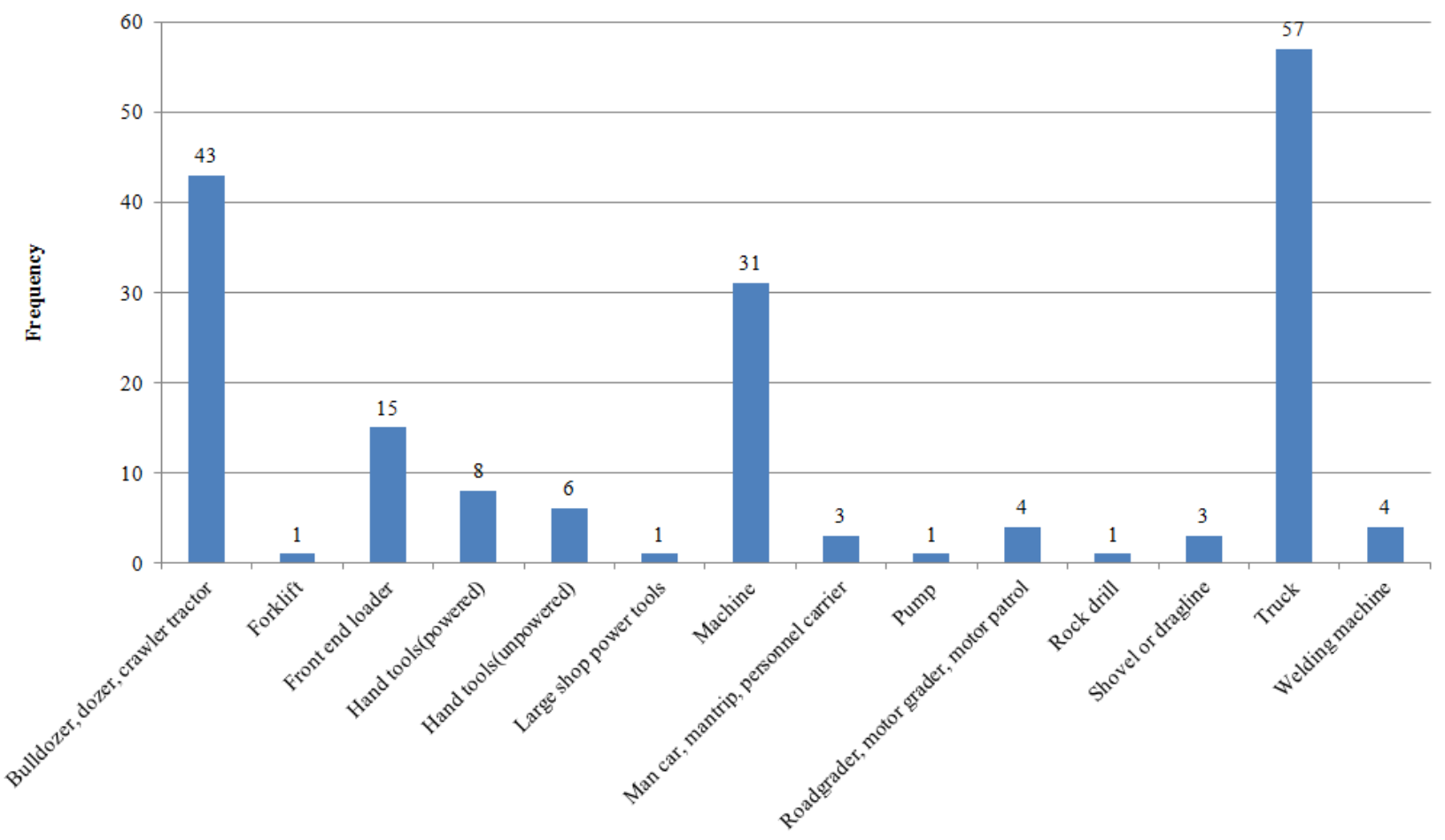

Figure 4.12 Distribution of injuries by mining equipment category 
The majority of injuries happened to workers between 24-39 years of age. The age category with the second most injuries was 40-54 year-olds. These two age categories together make up 76.8\% of the total truck-related injuries. The age category $18-24 \mathrm{yr}$ accounted for $14.3 \%$ of the truckrelated injuries in 2012 and 2013. Workers over 55 years old had the least (8.9\%) of injuries.

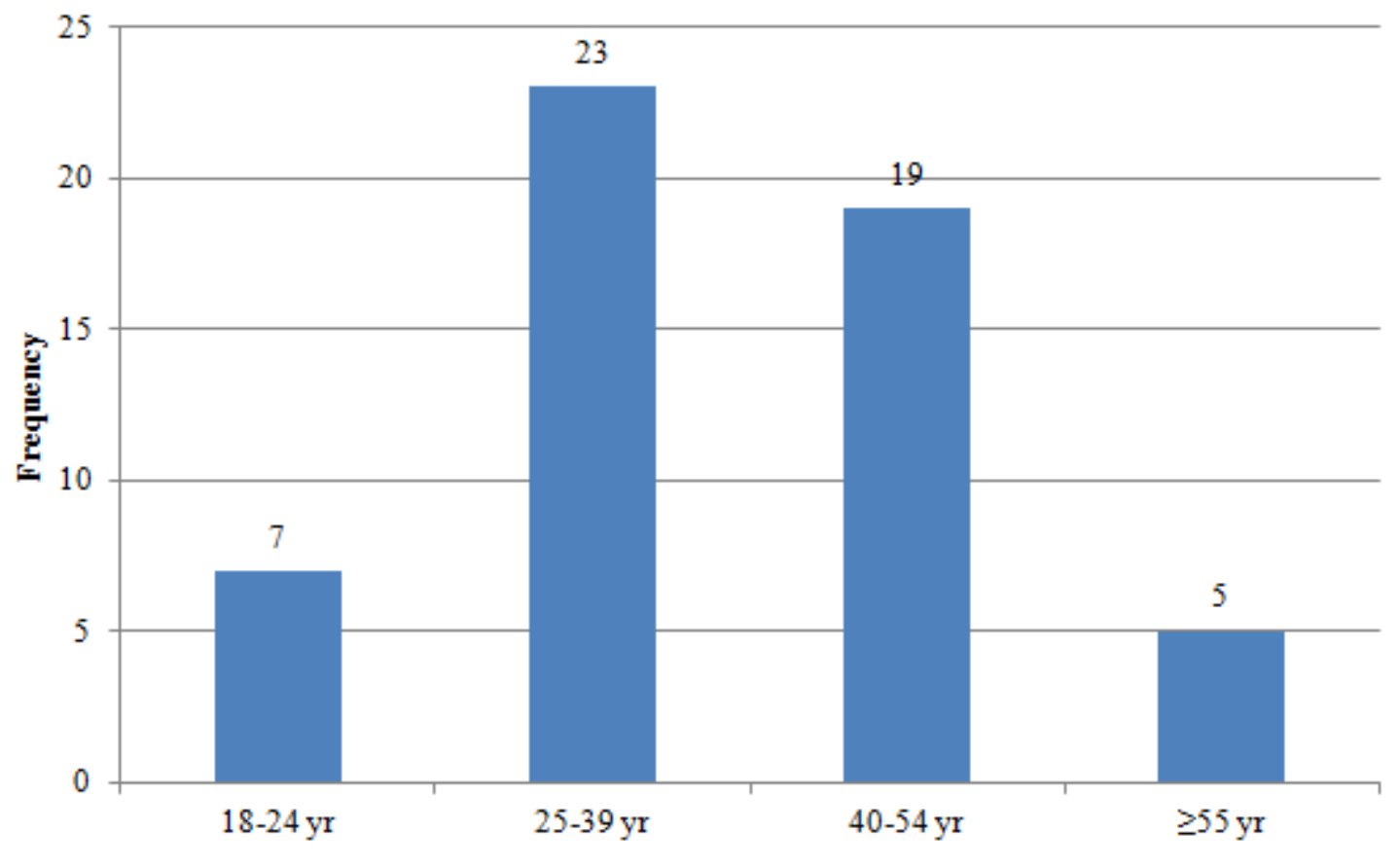

Figure 4.13 Distribution of injuries by age categories

The relationship between frequency of truck-related injuries and years at current job title is presented in Figure 4.14 (Five data on worker's experience at current job title were not available).

The result shows that a total of $27(52 \%)$ truck-related injuries occurred with the worker's years at current job title no more than five years. 


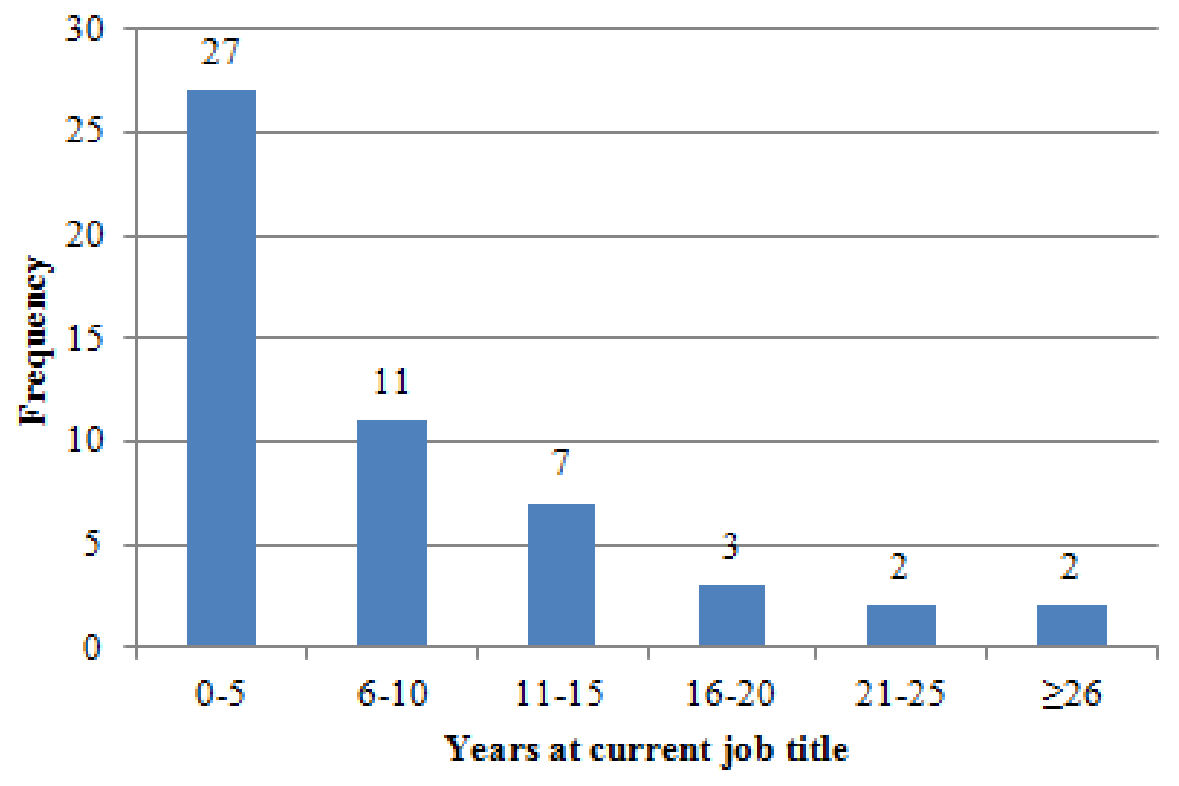

Figure 4.14 The relationship between truck-related injury frequency and years at current job title

An effort was also made to identify the relationship between truck-related injuries and worker's years at current mine. Similar to what was found in the relationship between injury frequency and years at current job title, a number of $36(69.2 \%)$ injuries occurred within the worker's first five years at the mine, as is shown in Figure 4.15. This finding is consistent with other researchers' work. Groves et al (2007) analyzed equipment-related injuries in the mines from 1995-2004, and found that workers have less five years of mining experience in $62 \%$ of truck-related injuries.

Both years at current job title and years at current mine can be viewed as truck operator's mining experience. The fact that the majority of injuries happened to those less experienced ( $0-5$ years) operators strongly demonstrates the need to provide adequate training and education to operators, new operators in particular. The fact that the number of injuries decreases when mining experience 
increases does not make training provided of experienced operators less important. Management and supervision should be in place to prevent operators from being complacent, which creates a hazardous situation. Wiehagen (2001) indicated that a worker's perception of risk is generally much lower than actual risk exposure. A vicious cycle occurs whereby every shift worked without an injury reinforces an "it is not going to happen to me" attitude which serves to further rationalize risk-taking behavior (MSHA, 2000).

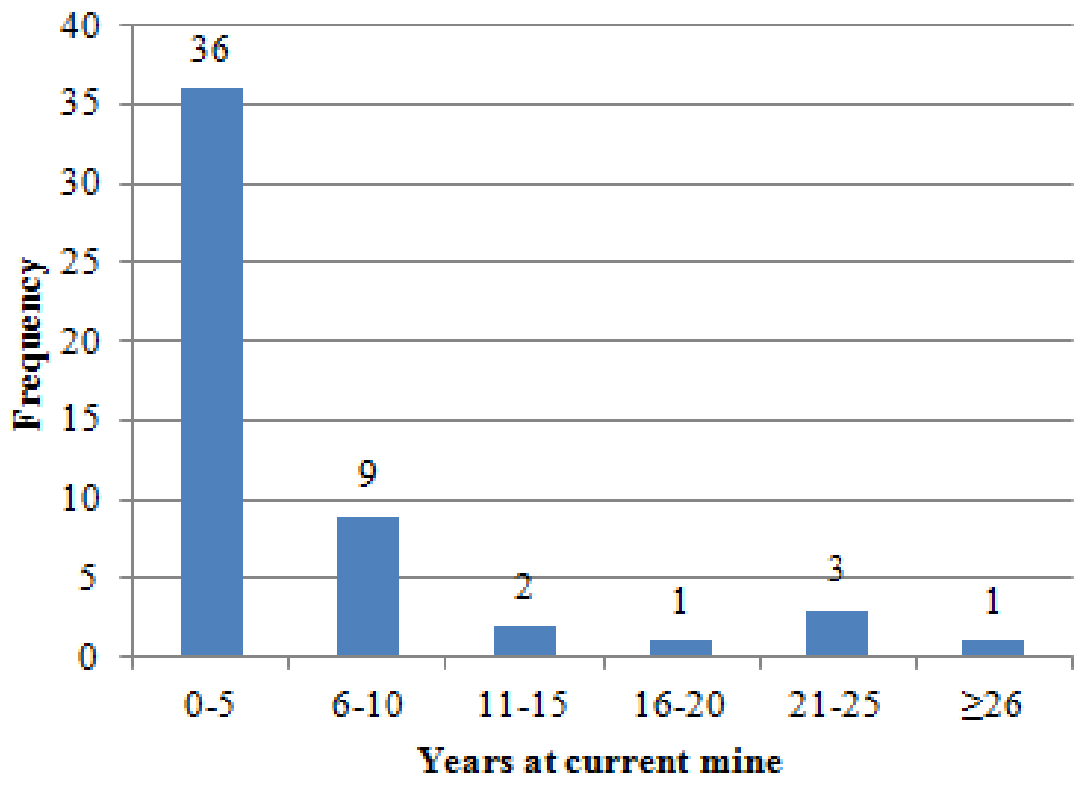

Figure 4.15 The relationship between truck-related injury frequency and years at current mine

Injury time was analyzed to identify what time of the day is of more concern. The shift time is categorized into three sections. The classification is shown in Table 4.12.

Table 4.12 Injury time classification

\begin{tabular}{|c|c|}
\hline Injury time & Designation \\
\hline
\end{tabular}




\begin{tabular}{|c|c|} 
6:00 a.m. - 2:00 p.m. & Section I \\
\hline 2:00 p.m. - 10:00 p.m. & Section II \\
\hline 10:00 p.m. - 6:00 a.m. & Section III \\
\hline
\end{tabular}

It was found that most truck-related injuries happened during "Section I" (51\%), followed by Section II (28\%) and Section III (20\%), as is shown in Figure 4.16. One possible reason for the decreasing portion from Section I to Section III is less personnel on each shift. Particular supervision and attention should be placed more on "Section I" since it accounted for the largest proportion of injuries.

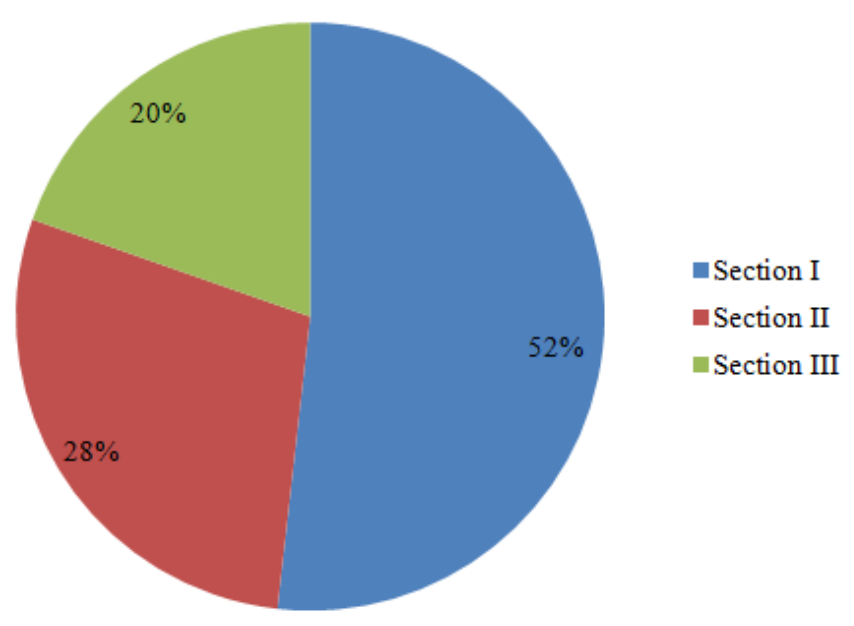

Figure 4.16 Distribution of truck-related injuries by injury time

An attempt was made to identify if any certain day in a week stands out with significantly more injuries than other days. After sorting the date by day of the week, it was found that almost half of the truck-related injuries happened on Monday and Tuesday, and the number decreased over the following five days, as shown in Figure 4.17. 
In order to find out if season affects the number of truck-related injuries, data were summarized by seasons, and it was found that the highest number of injuries was recorded in fall (Figure 4.18). However, the number of injuries in fall is not significantly higher than the other three. The finding suggests that the season has little to do with the number of truck-related injuries.

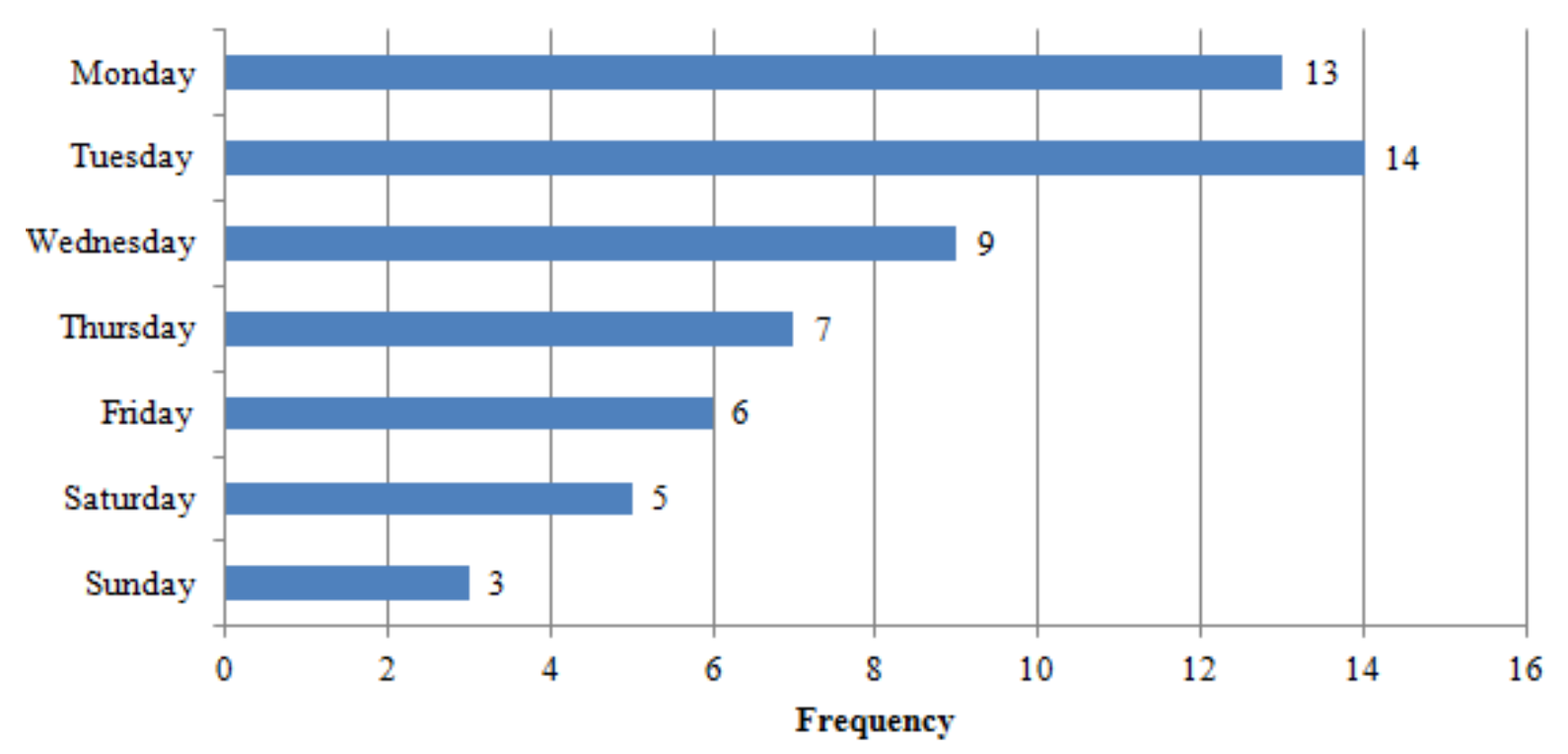

Figure 4.17 Distribution of injury frequency by day of the week 


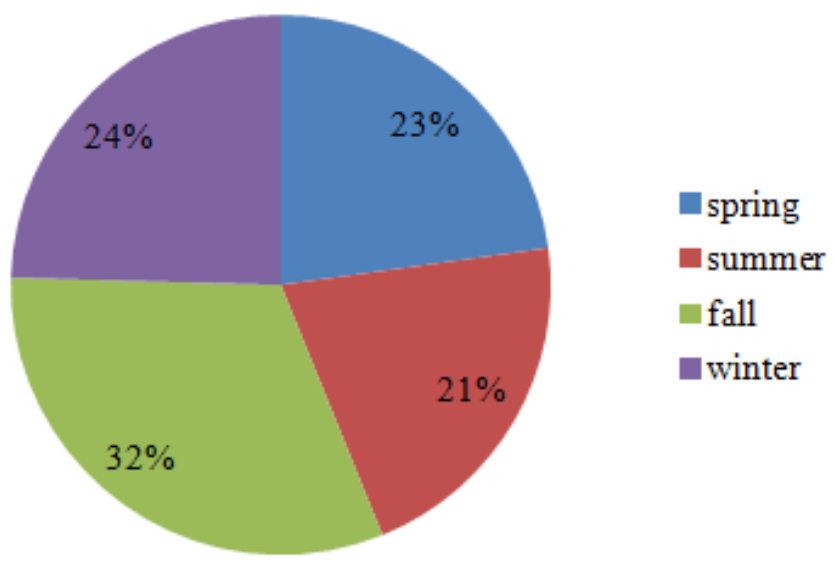

Figure 1.18 Distribution of truck-related injuries by seasons

It is important to find out what kinds of injuries happened to the miners, and how corresponding countermeasures could be better implemented. Categories "Other", "Unclassified", and "Not known" are not defined in the original data, therefore the difference among them are not known.

Table 4.13 Nature of injury and count

\begin{tabular}{|l|c|}
\hline Nature of injury & Count \\
\hline Sprains and strains & 18 \\
\hline Other & 9 \\
\hline Contusion & 8 \\
\hline Cut, laceration & 6 \\
\hline Fracture, chip & 6 \\
\hline Multiple injuries & 5 \\
\hline Crushing & 3 \\
\hline Unclassified & 1 \\
\hline Not known & 1 \\
\hline
\end{tabular}

About $32 \%$ of truck-related injuries were attributed to sprains and strains, which accounted for the most frequent type of injuries (Table 4.13). Esterhuizen and Gürtunca (2006) stated that strain and 
sprain injuries accounted for $40 \%$ of all injuries in the mining industry. A study conducted by Moore et al (2009) found the same result that the majority of injuries were sprains or strains. They also stated that some sprains and strains can increase risk of future incidents. Permanent damage to soft tissue structures such as stretching of ligaments can result from a sprain or strain. This may make individual vulnerable to dislocations or other joints injuries. Armour (2003) pointed out that equipment most often involved in sprain and strain injuries is haul trucks, and many of the injuries occurred inside trucks related to seating or vehicle access. According to Armour (2003), contributors to the sprain and strain claims were identified as follows:

1. An aging workforce exposed to high levels of vibration and poor handling practices over their careers,

2. An overweight workforce that does little physical exercise either at or away from work,

3. Changes in technology that have significantly increased the size and capacity of the equipment involved,

4. Increased capacity of machines and equipment that have not considered the human operator in their design (this is especially the case for dozers when pushing and ripping partings)

5. Reduction in numbers performing work, and

6. An increase in shift time.

For strains and sprains resulting from rough roads and shocks of loading or unloading, haul roads should be well maintained, and efficient loading and unloading techniques should be provided to concerned personnel (Randolph and Boldt, 2005). Additionally, the mine operator has the responsibility to ensure that equipment operator competency is achieved and evaluated on a regular 
basis, and that roads are well constructed and maintained, which can contribute to reducing the likelihood of sprains and strains.

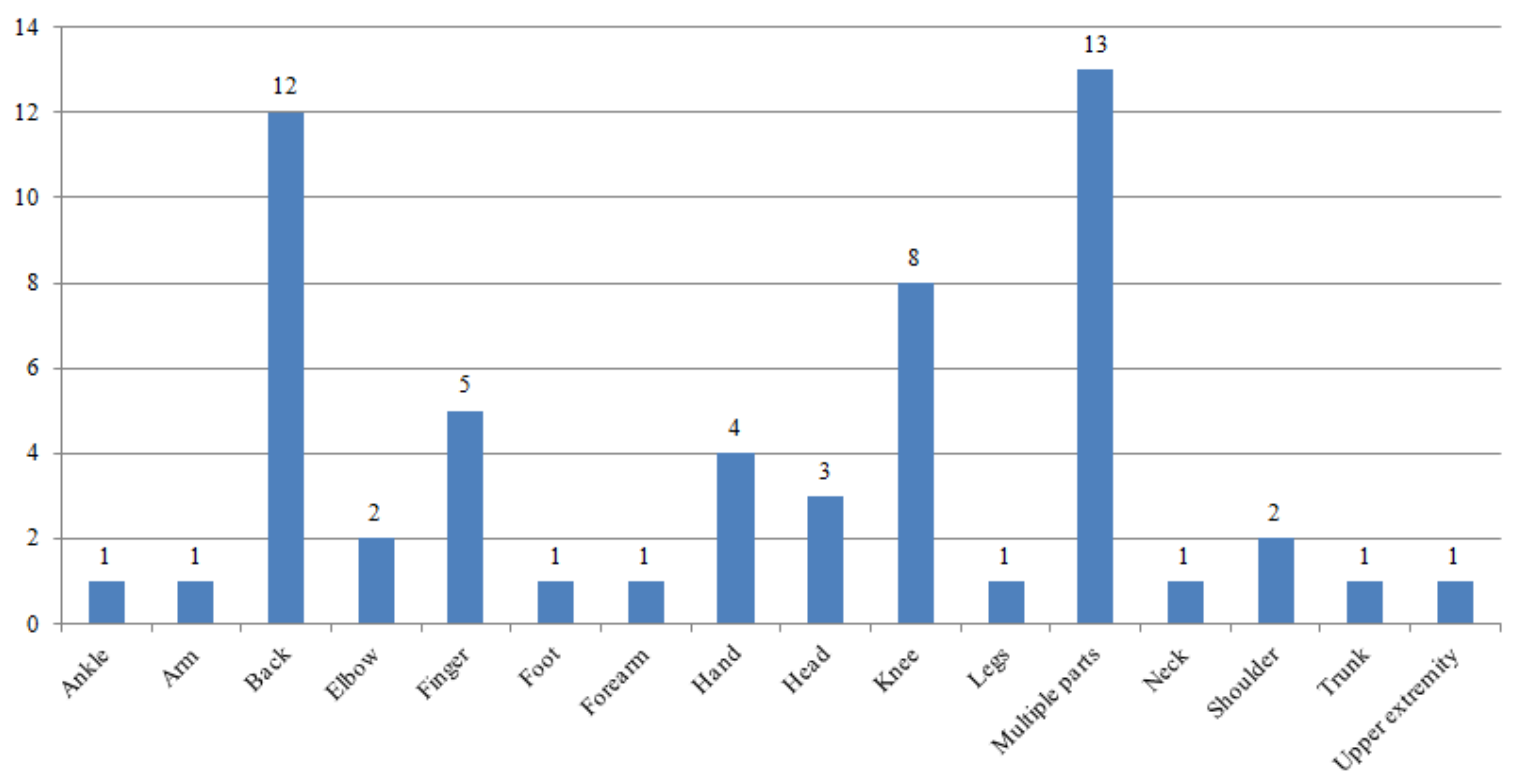

Figure 4.19 Truck-related injuries by injured body parts

Figure 4.19 shows the distribution of truck-related injuries by injured body parts. "Back" is listed as the second most frequently injured body part following "Multiple parts" According to MSHA (2014), back injuries account for about one-fourth of the lost-time injuries in the mining industry. Randolph and Boldt (2005) listed "Back" first in rank in lost-time injuries. Training and education on back conservation and maintenance are suggested. In addition, miners should be trained to pay attention to prevent sprains and strains, and corresponding education and best practices should be offered.

\subsection{Intervention strategies for haul truck-related fatal accidents}




\subsubsection{Safety Regulations}

The U.S. Department of Labor's Mine Safety and Health Administration (MSHA) is a federal regulatory agency that develops and enforces safety and health rules for all U.S. mines, and provides technical, educational, and other types of assistance to mine operators (MSHA, 2014a). This agency works cooperatively with industry, labor, and other federal and state agencies to improve safety and health conditions for all miners in the U.S. (MSHA, 2014a).

Each of the MSHA investigation reports related to haul truck-related fatalities in surface coal mining in $\mathrm{WV}$ contains a section related to corresponding corrective actions. Based on these reports, the Table 4.14 was compiled, which summarizes the root causes of haul truck-related fatalities and corresponding corrective actions proposed by MSHA.

The pertinent government safety standards for surface powered haulage, including haul trucks, can be found in Title 30 Code of Federal Regulations (CFR), Part 56 and 57 (30 CFR, 2013). These standards cover traffic rules, signals and warning signs, restriction for unauthorized persons on haulage roads, adequate brakes, equipment inspection, recording of and correction of defects, deenergizing machinery and locking prior to repairs, safe operation, berms, audible warning devices, unattended vehicles, operating speeds, seat belts, and the establishment of communication between equipment operators and pedestrians. 


\section{Table 4.14 Root causes and corrective actions}

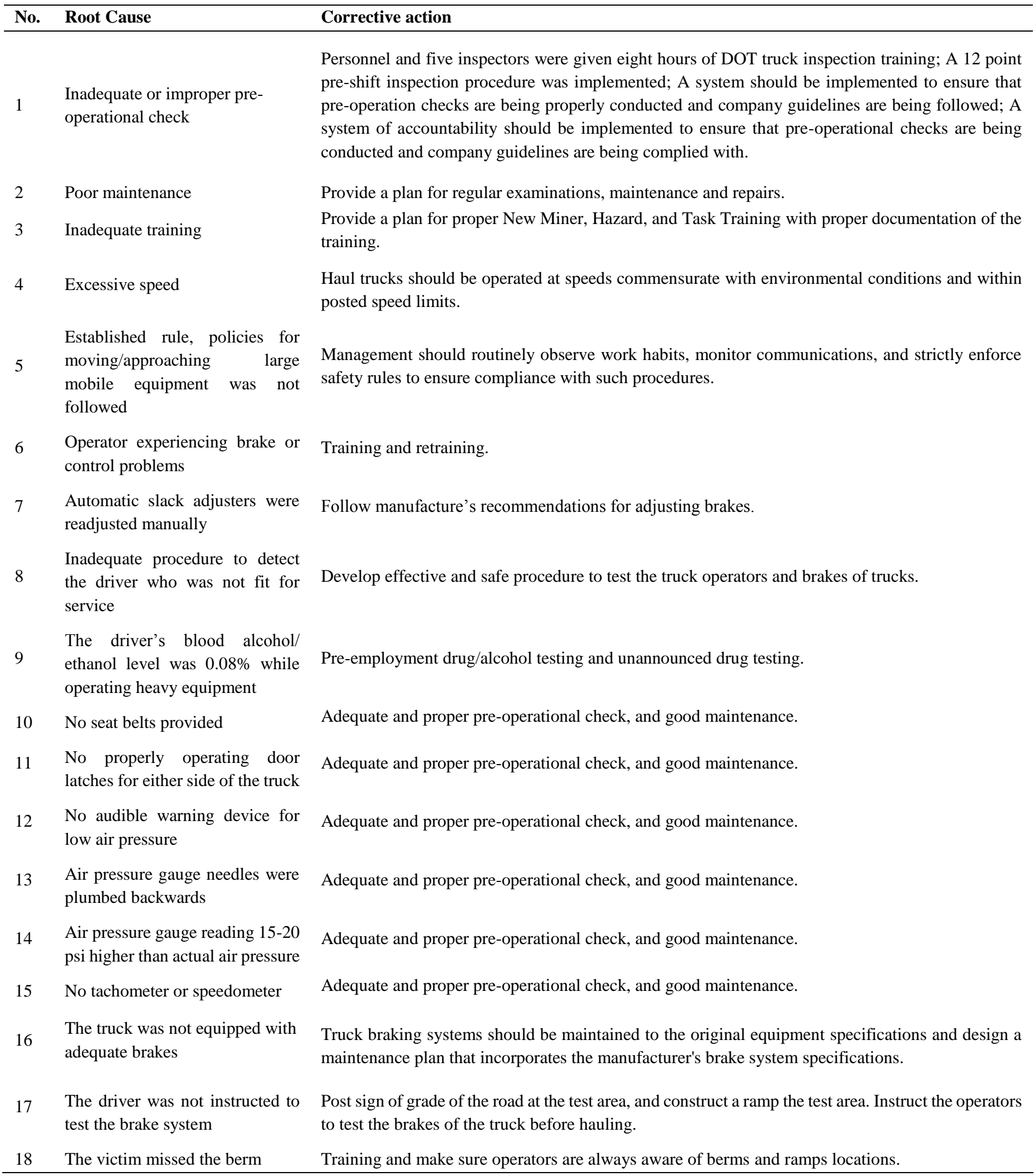


The 30 CFR Part 48 subpart B includes training and retraining regulations for miners working at surface mines, including minimum courses for training and retraining, hours of instructions, and records of training. Part 77 lists the requirement of mandatory safety standards for surface coal mines. Regulations in Part 77 that are closely related to haul trucks are: $30 \mathrm{CFR} \S 77.404$ (machinery and equipment; operation and maintenance), 30 CFR $§ 77.1605$ (loading and haulage equipment; installations), 30 CFR $\S 77.1606$ (loading and haulage equipment; inspection and maintenance), 30 CFR $\S 77.1607$ (loading and haulage equipment; operation), and 30 CFR $\S$ 77.1606 (dumping facilities).

The 30 CFR $§ 77.404$ (CFR, 2013) states that:

(a) Mobile and stationary machinery and equipment shall be maintained in safe operating condition and machinery or equipment in unsafe condition shall be removed from service immediately.

(b) Machinery and equipment shall be operated only by persons trained in the use of and authorized to operate such machinery or equipment.

(c) Repairs or maintenance shall not be performed on machinery until the power is off and the machinery is blocked against motion, except where machinery motion is necessary to make adjustments.

(d) Machinery shall not be lubricated while in motion where a hazard exists, unless equipped with extended fittings or cups.

The 30 CFR $\S 77.1606$ states that: 
(a) Mobile loading and haulage equipment shall be inspected by a competent person before such equipment is placed in operation. Equipment defects affecting safety shall be recorded and reported to the mine operator.

(b) Carriers on aerial tramways, including loading and unloading mechanisms, shall be inspected each shift; brakes shall be inspected daily; ropes and supports shall be inspected as recommended by the manufacturer or as physical conditions warrant. Equipment defects affecting safety shall be reported to the mine operator.

(c) Equipment defects affecting safety shall be corrected before the equipment is used.

The 30 CFR $\S 77.1708$ requires that a program of instruction with respect to safety regulations and procedures shall be established, maintained, and followed throughout the mine. The $30 \mathrm{CFR} \S$ 77.1713 states that the active working area shall be examined at least once during each working shift, and persons shall be withdrawn from the area affected if any hazard is found. Subpart $\mathrm{N}$ includes standards for first aid supplies and personal protective equipment, such as hard hats, protective footwear, eye protection, protective clothing, safety belts, and lines. Subpart S covers, but is not limited to, intoxicating beverages and narcotics in and around mines, housekeeping, and barricading/warning signs where subtle hazards exist.

MSHA (2008) proposed a rule regarding alcohol and drugs that applies to coal mines, coal contractors, and non-office employees. This proposed rule requires mine operators to establish an alcohol- and drug-free mine program to prevent workplace accidents, injuries, and fatalities in mines caused by the use or abuse of alcohol and/or drugs. MSHA stipulates that "each miner performing safety-sensitive job duties and their supervisors will be required to participate in pre- 
employment, random, post-accident, and/or reasonable-suspicion alcohol- and drug-testing, upon selection or at the request of management" (MSHA, 2008). Detailed regulations can be found in 30 CFR Parts 56, 57, and 66.

MSHA recommends "Reasonable Suspicion Testing," which is conducted when supervisors document observable signs and symptoms that lead them to believe someone may be using alcohol or drugs, or otherwise violating the alcohol- and drug-free mine policy (MSHA, 2007). MSHA (2007) suggests that deciding that there is reasonable suspicion that a miner is using or abusing alcohol or drugs typically relies on evidence such as direct observation of use or possession of alcohol or drugs, physical symptoms of being under the influence, or patterns of abnormal or erratic behavior. In addition, MSHA (2007) suggests that supervisors should also keep an eye on such signs as physical condition (chills, smell of alcohol, sweating, weight loss, physical deterioration), emotional condition (increased aggression, anxiety, burnout, denial, depression, paranoia), behavior (excessive talking, impaired coordination, irritability, lack of energy, limited attention span, poor motivation), and other signs, including continual missed appointments and excessive or unexplained absences or days off. Alcohol tests and operator's pre-operation mental outlook and behavior should be documented on a checklist before every shift. In addition, supervisors should note whether the operator is fatigued or in a bad mood. A checklist for the tests should be developed and recorded on a daily basis before every shift.

Knowledge and understanding of pertinent government safety standards for surface-powered haulage are very important, and safety regulations should always be strictly followed by mine personnel. 


\subsubsection{Training and Education}

Knowledge of and regular compliance with mandatory MSHA regulations are fundamental, but are not by themselves a guarantee of successful prevention. Compliance with rules and regulations must be combined with training and education.

Training and education are of critical importance in that they help to improve operators' safety awareness, safety skills and knowledge, and tendency to follow established safety rules. Mine safety and health professionals have long recognized education and training as a critical element of an effective safety and health program.

Workers who operate haulage machines, including haul trucks, should develop a "Zero Compromise" safety attitude (MSHA, 2006), meaning that they will not operate equipment that is not properly maintained. This requires operators to have enough knowledge of equipment information and pre-operational check. It is stated by MSHA (2006) that an operator's knowledge of the machine and how it works is directly proportional to operator's ability to safely operate the machine and to control it in an emergency situation. Federal regulations (30 CFR, Parts 46 and 48) require mine management to provide initial safety and health training to all new miners, as well as a minimum of 8 hours of refresher training each year (Peters, 2002).

Studies show that adults respond best through "personal experience, group support, or mentoring" (Kowalski and Vaught, 2002; Peters, 2002). It has been shown that hands-on training is superior to traditional training. By analyzing 95 studies from 1971 to 2003, Burke et al. (2006) identified that "the most engaging methods of safety training are, on average, approximately three times 
more effective than the least engaging methods in promoting knowledge and skill acquisition." It was also revealed that "the most engaging methods of safety training are, on average, most effective in reducing negative outcomes such as accidents."

Burke et al (2006) defined "most engaging methods" as hands-on training and behavioral modeling; "moderately engaging" was defined as instruction with direct feedback; and "least engaging" was defined as lectures and videos. Behavioral modeling is a type of training in which operators are encouraged to act and respond as their specified role models do in similar situations. Hands-on training and behavioral modeling should be provided regularly and frequently to truck operators.

Training regarding pre-operational check is of crucial importance in that inadequate or improper pre-operational check was the most frequent root cause in truck-related fatal accidents in WV. Schaum's findings (2007) revealed that pre-operational inspection training programs would address the significant contributing factors in haul truck-related accidents. McMahan et al (2010) also reported that problems not detected during pre-operational checks can result in costly mechanical failures and operator injuries.

It's probably not enough to provide only hands-on training in order to improve training in preoperational check; it also can be better complemented by the application of Virtual Reality technology. The Virtual Reality training program for pre-operational check was developed by Schaum (2007). This program enables operators to gain a better understanding of exactly what 
various truck parts need to be inspected for, and what the possible outcomes could be if the parts were left unchecked.

The parts of the truck include headlights, ride cylinders, brakes, tires, hydraulic hoses, tie rods, bell crank, fuel tank, mud flaps, bed cylinders, rock ejectors, pivot joints, struts, rear lights, dog bone, and hydraulic tank. The Virtual Reality training program consists of three major segments: a virtual tour, a pre-shift inspection, and the results. The program was developed assuming that the operator would have gone through the standard classroom-like safety training on haul trucks. To complete the Virtual Reality training program from start to finish, the operator can expect to spend approximately 30 minutes.

The first phase of the program introduces the operator to the information that is required to conduct adequate and proper pre-operational check. The operator is guided on a virtual tour around a haul truck to identify the parts. Information is displayed on a window to show the name of each part and to explain defects to look for and corresponding measures to take. Figure 4.20 shows an example of a hydraulic tank and the information window associated with it.

During the second phase of training, the operator is presented with a broken haul truck and asked to perform a pre-operational check. After the operator completes the pre-shift inspection, a resulting animation will play. If the operator either missed a broken part, or identified a critical problem as an after-shift problem, the animation will display that particular part failing. If the operator missed more than one item, the animation will show the consequences of missing the more severe part among the items that are missed. 


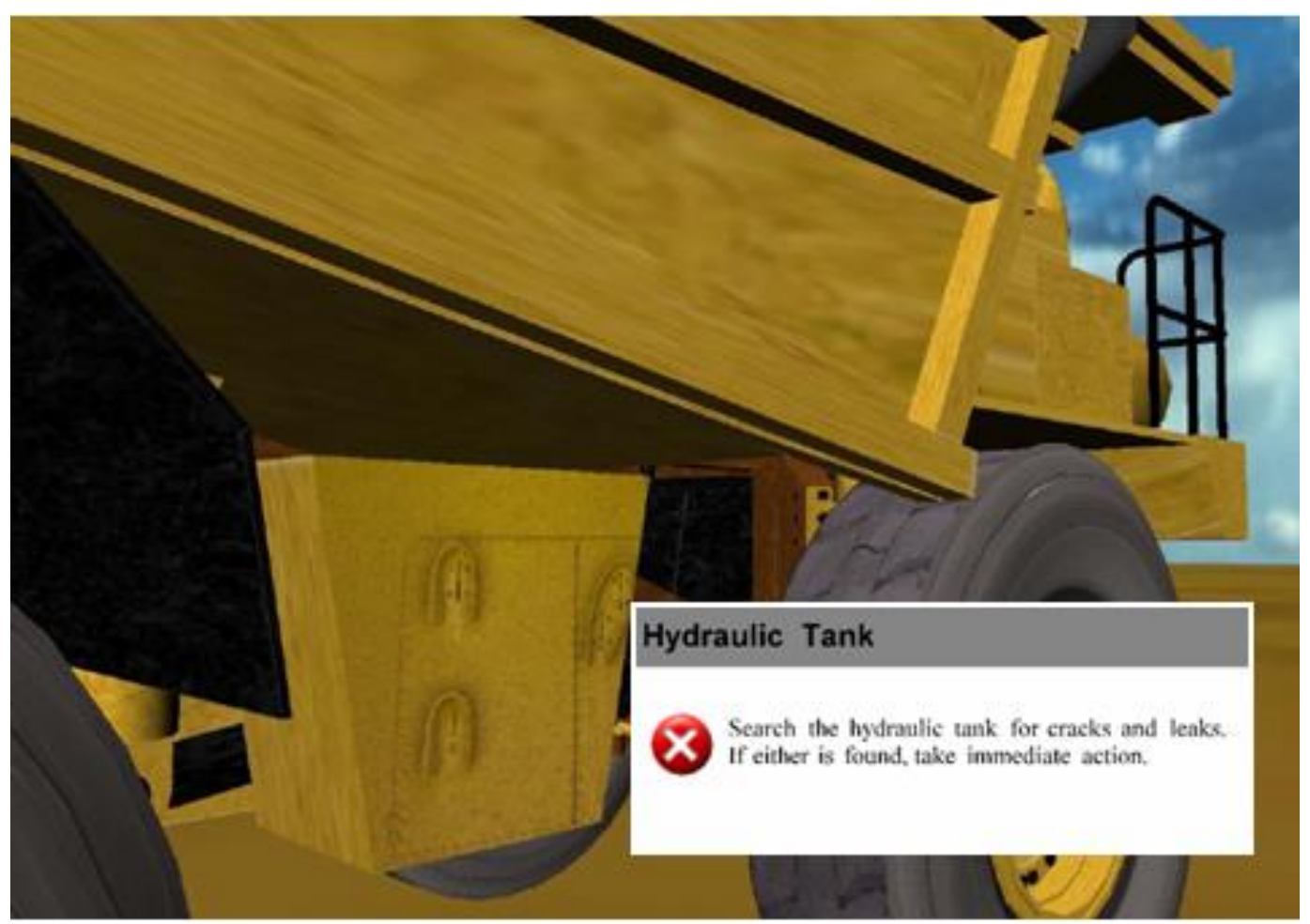

Figure 4.20 The hydraulic tank during the virtual tour (Schaum, 2007)

Operator training on pre-operational check could be greatly improved by using this Virtual Reality modeling system program as a complement to and reinforcement for on-site, hands-on preoperational check training. The Virtual Reality program saves time and money, as it does not require a truck to be brought from production. In addition, operators can easily refresh their preoperational check skills by using the Virtual Reality program.

Training and education does not simply improve and refresh operators' working and safety skills, but also increases their safety awareness and willingness to participate in and comply with safety rules. In every MSHA investigation report, best practices are proposed to prevent similar accidents from happening in the future. Table 4.15 shows all the best practices proposed by MSHA after the review of 12 truck-related fatal accident reports in WV. 


\section{Best Practices}

Never operate a truck or other mobile equipment without using a seat belt.

Know the truck's capabilities, operating ranges, load-limits and properly maintain the brakes and other safety features.

Observe all speed limits, traffic rules, and ensure that grades on haulage roads are appropriate for haulage equipment being used.

Conduct pre-operational checks to identify defects that may affect the safe operation of equipment before being placed into service.

Monitor work habits routinely and examine work areas to ensure that safe work procedures are followed.

Train all employees on proper work procedures, hazard recognition and avoidance, and proper use of roadway berms.

Always select the proper gear and downshift well in advance of descending the grade.

Maintain equipment braking and steering systems in good repair and adjustment.

Do not attempt to exit or jump from a moving vehicle.

Maintain control of equipment at all times.

Provide and maintain adequate berms and other barriers of mid-axel height for roadways where a drop-off exists.

Conduct thorough, in depth task training to cover potential hazards.

Ensure the stability of the roadbed. Avoid operating haulage equipment on soft shoulders.

Ensure that seat belts are in good condition and operating properly.

Operate loaded trucks in an appropriate gear for the grade, load, and speed.

Never operate a truck where the brakes will not stop it.

Never rely on engine brakes and transmission retarders as substitutes for keeping brakes properly maintained.

Use properly constructed berms and other impeding devices around sediment ponds.

Ensure, by signal or other means, that all persons are clear before moving equipment.

When approaching large mobile equipment, do not proceed until you make eye contact with, or obtain approval from, the equipment operator.

Minimize situations where smaller vehicles need to approach large haul trucks.

Do not park smaller vehicles in a large truck's potential path of movement.

Equip smaller vehicles with flags or strobe lights, positioned high enough to be seen from the cabs of haulage trucks. Equip larger vehicles with cameras to monitor blind spots and ensure that they are properly used.

Stagger the times that vehicles leave assembly areas and separate the parking and travel areas for larger and smaller vehicles.

Understand and follow the safe operating procedures for your equipment.

Parking brakes must be set before exiting the equipment.

Turn the engine off, place the transmission in gear, set the park brake and always make sure the equipment is securely blocked against motion, before performing repair or maintenance work.

Ensure that adequate brakes are provided and maintained. Preventive maintenance should be performed more frequently when trucks operate on steep grade.

Always operate trucks at speeds consistent with grades and road conditions. Use a lower gear on steep grades and do not change gears while descending steep grades.

Dumping locations should be physically and visually examined periodically, especially during periods of changing weather.

Trucks should dump one truck length back from tension cracks and the edge of unstable embankments, and a dozer should be used to push material.

Trucks should back perpendicular to the berm and not run up on the berm when dumping.

Construct roadway berms to appropriate strengths and geometries. 
It is advisable that mining companies follow these best practices enthusiastically. Furthermore, companies should always provide training and education pertaining to these best practices to their operators. Proper use of seat belts should be reflected more in company policies, and the importance of using a seat belt while operating a haul truck should always be emphasized to operators. The safest place to be during an accident is in the cab with a seat belt fastened (MSHA, 2001). Operators should never attempt to jump out of the truck as opposed to simply wearing a seat belt and remaining in the cab.

In addition, it should always be stressed that operators should follow the established rules and procedures, such as driving under speed limits, and follow traffic rules. Truck operators should be educated not to manually readjust automatic slack adjusters. The importance of performing adequate and proper pre-operational check can never be overstressed, and it should be emphasized as well in training classes. It is recommended that Table 4.15 be passed around to operators, and make sure they know these best practices.

Truck operators should be trained to operate the truck before they are assigned to a job task. Retraining and refresher training should be provided. MSHA (2013) listed all the training in 30 CFR Part 48, and training provided must be recorded by the operator on a MSHA Form 5000-23 (training certificate), or an MSHA-approved alternate form. All the MSHA-required training and forms are intended to ensure that operators are provided with advanced training in pre-operational check and other MSHA-approved best practices.

Training and education on truck maintenance is very important since proper and safe truck operation relies to a large extent on good operational truck condition, which is the result of good 
maintenance. After operation, the worker who takes charge of maintaining the equipment should have a checklist for maintenance, and the importance of keeping an accurate record of maintenance should always be stressed. All the brake systems should always be the top priority when being inspected and maintained. Attention should also be paid to the air system and steering linkage. MSHA (2004a) stated that the rear service brakes were found to be capable of providing $78 \%$ of their design braking capacity. Therefore, special attention should be paid to rear service brakes. In addition, the seat belt should be in operable condition. Also, door latches, audible warning device for low air pressure, air pressure gauge, tachometer, and speedometer need to be provided and functional. The maintenance of other parts and components are also of critical significance, as any small detail may cause something hazardous, and any deviation from normal operation should be corrected.

According to MSHA (2006), several steps should be taken to reduce risks during maintenance work: lockout/tag-out before doing work; set parking brake; chock wheels; if engine must be on, work with two people; block dump truck bed; and following manufacturer's recommendations. A well-managed maintenance program for surface powered haulage equipment should be established and strictly followed. The adoption of safe work procedures, incorporating manufacturers' recommendations, is essential in ensuring that workers are not exposed to hazards when performing maintenance or repair work (Kecojevic and Radomsky, 2004).

30 CFR $\S 77.404$ requires, in part, that (a) mobile and stationary machinery and equipment shall be maintained in safe operating condition and machinery or equipment in unsafe condition shall be removed from service immediately, and (b) repairs or maintenance shall not be performed on 
machinery until the power is off and the machinery is blocked against motion, except where machinery motion is necessary to make adjustments. As suggested by Kecojevic and Radomsky (2004), regularly scheduled examinations should be conducted and the equipment must be maintained to the original equipment manufacturer's specifications.

It should be made clear to everyone who performs maintenance work on equipment that poor maintenance may result in extremely dangerous working conditions for truck operators. It is vital to perform all maintenance adequately and thoroughly.

Gaining timely and effective feedback from operators improves the effect of training and education. Daniels (1994) defines feedback as an activator, which means communication precedes behavior in order to direct it. As stated by Geller (2000), interpersonal feedback was interpreted as a behavioral consequence. Geller (1996) concluded that feedback can be either an activator or a consequence, depending on whether it directs or motivates behavior. Whatever the feedback is, from operator or maintenance man to supervisor, it should always be prompt and effective. Operators need to share their ideas about the current training system. Supervisors should be notified if there is anything abnormal, either outside or inside the truck. Mine management should always encourage employees to report mistakes, challenge or question decisions, or provide constructive criticism, and should provide a working environment in which feedback is welcome and expected (Kosmoski, 2014).

Operators should always be encouraged to share near-misses; furthermore, a formal process for documenting these near-misses should be developed, in order to track incidents and determine if 
patterns are occurring. Feedback is critical to ensure a safe and secure working environment. Establishing a positive interaction of training and feedback between management and operators can be beneficial in improving operators' safety performance.

It was reported that on a national scale that the most common violations in surface and underground coal mining activities in 2009 were equipment operation, maintenance, and inspections (Caterpillar, 2009). It was recommended that, in addition to performing pre-operational check and vehicle inspection, Pre-Operational Checks and Machine Walk Around Toolbox Talks should be held to stress the critical role of pre-operational check in safety. Weekly toolbox talk can improve operators' safety awareness and sense of responsibility. In every toolbox talk, it is of great importance to make sure operators know that if, at any time, they find themselves working in what they consider an unsafe condition, putting either themselves or others at risk, they can and should stop, report the condition, and ask for help. MSHA has different weekly toolbox talk topics which are publicly accessible on the MSHA website (2014b).

Observation is important, not only in checking operators' mental and physical status to minimize health and safety risks, but also in increasing the possibility that working procedures are being carried out properly, in order to maximize efficiency and productivity.

It is suggested that a "safety score system" be introduced, in which every operator would be graded with a score ranging from 0 to 10 . Every operator would start his or her shift with a score of 10 , and one point would be deducted for every time the operator engaged in any unsafe behavior. A safety score would be given after every shift. A score of 10 indicates that operator's behavior is 
"safe," a score between 7 to 9 (including 7) indicates that the operator and management "need improvement," and a score below 7 indicates that operator's behavior is "dangerous," and relevant training and education should be provided to the operator in a timely manner. In addition, related supervision mechanism should follow up and make sure the operators are scored factually. Table 4.16 shows suggested safety score and corresponding indication.

Table 4.16 Safety score and rating

\begin{tabular}{cc}
\hline Safety Score & Score Rating \\
\hline 10 & Safe \\
$7-9$ & Need improvement \\
$0-6$ & Dangerous \\
\hline
\end{tabular}

The safety score should be recorded carefully, and discussed regularly. In addition an award mechanism is recommended for operators with scores of 10; likewise, a penalty mechanism can be introduced when a score below 7 is reached, despite the fact that such score may not necessarily cause an accident or near miss. Operators may be motivated and inspired to work more carefully and cautiously under the award and penalty mechanisms.

According to Whiting and Bennett (2003), establishing safety performance objectives tied to bonuses, merit increases, and promotions is viewed as the most effective strategy for gaining employee involvement. Almost 79 percent of companies surveyed have established such programs, and 63 percent of those rate them at eight (out of ten) or higher for effectiveness.

Safety scores should be analyzed and discussed in safety meetings on a weekly or other regular basis. Operators should be given a chance to share their thoughts on how to best operate in order to get a high safety score, as well as their own ideas about how to operate safely. In addition, 
suggestions on checklist revision, if any, should be proposed to make the checklists more practical and comprehensive.

It is also recommended that a "suggestion box" be introduced, in the case of operators who may be more willing to offer safety advice anonymously. In light of the fact that many people in management may not take the suggestions seriously (Kosmoski, 2014), the idea should be spread, especially among safety management professionals, that suggestions from operators should be carefully and seriously considered. The first and primary reason for this is that operators are the ones who know best about the condition of equipment, environment, and their colleagues. Also, if operators' suggestions are not taken seriously, it is highly likely that they may feel a sense of frustration and their enthusiasm would be negatively impacted. It may also give them an impression that safety is not very important in their mines since management does not appear to care about safety. If operators feel that what they say is constantly disregarded, they may lose enthusiasm for improving the safety environment, and then, safety is placed in danger.

Suggestions raised by operators should therefore be given careful attention and consideration, and their advice should be followed to modify any part where reasonable, applicable, and necessary. A positive interaction and open communication between management and operators helps greatly to decrease the possibility of accidents, keeping the whole system moving forward in a safely functioning direction.

Safety management has a significant influence on safety and can be achieved through various initiatives. Management communication has to be perceived as valid and crucially important by 
everyone in order to investigate whether a positive safety climate exists. The assessment of employees' perceptions and attitudes can be conducted through surveys. Perception surveys have been widely used as the most popular method for the assessment of the safety environment (Zhou, 2009; Zhou et al., 2011; Choudhry et al., 2009; Mohamed et al., 2009).

As reported by Neal et al. (2000), such surveys increase employees' safety knowledge and provide motivation to employees to ensure adherence to safety regulations and participation in safety activities. In addition, the results and finding from the surveys also reveal the strengths and weaknesses in current safety management practices for remedial actions. A revised questionnaire from the New South Wales government (NSW, 2010), aiming to assess the attitude towards safety, was applied in this study. The questionnaire can be found in Appendix A. It is recommended that this questionnaire be passed around to haul truck operators. Furthermore, questions in the questionnaire should be modified as the safety environment changes. All the questions should be answered, and only one answer should be provided to each question. If the operators are not sure about the exact answer, they should choose the closest statement. After collecting all the questionnaires, the answer to each question should be summarized, and the weak part(s) in the safety system should be determined. After determining the weak part(s) in the safety system, more attention and resources should be allocated accordingly. Countermeasures should be proposed and enforced in a timely manner.

\subsubsection{Conditions of Haul Trucks Working Environment}

The working environments of haul trucks include loading areas, haul roads, and dump sites. 
The loading areas are critical parts of any surface mine, and are often very congested. Truck operators should stay alert to other equipment that may be operating in the area and occasional unexpected pedestrians (MSHA, 2001). Truck operators are expected to make sure they can see clearly through the window and that their mirrors are properly adjusted. Alarms, especially backup alarms, should work properly.

Eight out of the 12 accidents in surface coal mines in WV occurred on haul roads, two were on access roads, one was on a dump site, and one was at a loading area. Obviously, the primary concern is on haul roads. Understandable and visible signs indicating slope grade and slope length should be provided along the haul road, as is shown in Figure 4.21. The triangle indicates that the operator is going down at a steep grade slope. 


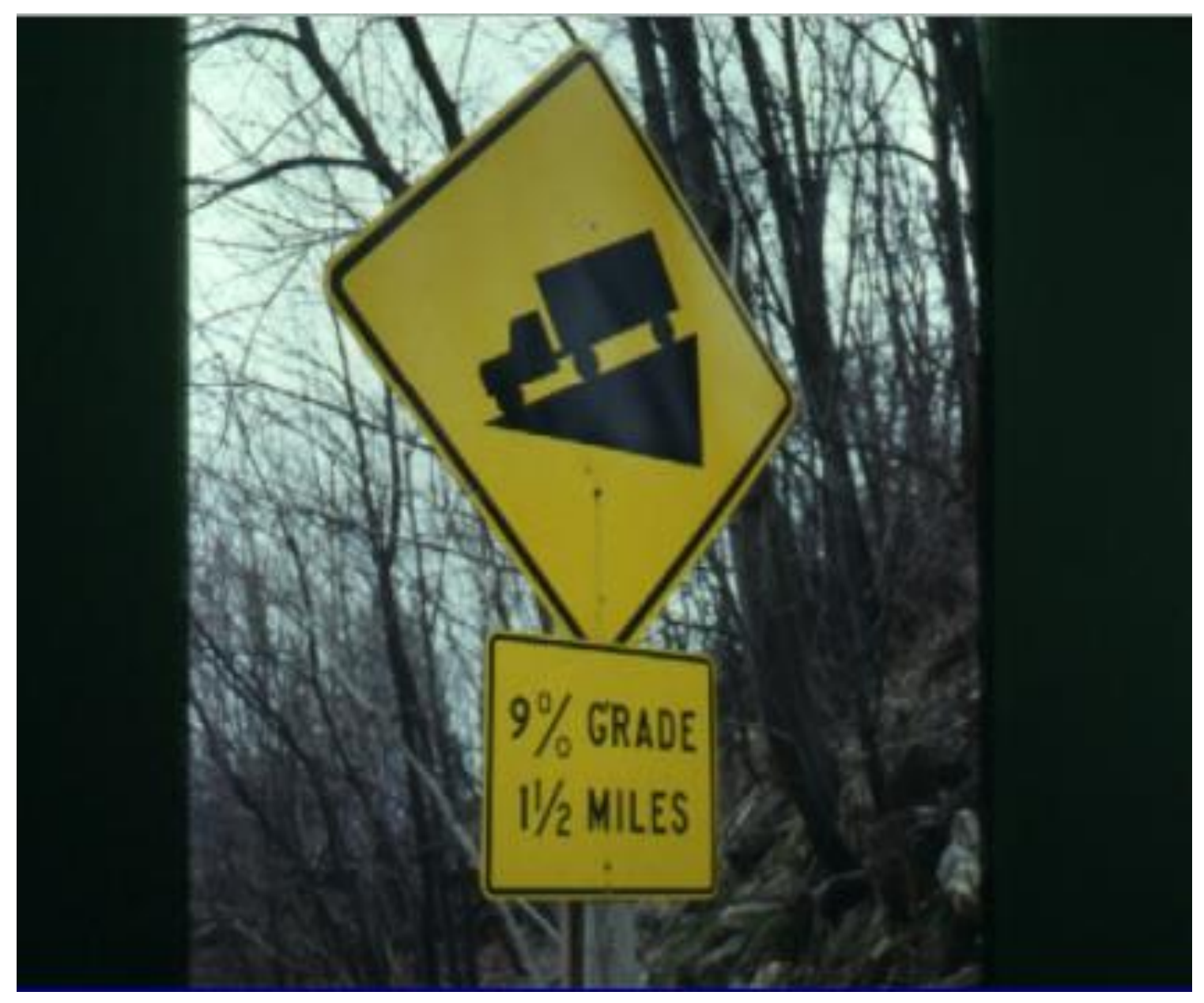

Figure 4.21 Steep grade slope warning sign (MSHA, 2004)

In addition to the steep grade sign, measures should be provided for runaway trucks in areas where grades are steep, such as escape ramps. "RUNAWAY TRUCK RAMP” signs (Figure 4.22) should indicate the direction of the ramp, informing truck operators of the presence and location of the escape ramp in case an operator loses control of a truck. Escape ramps and signs do not replace good maintenance, proper truck loading, and a sound driver training program, but do provide a form of safety insurance (MSHA, 2004). 


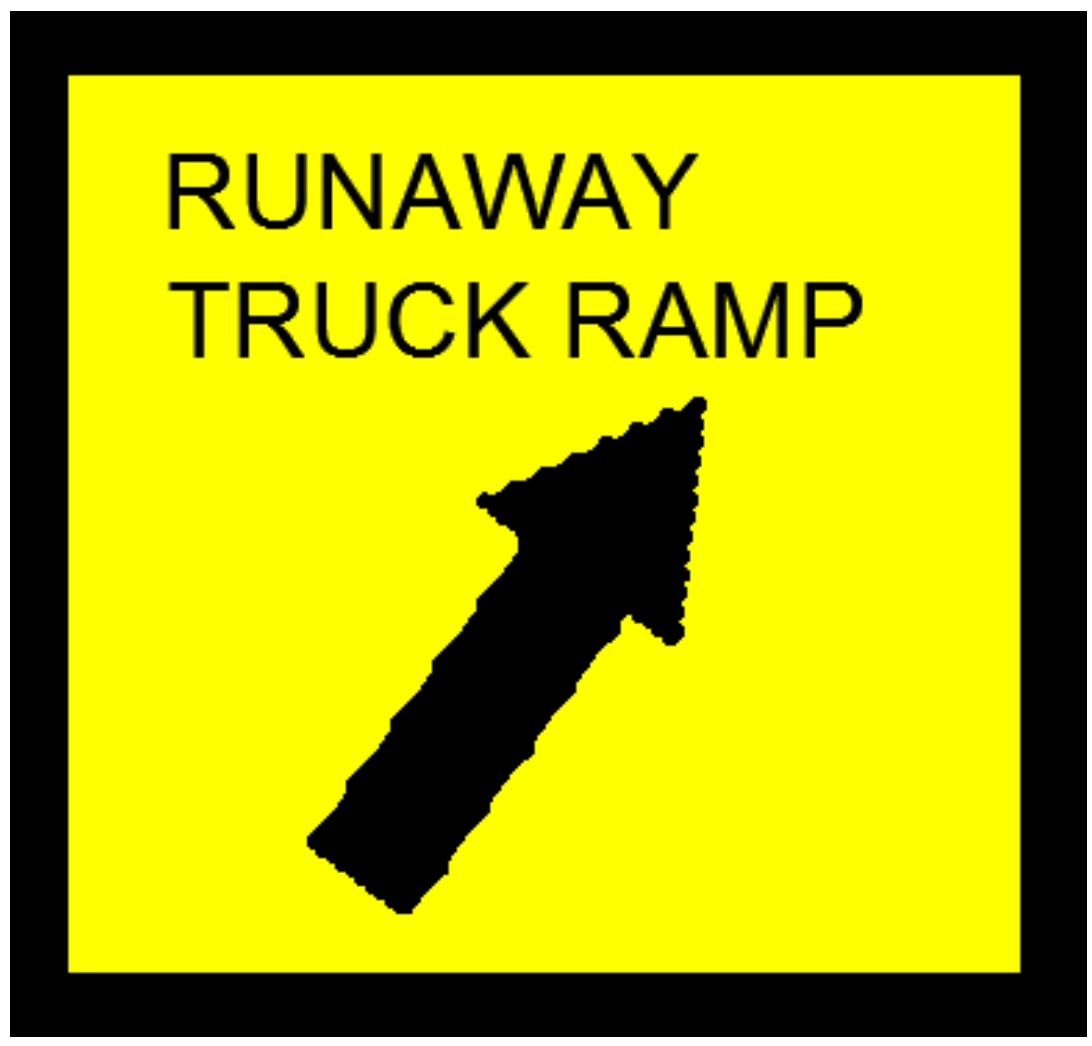

Figure 4.22 Runaway truck ramp sign (MSHA, 2004)

Only two victims in the 12 truck-related fatal accidents were confirmed to have been wearing seat belts when the accidents happened. A logical assumption can be made that the severity of the accidents could have been mitigated had the operators worn seat belts. In terms of environment, it is suggested that a "BUCKLE-UP" sign (Figure 4.23) be provided at the place where the trucks start hauling, in case operators forget to do so. Signs should be provided separately and wide apart in the event that operators may stare at the sign for too long and cause a hazardous situation for them.

Speed limit signs (Figure 4.24) are helpful in alerting operators of potentially adverse road conditions and warning them to be prepared. Speed limit signs should be provided where the haul road requires slower-than-normal speed to safely negotiate a hazardous condition. It should be 
noted that it is better to indicate the right-of-way rule if it is unusual on the mine property, especially for those who are not familiar with the rules in the mine. In addition, such signs should be placed on both sides of roadways for vehicles coming from two opposite directions.

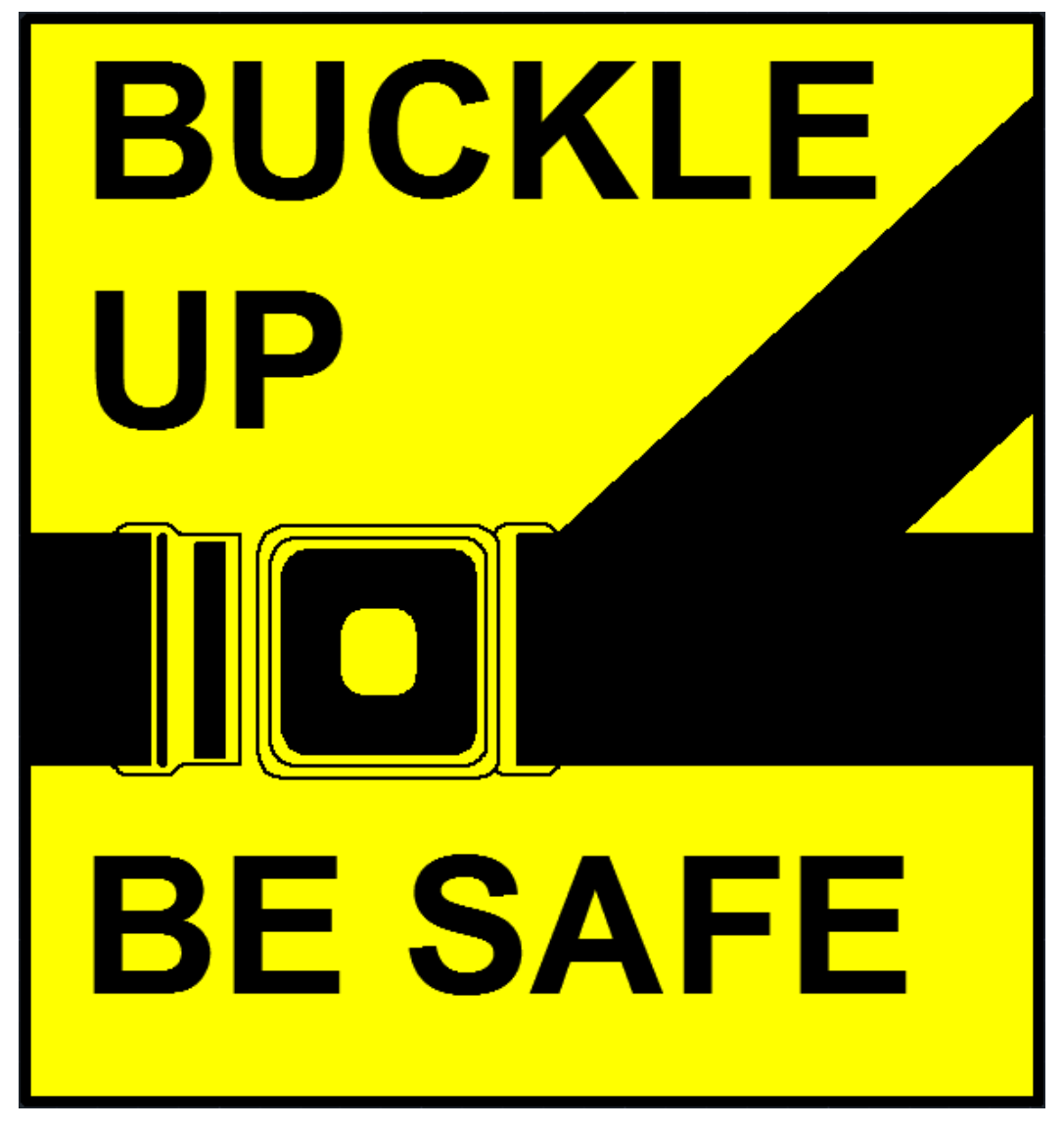

Figure 4.23 Buckle-up sign

It is advisable to reduce the slope grade as much as possible. According to Kaufman and Ault (1977), a safe haulage environment cannot be created if the grades are designed without consideration for braking limitations of equipment in use. The average slope grade of surface mining accident scenes in WV was $9.83 \%$, and Table 4.17 shows the stopping distance estimated 
in feet for $10 \%$ grade. It is clear that trucks call for a fairly long stopping distance on such a slope grade, regardless of its speed. The GWV represents a gross vehicle weight.

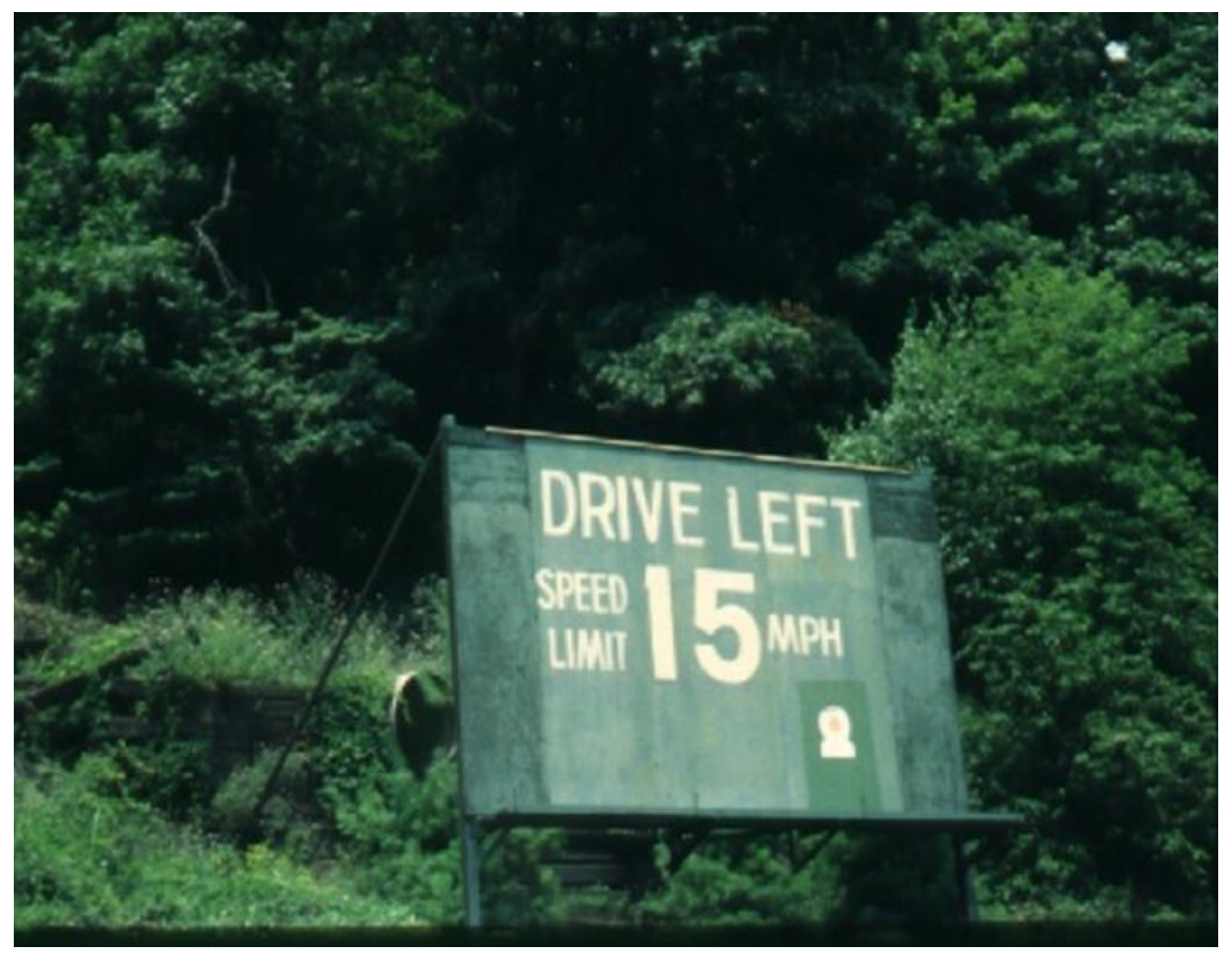

Figure 4.24 Speed limit sign (MSHA, 2004)

Figure 4.25 shows the relationship between the slope grade and truck speed. It is apparent that a reduction in grade significantly increases a vehicle's ability to attain uphill speed. Furthermore, as reported by MSHA (2004a), steep grades can reduce or eliminate driver's margin for error, especially if there is a lapse in equipment maintenance or if a truck is overloaded. 
Table 4.17 Truck's stopping distance (ft) when the slope grade is 10\% (MSHA, 1999)

\begin{tabular}{|l|r|r|r|r|r|}
\hline Friction $=0.15$ & \multicolumn{5}{|c|}{ Truck Speed, (mph) } \\
\hline $\begin{array}{l}\text { Truck GVW, } \\
\text { (tons) }\end{array}$ & 10 & 15 & 20 & 25 & 30 \\
\cline { 2 - 6 } & \multicolumn{5}{|c|}{ Stopping distance, $(\mathrm{ft})$} \\
\hline 1 to 18 & 101 & 187 & 296 & 430 & 588 \\
\hline 18 to 35 & 119 & 212 & 330 & 471 & 637 \\
\hline 35 to 70 & 138 & 239 & 365 & 514 & 687 \\
\hline 70 to 125 & 158 & 268 & 401 & 558 & 739 \\
\hline 125 to 200 & 169 & 282 & 420 & 581 & 766 \\
\hline over 200 & 180 & 298 & 439 & 604 & 793 \\
\hline
\end{tabular}

\begin{tabular}{|l|r|r|r|r|r|}
\hline Friction $=0.30$ & \multicolumn{5}{|c|}{ Truck Speed, (mph) } \\
\hline $\begin{array}{l}\text { Truck GVW, } \\
\text { tons) }\end{array}$ & 10 & 15 & 20 & 25 & 30 \\
\cline { 2 - 6 } 1 Stopping distance, (ft) \\
\hline 18 to 18 & 62 & 105 & 155 & 212 & 277 \\
\hline 35 to 35 & 74 & 121 & 176 & 238 & 309 \\
\hline 70 to 125 & 86 & 138 & 198 & 266 & 341 \\
\hline 125 to 200 & 99 & 156 & 221 & 294 & 374 \\
\hline over 200 & 106 & 166 & 233 & 308 & 391 \\
\hline
\end{tabular}

\begin{tabular}{|l|r|r|r|r|r|}
\hline Friction $=0.45$ & \multicolumn{5}{|c|}{ Truck Speed, (mph) } \\
\hline $\begin{array}{l}\text { Truck GVW, } \\
\text { (tons) }\end{array}$ & 10 & 15 & 20 & 25 & 30 \\
\cline { 2 - 6 } 1 to 18 & 55 & 89 & 128 & 171 & 218 \\
\hline 18 to 35 & 65 & 104 & 147 & 194 & 246 \\
\hline 35 to 70 & 76 & 119 & 167 & 219 & 275 \\
\hline 70 to 125 & 88 & 135 & 187 & 244 & 305 \\
\hline 125 to 200 & 94 & 143 & 198 & 256 & 210 \\
\hline over 200 & 100 & 152 & 208 & 269 & 335 \\
\hline
\end{tabular}

\begin{tabular}{|l|r|r|r|r|r|}
\hline Friction $=0.60$ & \multicolumn{5}{|c|}{ Truck Speed, (mph) } \\
\hline \multirow{2}{*}{$\begin{array}{l}\text { Truck GVW, } \\
\text { (tons) }\end{array}$} & 10 & 15 & 20 & 25 & 30 \\
\cline { 2 - 6 } & \multicolumn{5}{|c|}{ Stopping distance, (ft) } \\
\hline 1 to 18 & 52 & 83 & 116 & 153 & 194 \\
\hline 18 to 35 & 62 & 96 & 134 & 176 & 220 \\
\hline 35 to 70 & 72 & 113 & 153 & 199 & 247 \\
\hline 70 to 125 & 83 & 126 & 173 & 222 & 275 \\
\hline 125 to 200 & 89 & 134 & 183 & 235 & 290 \\
\hline over 200 & 95 & 142 & 193 & 247 & 304 \\
\hline
\end{tabular}

As to the relationship between the stopping distance and the vehicles in the $100,000 \mathrm{lb}$ to 200,000 lb category, MSHA (1999) reported that a 5\% grade reduction translates to a descent speed increase of $6 \mathrm{mph}$ without exceeding safe stopping distance limitations. 


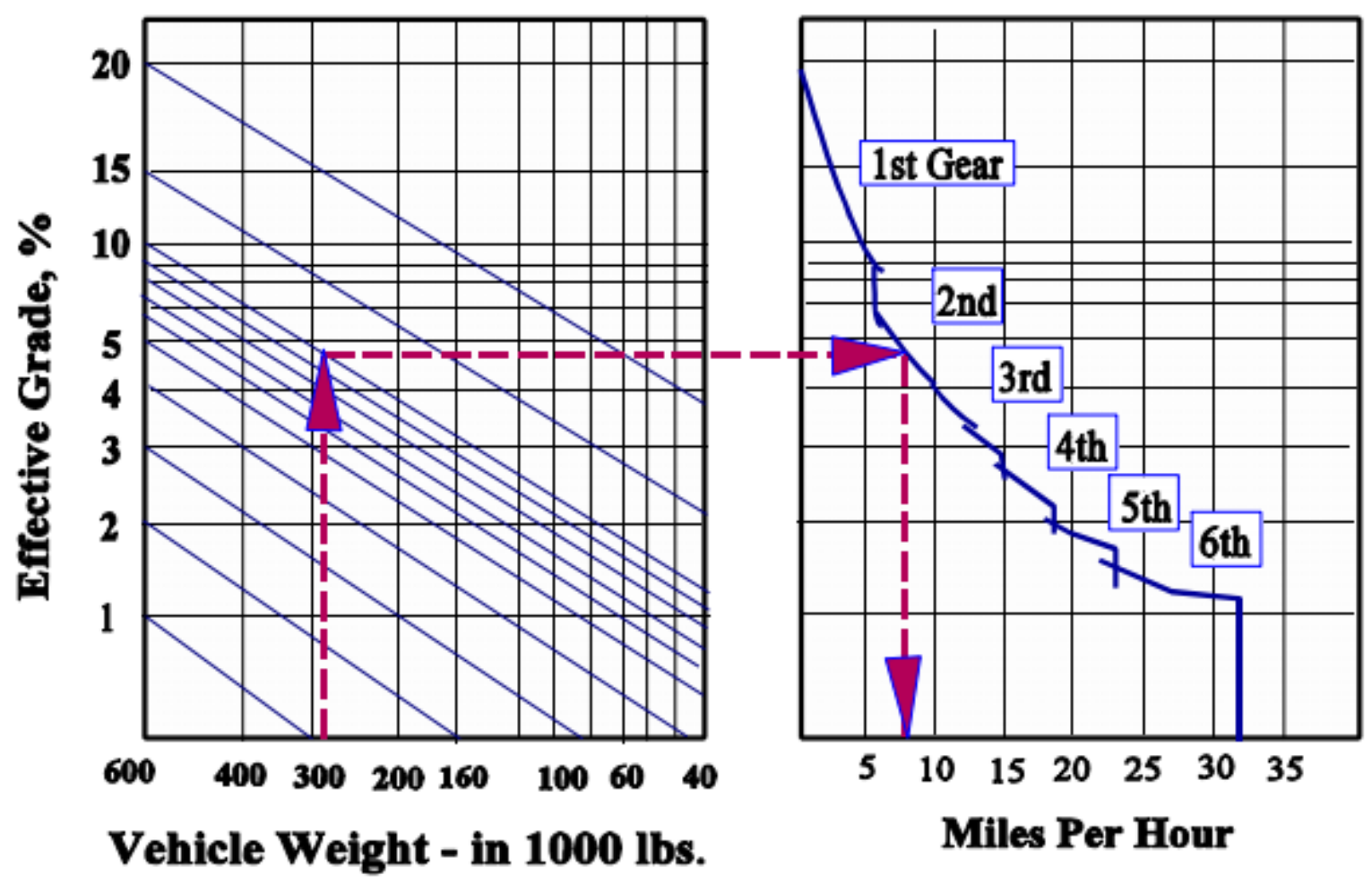

Figure 4.25 Relationship between truck speed and slope grade (MSHA, 1999)

Admittedly, lower grade brings decreased amount of benefits to mine production; also, earthmoving to create flatter gradients would incur greater costs in most cases. Moreover, it is not realistic to modify slope grade flexibly at many mines because of physical constraints, such as adverse geological and topographical conditions. Therefore, it would not be feasible to recommend one optimum maximum grade to suit all operations. Some state regulations limit the maximum grades on haul roads. The maximum overall grade is typically restricted to $10 \%$, with grades to 15\% permitted only for short distances (MSHA, 1999). According to MSHA (1999), on any grade over $10 \%$ it is important that the operator's manual be checked to ensure that the truck can be safely operated and to be aware of what precautions need to be taken. Holman (2006) advised to limit haul road grades to $8 \%-10 \%$ with $2 \%$ rolling resistance. 
Apart from the slope grade of the haul road, the surface condition of the haul road is important with respect to safety as well. If the road surface is not well and regularly maintained, rutting will occur and create haulage intervals where trucks have to slow down to negotiate adverse road conditions. Rough haul roads dramatically increase component wear and maintenance costs. More importantly, these conditions pose a serious threat to truck maneuverability. Therefore, the stability of the entire length of the haul road should be well maintained to create a safer working condition.

Unlike passenger and commercial vehicles with somewhat "standardized" dimensions, surface mine trucks varies drastically in size from one production capacity rating to another. The varying sizes of trucks have to be considered when deciding on the haul road width. As stated by MSHA (1999), a good safety practice with mining equipment is that each lane of travel should provide clearance, on both sides, equal to one-half the width of the widest vehicle in use. Holman (2006) recommends a minimum of 2 - 2.5 truck widths for one-way straights and corners. For two-way traffic, a minimum of $3-3.5$ truck widths in straights and $3.5-4$ truck widths in corners is recommended. The recommended minimum road widths for one-way (straights/corners), two-way (in straights), and two-way (in corners) are shown in Figure 4.26. 


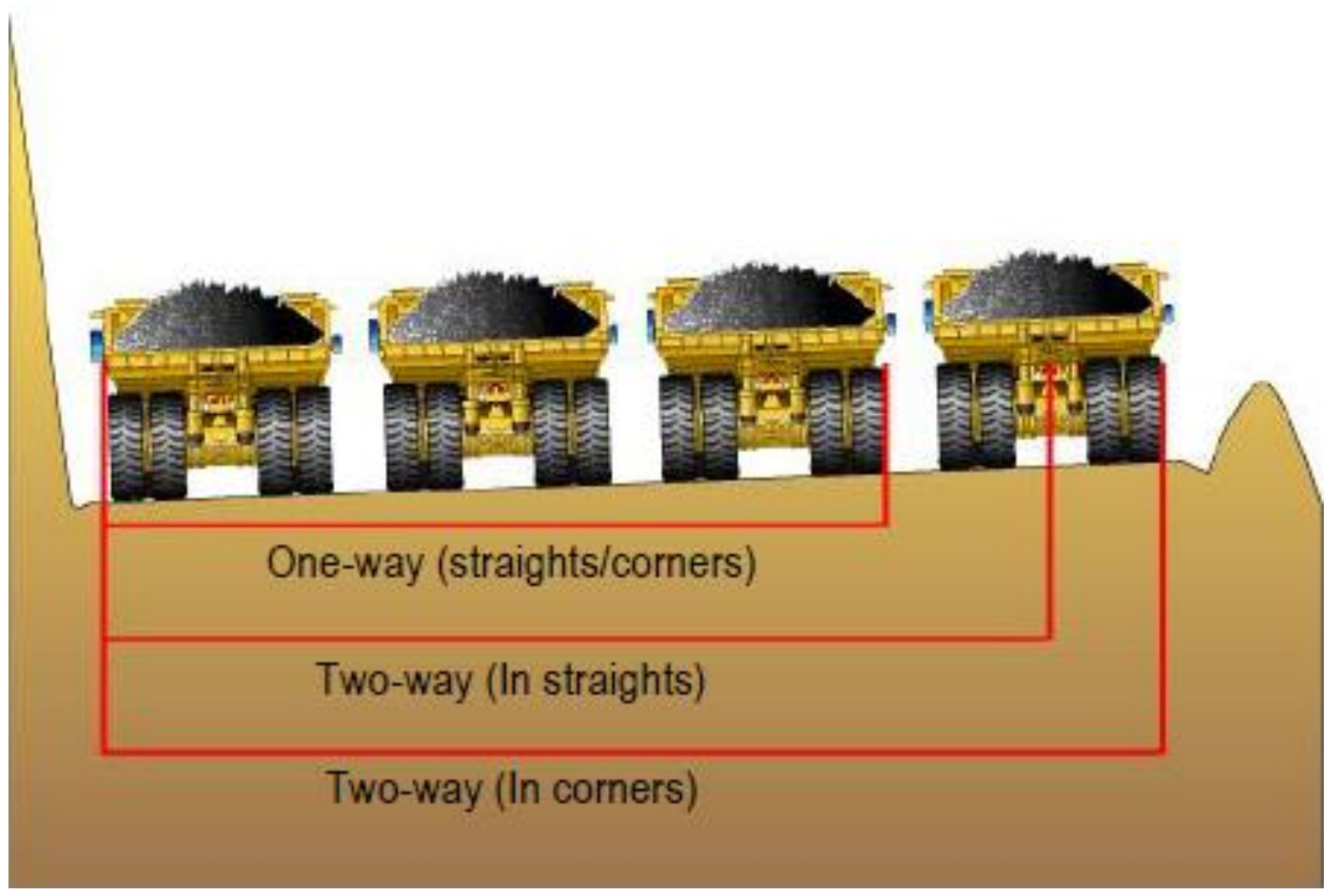

Figure 4.26 Recommended minimum road width (Holman, 2006)

As stated by MinEx (2008), the hazards of working around stockpiles or dump point are generally associated with the nature of (a) the material being stockpiled or dumped; (b) the configuration and placement of the stockpile or dump; (c) the mobile equipment being used; (d) the immediate and overhead environment; (e) the degree of moisture and drainage of the stockpile or dump; and (f) the method of material retrieval. These hazards can result in vehicles colliding, going over the face, slipping down subsided edges, rolling over, contacting power lines, getting buried, or any combination of these. According to the Dump-point Inspection Handbook (MSHA, 2001a), the most common fatal dump-point accidents involve trucks going over the edge of piles. The reasons may either be unsafe dump site condition, unsafe dumping practices, or both. Unsafe equipment dumping practices include: (i) Attempting to dump over the edge of the pile even though there is 
no berm, or the berm is inadequate; (ii) Attempting to dump over the edge even though the area below the dump point has been loaded out and made steeper than the material's angle of repose; (iii) Attempting to dump over the edge in an area where there are cracks; (iv) Backing up at an angle to the edge; (v) Hitting into a berm; (vi) Jamming on the brakes; (vii) Raising the bed too high when the material sticks in the bed; (vii) Operating equipment while not wearing seatbelt; and (viii) Using a truck with defective brakes.

It is of critical importance that dump site be carefully examined for unsafe conditions. Dump site conditions change over time, as well as factors like weather, or new materials being dumped. 30 CFR § 77.1608 stipulates that: (a) dumping locations and haulage roads shall be kept reasonably free of water, debris, and spillage; (b) where the ground at a dumping place may fail to support the weight of a loaded dump truck, trucks shall be dumped a safe distance back from the edge of the bank; (c) adequate protection shall be provided at dumping locations where persons may be endangered by falling material; (d) grizzlies, grates, and other sizing devices at dump and transfer points shall be anchored securely in place; and (e) if truck spotters are used, they shall be well in the clear while trucks are backing into dumping position and dumping; and (f) lights shall be used at night to direct trucks.

30 CFR $§ 77.1713$ requires, in part, that (a) at least once during each working shift, and more often if necessary for safety, each active work area be examined by a certified person for hazardous conditions, and any hazardous conditions be reported to the operator and corrected; (b) the operator withdraw persons from any area where a hazardous condition creates an imminent danger; (c) a 
written report be made of the conditions found; and (d) a report be made of the action taken to abate any hazardous conditions. 30 CFR $\S 77.1004$ states, in part, that (a) highwalls, banks, benches, and terrain sloping into the working areas be examined after every rain, freeze, or thaw before operators work in such areas; and (b) overhanging banks be taken down and other unsafe ground conditions be corrected promptly, or the area be posted.

It's highly recommended by MSHA (2001a) that:

The dump site areas should be routinely inspected for any hazardous or potentially hazardous conditions, such as cracks, inadequate berms, unsafe ground, weakened edge of a pile, a pile that runs downgrade the berm, a soft area near the edge of the pile, inadequate illumination for night operations. Such site conditions should be reported and corrected as soon as possible.

Check with supervisors to see if they routinely observe dumping operations to make sure the unsafe dumping practices are not being used.

Mine operators are encouraged to route the trucks to the dump area in a way that provides truck drivers the best opportunities to observe and examine routinely the dump site areas before they back towards the dump site, since it is difficult for the drivers to detect the unsafe conditions once the truck is backing to the dump point.

With the large blind spot to the right side of haul trucks, dump sites are readily visible if they are to the driver's left side as the driver makes the turn before backing to the dump point. This is why some mines have "drive left" rules on their dump sites. 
Hazardous geological conditions should be recognized by both mine management and equipment personnel. Dumping locations should be inspected prior to work commencing, and material should be dumped back from the edge where the ground is unstable (Kecojevic and Radomsky, 2004). If there is any question or uncertainty about the safety of the dump point, then materials should be dumped one truck-length back from the edge, or from any cracks, and then pushed over (MSHA, 2001a).

The use of berm has long been accepted as a safety feature in surface mine operations, especially in areas where a haulage vehicle could possibly run over the edge of a haul road or a dump site. The berms also provide truck operators a visual indication of where the edge of road is. Restraints from the berms also give operators the opportunity to regain control of the truck and keep the truck from leaving the roadway. In this sense, berms are to a surface mine, more or less, as curbs are to public roadways. It should be made certain that berms are of sufficient height and strength in order to stop the equipment. Conventionally, berms are constructed with a minimum of half the wheel height, and placed along the edge of the dump area and all haul road edges with gaps for drainage (Holman, 2006). Figure 4.27 shows the safety berms constructed along a haul road and a dump area. MSHA (2004) suggested that larger berms should be used where the chances or the consequences of a truck leaving the haul road are more severe. For example, the chances of a truck leaving the haul road may be greater if there is a curve at the bottom of a grade; the consequences may be greater where a road runs near a pond. Berms in the more critical areas should be constructed with larger than axle-height. 

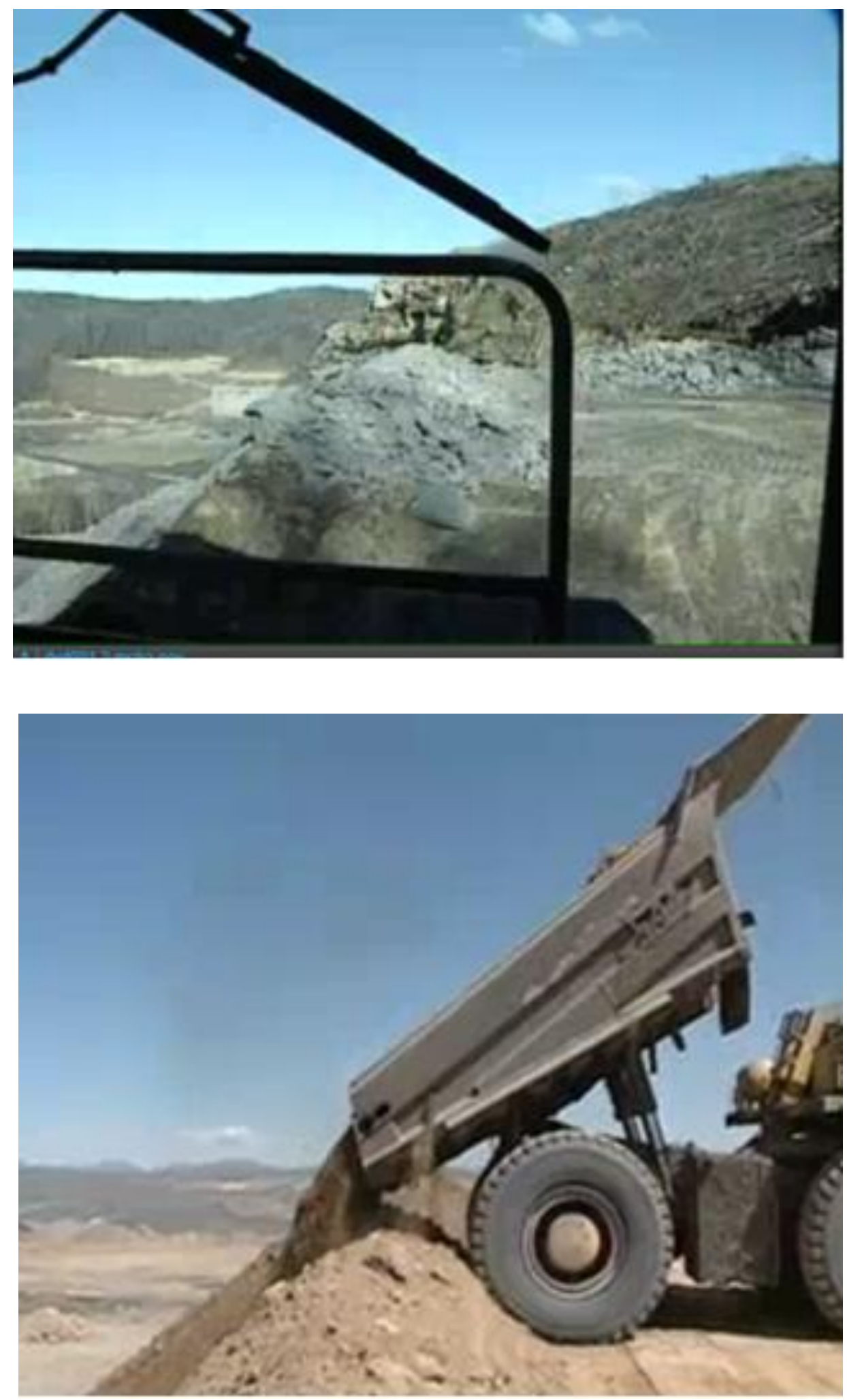

Figure 4.27 Safety berms along haul road and dump area (MSHA, 2014) 
During inspection, it should be made sure that berms are functional. To do so, the height of berms must be at least mid-axle height of the largest haul truck (Figure 4.28). It should also be noted that the height requirement of berms is normally judged based on the minimum value; it is advisable to provide as large a berm as practical. Furthermore, the effectiveness and reliability of berms are not only dependent on its height, but also its thickness and firmness.

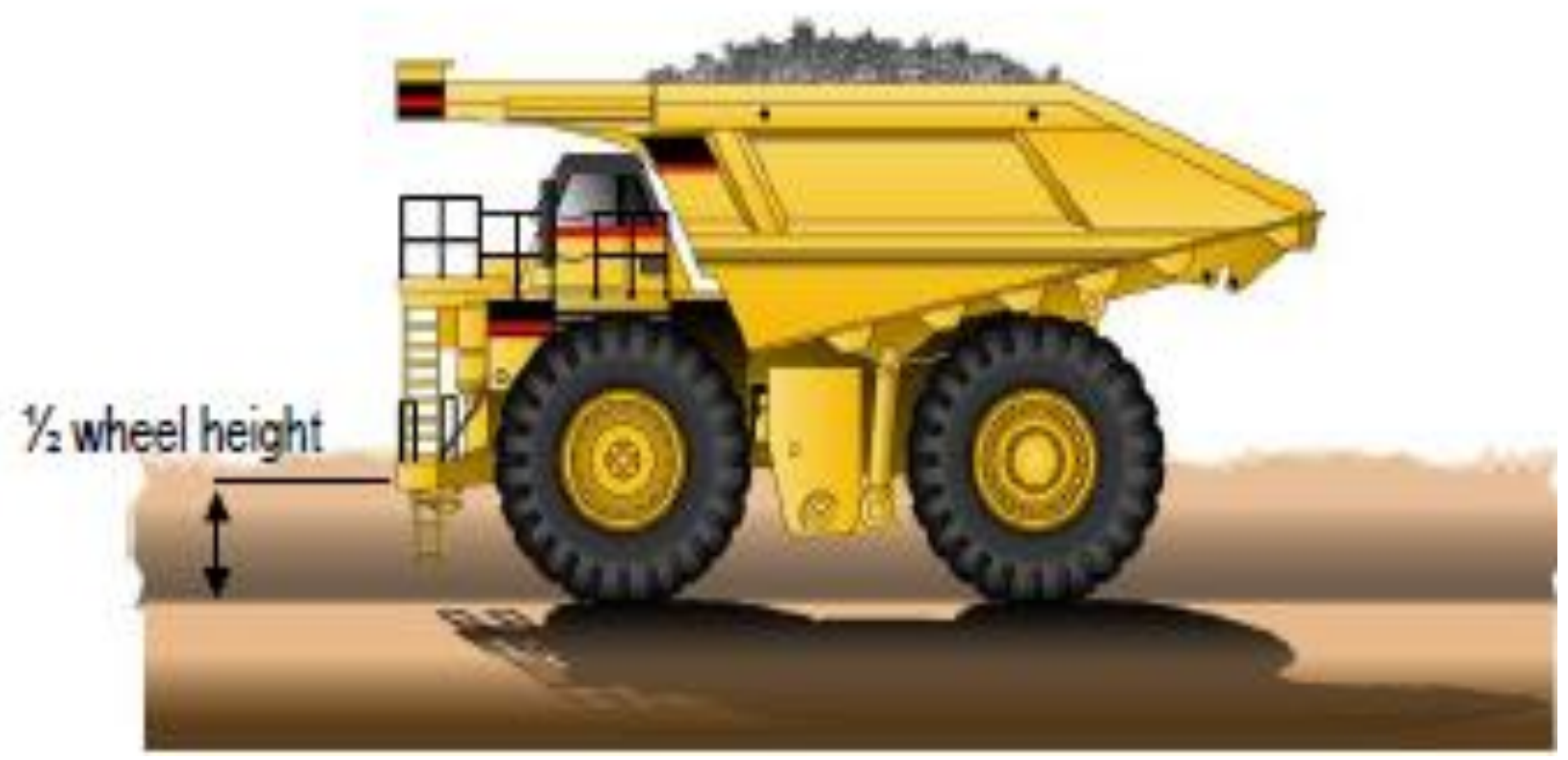

Figure 4.28 Minimum safety berm height (Holman, 2006)

It is always of concern when heavy equipment is operated near the edge of a slope. Operators should be trained to recognize hazardous conditions at the working site, and adequate berms should be provided to prevent over-travel at dump locations. Truck operators should be trained to learn that it's not a good safety practice to continue backing until they feel their tires contact the berm. The operator should stop the truck before the tires come in contact with the berm. Accidents have 
happened in which truck backed over the edge of a dump and overran the berm. Truck operators must make sure they only dump where adequate and solid berms are provided.

Dump sites should always be visually checked in case the ground is not strong and solid enough to support the truck. Trucks should back perpendicular to the berm and not run up on the berm when dumping (MSHA, 1999).

It is recommended that the working environment be daily examined for any unsafe working condition. In particular, more attention should be paid to haul roads and access roads; dump sites and loading areas are also important as fatal accidents have happened at those locations. Any abnormal condition should be recorded, reported, and corrected in a timely manner.

\subsubsection{Truck-related Safety Technologies}

Several safety technologies have been developed over the years to reduce the likelihood of haul trucks accidents. These technologies include: training simulator, maintenance monitoring and assistant system, proximity detection and warning system, fatigue monitoring system, collision avoidance system, and back-up alarm systems.

The current truck operator training process can be enhanced by introduction of Mining Haul Truck Training Simulators developed by the Immersive Technologies. Conversion Kits ${ }^{\circledR}$ are Immersive 
Technologies' (2014) interchangeable equipment modules that fit onto base simulator platforms, allowing a range of different truck models to be simulated, including Caterpillar, Komatsu, Liebherr, and Hitachi.

The simulators provide a virtual reality environment in which the operators are faced with a range of possible emergency situations, including simulated weather and road condition, speeding, and ramp situations. Operators can be taught and assessed for proper operating skills more quickly and accurately than with traditional methods. Moreover, the simulators provide a training platform that eliminates the need to use actual trucks from production. It allows new operators to practice many skills before they are placed into the actual operation and production activities.

The results of FTA showed that poor maintenance was the second most common root cause for the haul truck-related fatal accidents. CAT ® MINESTARTM SYSTEM (Caterpillar, 2012) is able to deliver critical event-base equipment conditions and operating data. The capability of monitoring and diagnosing comprehensive equipment health and asset condition can greatly improve the maintenance performance as well as haul truck safety condition.

Maintenance Assistant CMMS (MA CMMSTM, 2014) is an online collaboration tool that tracks the maintenance activities on equipment and assets. It shows what maintenance work needs to be done and what part(s) need attention based on the data shown on the dashboard. A detailed work order can be directly created once anything breaks down, and a specific technician can be assigned 
within the online order. Things like parts consuming rate, meter readings, and cost for changing components can be also tracked by the software.

There are several available systems developed for haul truck safety purposes, such as SAFEmine ${ }^{\mathrm{TM}}$, Modular Mining RoadMap ${ }^{\mathrm{TM}}$, Acumine ACASS, and 3D-P Proxis ${ }^{\mathrm{TM}}$. The proximity detection standards that are being used are ISO 5006: earth moving machineryOperator's field of view (ISO, 2006); ISO 14401: field of vision of surveillance and rear view mirrors (ISO, 2009); ISO 16001: earth moving machinery-Hazard detection systems and visual aids (ISO, 2008), and SAE J1741: Discriminating back-up alarms system standard (SAE, 1999).

SAFEmine's Traffic Awareness and Collision Avoidance System (CAS) works based on instant vehicle-to-vehicle Radio Frequency (RF) communication and back-to-base data link (SAFEmine, 2014). Traffic-awareness and collision-avoidance functions are based on position, speed, heading, and vehicle type (Schmidt, 2014). When it comes to collision avoidance, path prediction and dynamic safety zones are incorporated into the system. A remote display with LED indicators shows the direction of location of nearby vehicles and an audible collision alarm goes off when two or more vehicles are on a collision course. It provides a $360^{\circ}$ view of coverage with no blind spot, and up to 50 vehicles can be displayed on the unit at the same time (Schmidt, 2014). 
Generally, collision technology sensors developed for road transportation, in terms of surface mining operations, can often be adapted by using radar, Wi-Fi, camera, Radio Frequency Identification, GPS, or ultrasonic devices.

The Advisory System for Tired Drivers (ASTiD) was developed by Modular Mining, and it was designed to be an unobtrusive and predictive fatigue-risk determination system. It provides an electronic template predicting hour by hour the likelihood of the driver falling asleep over a 24hour period. Another function of the system is to detect monotonous driving conditions and vehicle steering characteristics, which may indicate sleepy driving (FMI, 2014).

OpGuard, developed by Guardvant (2014), is a non-intrusive driver fatigue sensor network that continuously monitors operators' behavior to detect and alert fatigue. The system monitors the operator for percentage eyelid closure (PERCLOS), facial and 3D head movements, and other unsafe behavior (Guardvant, 2014). The system also monitors operators' blind rates and blink durations.

The MR688 fatigue monitor developed by CareDrive (2014) is designed to predict operator drowsiness using face-recognition technology. The sensor inside the monitor captures infra-red images of the operator, and there is a high speed digital signal processor for digital image processing and analysis. The monitor has excellent detection ability, even if the operator is wearing glasses or sunglasses. The monitor measures the percentage of operator eyelid closure, and also 
uses mesh-membrane pupil detection technology to measure pupil contraction. MR688 can detect and analyze driver fatigue prior to falling asleep. Normally, the driver gets less and less sensitive to lighting before falling into a sleepy state, and the MR688 continually detects and analyzes that data, then makes a sharp and loud warning sound when necessary to awaken the driver.

Seeing Machines (2014) developed a DSS In-Vehicle System (IVS) that uses an automatic dashmounted camera that does not require any manual calibration. The DSS-IVS camera and IR pods are part of the truck and don't impede the operator. The DSS continuously measures the movement of operator's eye and eyelid to detect and determine the onset of fatigue and micro sleeps. In-cab audio and seat vibration alarms alert truck operators in the event of fatigue (Seeing Machines, 2014).

IronSyte Monitors developed a new seat belt monitor that verifies if operators are properly wearing their seat belt when the equipment is in use (IronSyte, 2014). If the seat belt is not in use while the monitored piece of equipment is in operation, a warning signal will start flashing on the real time and history screen of the IronSyte Viewer, and a report will be generated showing the date and time of the occurrence. Additionally, a phone call or text message can automatically be sent.

It is always hazardous to be present in the blind spots around a haul truck. PreView (2014) developed a radar system in which one monitor is installed in the cab and four cameras around the haul truck. Five PreView sensors are mounted on the haul truck to detect any presence in the blind 
spots, and the in-cab monitor provides an audible alert to the driver when an object is in a hazardous zone. Once something is detected, the screen will switch from the multiple screen camera mode to a single camera mode to give the driver a better visual of the area.

In order to tackle the issue of operator loss of control of the truck, Nebot et al (2006) suggested using laser technology and artificial infrastructure. The system can give an early warning to the truck operator and other trucks in the area when the truck is out of control, such as veering to the side of road or crossing the center of the haul road. The system also uses GPS to provide information about truck speed and location. 


\section{CHAPTER 5}

\section{CONCLUSIONS AND RECOMMENDATIONS FOR FUTURE RESEARCH}

FTA is a useful and effective method of identifying the root causes of certain accidents. In this study, FTA was used to show how root causes, which are also the basic events in the FT, interacted to cause the fatal accident (top event of the FT) to happen. The results show that the two most common root causes of these accidents are inadequate or improper pre-operational check and poor maintenance. Failure to wear a seat belt and inadequate training were also important contributing factors in the twelve accidents. Analysis of the relationship between the number of accidents and their location indicates that eight out of 12 accidents occurred on haul roads. Analysis also shows that truck's activity "moving forward" accounts for the largest number of accidents. Analysis of the frequency of violation of 30 CFR helped to understand the root causes, and the result shows the two most commonly violated provisions were $30 \mathrm{CFR} \$ 77.404$, and $30 \mathrm{CFR} \$ 77.1606$, both related to inspection and maintenance of equipment.

Truck-related injuries are of more concern because of their frequency compared to other surface mining equipment. In identifying the age category that has the highest number of injuries, it was found that the age category of "25-39 yr" accounted for the largest proportion.

Most workers suffered injuries within their first five years at current job title and first five years at current mine. Shift time was also analyzed in an attempt to identify the period in which more 
injuries took place. It was found that most injuries happened during "Section I," which is 6:00 a.m. - 2:00 p.m. A descending trend was observed when analyzing which day of week has more injuries recorded. Monday and Tuesday take up almost half of the total truck-related injuries, and the number started decreasing from Wednesday to Sunday. Most truck-related injuries happened in fall, followed by winter. When analyzing the nature of truck-related injury, sprains and strains are the highest proportion, and "Multiple parts" category is the most commonly injured body part when a truck-related injury accident happens.

Both traditional and innovative methods were proposed in this research to help eliminate truckrelated fatal accidents in surface coal mines in West Virginia.

The MSHA corresponding corrective actions, based on root causes of these fatalities, were summarized, and the safety regulations, particularly government safety standards for haul trucks were discussed. Knowledge and understanding of pertinent government safety standards is very important, and safety regulations should always be strictly followed by mine personnel.

Knowledge of and regular compliance with mandatory MSHA regulations are fundamental but are not by themselves a guarantee of successful accident prevention. Compliance with rules and regulations must be combined with training and education. Training should be given adequate and significant attention by management before operators are actually assigned to job tasks; it should also be a continuous process in which operators are retrained. Refresher training should hold equal 
importance as training provided to new employees. Given the fact that fatal accidents happened to operators with many years of experience (five years and above), it is advisable to provide refresher training as required by the MSHA. It should be a shared conviction that safety would always be a priority regardless of the age or working experience of any truck operator.

Training regarding pre-operational check is of crucial importance in that inadequate or improper pre-operational check was the most frequent root cause in truck-related fatal accidents in WV. Current training in pre-operational check can be better complemented by the application of Virtual Reality technology, i.e. the Virtual Reality training program. Training and education on truck maintenance is also very important since proper and safe truck operation relies to a large extent on good operational haul truck conditions, which require a good maintenance program.

The MSHA best practices, proposed to prevent similar accidents from happening in the future, should be followed enthusiastically. Furthermore, operators should receive training and education pertaining to these best practices.

Special attention should be paid to the conditions of the working environment of haul trucks, i.e., loading areas, haul roads, and dump site, with primary attention being paid to haul roads. Understandable and visible signs indicating slope grade and slope length should be provided along the haul road. In addition to the steep grade sign, measures should be provided for runaway trucks where grades are steep, such as escape ramps. Seat belts should always be worn, speed limits 
should always be observed, and proper surface condition of the haul road should always be maintained. The hazards of working around stockpiles or dump points should be recognized, and it is of critical importance that dump sites be carefully examined for unsafe conditions. Appropriate berms at haul roads and dump points should be constructed and maintained.

The application of truck-related safety technologies such as training simulators, proximity detection and warning systems, fatigue monitoring systems, collision avoidance systems, and back-up alarm systems were discussed in details. These technologies have the potential to reduce the likelihood of haul truck accidents.

This study was focused on analysis of the root causes of haul truck-related fatal accidents, as well as many intervention strategies that could be applied. However, in light of the fact that the study was only focused on the fatalities in West Virginia, the study may encounter some limitations, which need to be considered in the future. The researcher in the future may take a further step to collect more fatal accident data on a national scale as opposed to merely focusing on West Virginia.

In addition, the FTA in this study primarily addressed qualitative analysis for the accidents. It is recommended that a unique Fault Tree be constructed, and more quantitative analysis such as Fussel-Vesely (FV) and Risk Achievement Worth (RAW) be introduced to make the FTA more comprehensive and thorough. 
The retrieved injury data is not complete in that some of the data, such as years at current job title, are left empty. Efforts should be made to clarify the type of equipment categorized as "Machine". There is also a need to specifically indicate what kinds of injuries are defined as "Other", "Unclassified", and "Unknown". Additionally, root causes for these injuries are not given, which made it impossible to conduct FTA to further analyze the injury accidents. 


\section{REFERENCES}

Armour, J., 2003. Effectiveness of Current Methods to control Sprain and Strain injuries in the coal industry. Health \& Safety Trust, Report NO. 20251.

Beamish, B., Sutherland, T., Walker, D., Day, G., 2010. Application of fault tree analysis to coal spontaneous combustion. In: Proceedings of the 10th Underground Coal Operators' Conference, University of Wollongong and The AusIMM, Wollongong, Australia.

Bennett, J., Passmore, D., 1986. Multinomial logit analysis of injury severity in U.S. underground bituminous coal mines. Accident Analysis and Prevention, 17 (5): 399-408.

Burgess R., 2006. Identifying injury risks associated with underground coal mining equipment. In: Proceedings of the International Ergonomics Association Congress (Pikaar R N, Koningsveld E A P, Settels P J M, eds.). Amsterdam: Elsevier.

Burgess, R., Steiner, L., 2007. Preventing equipment related injuries in underground U.S. coal mines. Mining Engineering, 59(10): 20-32.

Burhan, A., 2010. Fault Tree Analysis as a modern technique for investigating causes of some construction project problems. Journal of Engineering, 16(2): 5214-5224.

Burke, M., Sarpy, S., Smith-Crowe, K., Chan-Serafin, S., Salvador, R., Islam, G. 2006. Relative effectiveness of worker safety and health training methods. American Journal of Public Health, 96(2):315.

Butani, J., 1988. Relative risk analysis of injuries in coal mining by age and experience at present company. Journal of Occupational Accidents, 10, 209 - 216.

Care Drive, 2014. MR688 information. Available from: http://www.care-drive.com/product_infoMR688_Driver_Fatigue_Monitor-id-1.html.

Caterpillar, Inc., 2009. Help prevent MSHA's top 10 violations for coal mining. Available from: < http://safety.cat.com/cda/files/2133579/7/MSHA\%20violations-Safety\%20Training.pdf> 
Caterpillar, Inc., 2012. CAT $^{\circledR}$ MINESTARTM SYSTEM overview. Available from: http://www.catminestarsystem.com/

Chang, S., Lin, C., Chang, C., 2002. A fuzzy diagnosis approach using dynamic fault trees. Chemical Engineering Science, 57 (5): 2971-2985.

Chao, W., 1995. Fault Tree Analysis of spontaneous combustion of sulphide ores and its risk assessment. Journal of Central South University, 2(2).

Choudhry, R., Fang, D., Lingard, H., 2009. Measuring safety climate of a construction company. Journal of Construction Engineering and Management, 135: 890-899.

Circadian, 2014. The Circadian Alertness Simulator (CAS) information. Available from: http://www.circadian.com/247-industries/aviation/cas-5-fatigue-risk-model.html

Coleman, P., Kerkering, J., 2007. Measuring mining safety with injury statistics: Lost workdays as indicators of risk. Journal of Safety Research, 38: 523-533.

Cooke, R., Ross, H., Stern, A., 2011. Precursor Analysis for Offshore Oil and Gas Drilling: From Prescriptive to Risk-Informed Regulation, Ed. Resources for the Future, Washington, USA.

Daniels, A., 1994. Bringing out the best in people. McGraw Hill Professional, New York, NY.

Do, M., 2012. Evaluating the normal accident theory in complex systems as a predictive approach to mining haulage operations safety. Ph.D dissertation, University of Arizona, AZ.

Dong, Y., Yu, D., 2005. Estimation of failure probability of oil and gas transmission pipelines by fuzzy fault tree analysis. Journal of Loss Prevention in the Process Industries, 18 (2): 83-88.

Drury, C., Porter, W., Dempsey, P., 2012. Patterns in mining haul truck accidents. In: Proceedings of the Human Factors and Ergonomics Society Annual Meeting. Boston, MA.

Ericson, C., 1999. Fault Tree Analysis - A history. In : Proceedings of the $17^{\text {th }}$ international system safety conference. Orlando, FL.

Esterhuizen, G., Gürtunca, R., 2006. Coal mine safety achievements in the USA and the contribution of NIOSH research. Journal of South African Institute of Mining and Metallurgy, 106(12): 813-820. 
Fatigue Monitoring International Limited (FMI), 2014. ASTiD information. Available from: http://www.fmig.org/astidM.html.

Fatigue Science, 2013. Readiband information. Available from:

http://fatiguescience.com/solutions/readiband/

Fesak, G., Breland, R., Spadaro, J., 1996. Analysis of surface powered haulage accidents - January 1990 to July 1996. Holmes Safety Association Bulletin, Washington, DC: Mine Health and Safety Administration.

Geller, S., 1996. The Psychology of Safety: How to Improve Behaviors and Attitudes on the Job. CRC Press LLC, Boca Raton, Florida.

Geller, S., 2000. Ten leadership qualities for a Total Safety Culture: Safety management is not enough. Professional Safety, 45(5): 38-41.

Goodbody, A., 2013. Feeling tired? Mining Magazine. 7: 38-48.

Garyson, L., Althouse, R., Klishis, M., 1992. Risk indices for roof bolter injuries using microanalysis. Mining Engineering, pp. 164-166.

Groves, W., Kecojevic, V., Komljenovic, D., 2007. Analysis of fatalities and injuries involving mining equipment. Journal of Safety Research, 38: 461-470.

GuardVant, 2014. OpGuard information. Available from: http://guardvant.com/products/driver-fatigue/.

Helander, M., Krohn, G., 1983, Human Factors Analysis of Underground Metal and Non metal Mines United State Bureau of Mines (USBM) report PB84-158732.

Helander, M., Krohn, G.. Curtin, R., (1983), Safety of roof-bolting operations in underground coal mines. Journal of Occupational Accidents, 5: 161-175.

Holman, P., 2006. Caterpillar® haul road design and management. Presented at Big Iron University, St.Charles, IL.

Immersive Technology, 2014. Conversion Kit information. Available from: http://www.immersivetechnologies.com/products/Haul-Truck-Training-Simulators.htm. 
ISO 5006. 2006. Earth moving machinery - Operator's field of view - Test method and performance criteria. Geneva: International Organization for Standardization. Available from: www.iso.org.

ISO 14401. 2009. Field of vision of surveillance and rear view mirrors. Geneva: International Organization for Standardization. Available from: www.iso.org.

ISO 16001. 2008. Earth moving machinery- Hazard detection system and visual aids. Geneva: International Organization for Standardization. Available from: www.iso.org.

IronSyte, 2014. Seat belt monitor information. Available from: http://www.ironsyte.com/safety.html.

Iverson, S., Kerkering, J.C., Coleman, P., 2001. Using fault tree analysis to focus mine safety research. In: Proceedings of the 108th annual meeting of the society for mining, metallurgy and exploration, 1-10.

Joshua, C., Garber, J., 1991. A causal analysis of large vehicle accidents through fault-tree analysis. Risk Analysis, 12(2): 173-188.

Kaufman W., Ault J., 1977. Design of surface mining haulage roads - a manual. Information Circular IC8758. Washington, DC: U.S. Bureau of Mines.

Kecojevic, V., Komljenovic, D., Groves, W., Radomsky, M., 2007. An analysis of equipment-related fatal accidents in U.S. mining operations: 1995-2005, Safety Science, 45: 864-874.

Kecojevic, V., Radomsky, M., 2004. The causes and control of loader and truck-related fatalities in surface mining operations. Injury Control and Safety Promotion, 11 (4): 239-251.

Kecojevic, V., Md-Nor, Z.A., 2009. Hazard identification for equipment-related fatal incidents in the U.S. underground coal mining. Journal of Coal Science and Engineering, 12 (1): 1-6.

Komljenovic, D., Kecojevic, V., 2007. Risk management program for occupational health and safety in surface mining operations. International Journal of Risk Assessment and Management, 7(5): 620-638.

Kosmoski, C., 2014. Assess the safety culture of underground coal mining: results and recommendation. Preprint No. 14-029. 2014 SME Annual Meeting. February 22-27. Salt Lake City, UT.

Kowalski, K., Vaught, C., 2002. Strategies for Improving Miners’ Training. Information Circular IC-9463. Washington, DC: NIOSH. Pp. 3-8. 
Lavasani, M., Wang, J., Yang, Z., Finlay, J., 2011. Application of fuzzy fault tree analysis on oil and gas offshore pipelines. International Journal of Marine Science and Engineering, 1(1): 29-42.

MA 20140. MA CMMSTM overview. Available from: http://www.maintenanceassistant.com/cmms/industry-solutions/mine-maintenance-software/.

McCann, M., 2006, Heavy equipment and truck-related death on excavation work sites. Journal of Safety Research 37: 511-517.

McMahan, R., Schafrik, S., Bowman, D., Karmis, M., 2009. Virtual environments for surface mining powered haulage training. In: Proceedings of SME symposium celebrating 100 years of mining research, Phoenix, AZ.

Md-Nor, Z.A., 2008. Risk assessment for equipment-related fatalities in mining, M.S. thesis, Pennsylvania State University, PA.

Md-Nor, Z.A., Kecojevic, V., Komljenovic, D., Groves, W., 2008. Risk assessment for haul truck-related fatalities in mining, Mining Engineering 60(3): 43-49.

Mine Safety and Health Administration (MSHA), 1999. MSHA Handbook Series - Haul Road Inspection Handbook. Handbook Number PH 99-I-4. Washington, D.C: U.S. Government Printing Office.

Mine Safety and Health Administration (MSHA), 2000. Review of fatal accidents in metal/non-metal mining 1995-1998. Report NO. 2E-06-001-0004.

Mine Safety and Health Administration (MSHA), 2001a. MSHA Handbook Series - Dump-point Inspection Handbook. Handbook Number PH 01-I-6. Washington, D.C: U.S. Government Printing Office.

Mine Safety and Health Administration (MSHA), 2001. Safety Manual Series, SM 27- Stockpiling safety. Washington, D.C: U.S. Government Printing Office.

Mine Safety and Health Administration (MSHA), 2004a. Surface haulage accidents...ways to prevent them. Available from:

http://www.msha.gov/techsupp/techexchange/Haulroad/Haulroadsafety.pdf

Mine Safety and Health Administration (MSHA), 2004. Equipment safety and health information. Available from: http://www. msha.gov/. 
Mine Safety and Health Administration (MSHA), 2006. Pre- \& Post- Operational Inspection of Surface Haulage Equipment. Available from:

<http://www.msha.gov/s\&hinfo/bpcards/GenInfo/MSHA\%201008\%20(BP-

8) $\% 20$ Pre $\% 20 \% 20$ Post $\% 20$ Op\%20Insp.pdf>.

Mine Safety and Health Administration (MSHA), 2007. Alcohol and drug free mines sample policy and training materials. Washington, D.C: U.S. Government Printing Office. Available from: http://www.msha.gov/DrugFree/DrugFreeMines.asp.

Mine Safety and Health Administration (MSHA), 2008. Preliminary regulatory economic analysis for alcohol- and drug-free mines: policy, prohibitions, testing and assistance proposed rules. Office of Standards, Regulations and Variances. Arlington, VA.

Mine Safety and Health Administration (MSHA), 2013. Equipment safety and health information. Available from: <http://www.msha.gov/>.

Mine Safety and Health Administration (MSHA), 2014a. Mine Safety and Health. Available from: http://www.msha.gov/MSHAINFO/FactSheets/MSHAFCT1.HTM.

Mine Safety and Health Administration (MSHA), 2014. The purpose of berms. Available from: https://archive.org/details/gov.msha.dvd001.2?start=149.5.

Mine Safety and Health Administration (MSHA), 2014b. Small mine consultation program weekly toolbox talks. Available from: http://www.msha.gov/smallmineoffice/toolbox/tboxtalks.htm.

MinEx, 2008. Guidelines for the control of hazards in stockpiles and dumps. MinEx Health \& Safety Council. Wellington, New Zealand.

Modular Mining, 2014. Modular Mining DISPATCH information. Available from: http://modularmining.com/product/dispatch/\#tab-4.

Mohamed, S., Ali, T, Tam, W., 2009. National culture and safe work behavior of construction workers in Pakistan. Safety Science, 47 (1): 29 - 35.

Moore, S., Porter, W., Dempsy, P., 2009. Fall from equipment injuries in US mining: identification of specific research areas for future investigation. Journal of Safety Research, 46(6) 455-460. 
National Aeronautics and Space Administration (NASA), 2002. Fault tree handbook with aerospace applications, Office of Safety and Mission Assurance, Washington, DC.

Neal, A., Griffin, M., Hart, P, 2000. The impact of organizational climate on safety climate and individual behaviour. Safety Science, 34: 99-109.

Nebot, E., Guivant, J., Worrall, S., 2006. Haul truck alignment monitoring and operator warning system. Journal of Field Robotics, 23 (2): 141-161.

New South Wales government (NSW government), 2010. Safety culture survey. Available from: http://www.workcover.nsw.gov.au/formspublications/publications/Pages/safetyculturecd.aspx

Orsulak, M., Kecojevic, V., Grayson, L., Nieto, A., 2010. Risk assessment of safety violations for coal mines, International Journal of Mining. Reclamation and Environment, 24: 244-254.

Ortmeier, F., Schellhorn, G., 2006. Formal Fault Tree Analysis: practical experiences. Electronic Notes in Theoretical Computer Science, 185 (13): 139-151.

Peters, R., 2002. Strategies for Improving Miners' Training. National Institute for Occupational Safety and Health (NIOSH). Spokane, WA.

PreView, 2014. PreView radar system on haul truck information. Available from: http://www.previewradar.com/vehicle/mining-haul-truck.html.

Randolph, R., Boldt, C., 2005. Safety analysis of surface haulage accidents-part 1, Holmes Safety Association Bulletin, May-June: 1-7.

RIEGL, 2014. RIEGL VZ-400 information. Available from: http://riegl.com/nc/products/terrestrialscanning/produktdetail/product/scanner/5/

Ruff, T., Coleman, P., Martini, L., 2011, Machine-related injuries in the US mining industry and priorities for safety research. International Journal of Injury Control \& Safety Promotion, 18(1): 11-20.

SAFEmine, 2014. SAFEmine CAS information. Available from: http://www.safemine.com/index.php/products.

SAE- J 1741. Discriminating back-up alarm system standard. Society of Automotive Engineers, Warrendale, PA. 
Saleh, J., Cummings, A., 2011. Safety in the mining industry and the unfinished legacy of mining accidents: safety levers and defense-in-depth for addressing mining hazards. Safety Science, 49(6): 764-777.

Santos, B., Porter, W., Mayton, A., 2010. An analysis of injuries to haul truck operators in the U.S. mining industry. In: Proceedings of the Human Factors and Ergonomics Society Annual Meeting. 54 (21): 1870-1874.

Schaum, M., 2007. Increasing the haul truck safety through the use of virtual pre-shift inspect training. M.S. thesis, Virginia Polytechnic Institute and State University, VA.

Schmidt, D., 2014. Teck, SAFEmine team up for collision avoidance system. Coal Age. Available from: http://www.coalage.com/features/3523-teck-safemine-team-up-for-collision-avoidanceprogram.html\#.U2uMtfldWSo.

Seeing Mahines, 2014. DSS information. Available from: http://www.dssmining.com/.

SmartCap, 2013. SmartCap information. Available from:

http://www.smartcap.com.au/smartcap_information.html

Smith, E., 2013. New single-operator interface for safety. Mining Review 10: 25.

Sun, E., Nieto, A., Li, Z., Kecojevic, V., 2010. An integrated information technology assisted driving system to improve mine trucks-related safety. Safety Science, 48: 1490-1497.

United States Nuclear Regulatory Commission (NRC), 1981. Fault tree handbook, NUREG-0492. Systems and Reliability Research Office of Nuclear Regulatory Research, Washington, D.C.

Venkatakrishnaiah, R., Swarna, M., 2014. Analysis of risk management in construction sector using Fault Tree Analysis. Research in Civil and Environmental Engineering,2(02): 66-73.

Vesely, W., Stamatelalos, M., Dugan, J., Fragola, J., Minarick, J., 2002. Fault Tree Handbook with Aerospace Applications. Report by NASA Office of Safety and Mission Assurance.

Watson, H., 1961. Launch control safety study. Bell Telephone Laboratories, Murray Hill, NJ.

West Virginia Board of Coal Mine Health and Safety, 2014. Mine safety and health information. Available from: http://www.wvminesafety.org/. 
Whiting, M., Bennett, C., 2003. Driving toward “0”: best practices in corporate safety and health. The conference board, Inc.

Wiehagen, W., Mayton, A., Jaspal, J., Turin, E., 2001. An analysis of serious injuries to dozer operators in the U.S. mining industry. Circular IC-9455. Washington, DC: NIOSH.

Xia, M., Li, X., Jiang, F., Wang, S., 2012. Cause analysis and countermeasures of locomotive runaway accident based on fault tree analysis method. Procedia Engineering, 45: 38-42.

Xing, L., Amari, S., 2008. Fault Tree Analysis, Handbook of performability engineering. Pp. 595-620.

Zheng, K, Jiang, F., 2012. Resaerch on intrinsic safety method for open-pit mining. Procedia Engineering, 43: 453-458.

Zhou, Q., 2009. Safety Climate in Construction Companies: Theoretical and Empirical Research. Ph.D. Dissertation. Tsinghua University, Beijing, China.

Zhou, Q., Fang, D., Mohamed, S., 2011. Safety climate improvement: case study in a Chinese construction company. Journal of Construction Engineering and Management, 137: 86-95.

Zhou, S., 2013. Application of Fault Tree Analysis in coal mine fire accidents. In: Proceedings of 2013 International Conference on Quality, Reliability, Risk, Maintenance, and Safety Engineering. Cheng du, China.

30 CFR, 2013. Mineral resources. U.S. Department of Labor, Mine Safety and Health Administration, Code of Federal Regulations. Washington, DC: U.S. Government Printing Office, Office of the Federal Register. 


\section{APPENDIX A- Safety Survey Questionnaire (revised from NSW, 2010)}

\begin{tabular}{|c|c|c|}
\hline QUESTION 1 & \multicolumn{2}{|r|}{ Do you get introduction training when you start? } \\
\hline & $\square$ & We all get introduction training when we start \\
\hline & $\square$ & Not everyone gets introduction training when they start \\
\hline & $\square$ & We don't get introduction training when we start \\
\hline \multirow[t]{4}{*}{ QUESTION 2} & \multicolumn{2}{|r|}{ Do you get trained in safe work procedures for your jobs? } \\
\hline & $\square$ & \multirow{3}{*}{$\begin{array}{l}\text { We all get trained in safe work procedures for our jobs } \\
\text { Some people missed out on safety work procedures training for their jobs } \\
\text { We don't get trained in safe work procedures for our jobs }\end{array}$} \\
\hline & $\square$ & \\
\hline & $\square$ & \\
\hline \multirow[t]{4}{*}{ QUESTION 3} & \multicolumn{2}{|r|}{ Does your manager/supervisor make sure you can do the work safely? } \\
\hline & $\square$ & \multirow{3}{*}{$\begin{array}{l}\text { Our manager/supervisor makes sure we can do the work safely } \\
\text { Our manager/supervisor sometimes checks we can do the job safely } \\
\text { No one checks if you can do the job safely }\end{array}$} \\
\hline & $\square$ & \\
\hline & $\square$ & \\
\hline \multirow[t]{4}{*}{ QUESTION 4} & \multicolumn{2}{|r|}{ Does anyone make you aware of safety issues? } \\
\hline & $\square$ & We are always made aware of safety issues \\
\hline & $\square$ & Mostly someone makes us aware of safety issues \\
\hline & $\square$ & We are not made aware of safety issues \\
\hline \multirow[t]{4}{*}{ QUESTION 5} & \multicolumn{2}{|r|}{ Has your company worked out all the jobs/tasks in your area that have safety risks? } \\
\hline & $\square$ & Our company has worked out all the jobs/tasks in my area that have safety risks \\
\hline & $\square$ & Our company has worked out most of the jobs/tasks in my area that have safety risks \\
\hline & $\square$ & Our company hasn’t worked out what jobs/tasks in my area have safety risks \\
\hline \multirow[t]{4}{*}{ QUESTION 6} & \multicolumn{2}{|r|}{ Does your company have safe work procedures for all task-based activities in your area that have safety risks? } \\
\hline & $\square$ & \multirow{3}{*}{$\begin{array}{l}\text { Our company has safe work procedures for all task-based activities in my area that have safety risks } \\
\text { Our company has safe work procedures for most task-based activities in my area that have safety risks } \\
\text { Our company doesn't have safe work procedures for any task-based activities in my area that have safety } \\
\text { risks }\end{array}$} \\
\hline & $\square$ & \\
\hline & & \\
\hline \multirow[t]{4}{*}{ QUESTION 7} & \multicolumn{2}{|r|}{ Are workers involved in reviewing safe work procedures? } \\
\hline & $\square$ & Workers are always involved in reviewing safe work procedures \\
\hline & $\square$ & Workers are usually involved in reviewing safe work procedures \\
\hline & & Workers aren't involved in reviewing safe work procedures \\
\hline \multirow[t]{4}{*}{ QUESTION 8} & \multicolumn{2}{|r|}{ Do you follow safe work procedures? } \\
\hline & $\square$ & We always follow safe work procedures \\
\hline & $\square$ & We have safe work procedures but don't/can't always follow them \\
\hline & $\square$ & We don't follow/have safe work procedures \\
\hline \multirow[t]{4}{*}{ QUESTION 9} & \multicolumn{2}{|r|}{ Does your company review and update your safe work procedures regularly? } \\
\hline & $\square$ & \multirow{3}{*}{$\begin{array}{l}\text { Our company reviews and updates our safe work procedures regularly } \\
\text { Some safe work procedures are not up to date } \\
\text { Our company doesn't update our safe work procedures }\end{array}$} \\
\hline & $\square$ & \\
\hline & & \\
\hline \multirow[t]{4}{*}{ QUESTION 10} & \multicolumn{2}{|r|}{ Do you have enough time to learn your safe work procedures? } \\
\hline & $\square$ & We have enough time to learn our safe work procedures \\
\hline & $\square$ & Sometimes we get enough time to learn our safe work procedures \\
\hline & $\square$ & We don't get enough time to learn our safe work procedures \\
\hline
\end{tabular}




\begin{tabular}{|c|c|c|}
\hline \multirow[t]{4}{*}{ QUESTION 11} & \multicolumn{2}{|r|}{ Do you do a risk assessment when you start a new process or when a process is changed? } \\
\hline & & We always do a risk assessment when we start a new process or when a process is changed \\
\hline & $\square$ & We usually do a risk assessment when we start a new process or when a process is changed \\
\hline & $\square$ & We don't do risk assessments when we start a new process or when a process is changed \\
\hline \multirow[t]{4}{*}{ QUESTION 12} & \multicolumn{2}{|r|}{ Do managers communicate with you and listen to you about health and safety? } \\
\hline & $\square$ & \multirow{3}{*}{$\begin{array}{l}\text { Managers communicate with us and listen to us about health and safety } \\
\text { We have a way of communicating with managers about health and safety but it doesn't work very well } \\
\text { We haven't got a way of communicating with managers about health and safety }\end{array}$} \\
\hline & $\square$ & \\
\hline & $\square$ & \\
\hline \multirow[t]{4}{*}{ QUESTION 13} & \multicolumn{2}{|r|}{ How often are you involved in safety matters? } \\
\hline & $\square$ & \multirow{3}{*}{$\begin{array}{l}\text { We are always involved in safety matters } \\
\text { We are sometimes involved in safety matters } \\
\text { We are not involved in safety matters }\end{array}$} \\
\hline & $\square$ & \\
\hline & $\square$ & \\
\hline \multirow[t]{4}{*}{ QUESTION 14} & \multicolumn{2}{|r|}{ Does management take notice of what you say about safety? } \\
\hline & $\square$ & Management takes notice of what we say about safety \\
\hline & $\square$ & Management sometimes takes notice of what we say about safety \\
\hline & $\square$ & Management doesn't take notice of what we say about safety \\
\hline \multirow[t]{4}{*}{ QUESTION 15} & \multicolumn{2}{|r|}{ Are you involved in putting together procedures? } \\
\hline & $\square$ & We are involved in putting together procedures \\
\hline & $\square$ & We are sometimes involved in putting together procedures \\
\hline & $\square$ & We are not involved in putting together procedures \\
\hline \multirow[t]{4}{*}{ QUESTION 16} & \multicolumn{2}{|r|}{ Do you get feedback on what's happening with your safety issues within seven days? } \\
\hline & & $\begin{array}{l}\text { We always get feedback (e.g., minutes, tool box talks) on what's happening with our safety } \\
\text { issues within seven days }\end{array}$ \\
\hline & $\square$ & We usually get feedback on what's happening with our safety issues within seven days \\
\hline & $\square$ & We don't get feedback about what's happening with our safety issues within seven days \\
\hline \multirow[t]{4}{*}{ QUESTION 17} & \multicolumn{2}{|r|}{ Do you know who your safety committee member is? } \\
\hline & $\square$ & We know who our safety committee member (or safety rep) is \\
\hline & $\square$ & We have a safety committee member (or safety rep) but we're not sure who it is \\
\hline & $\square$ & We don't have a safety committee (or safety rep) or we don't know who it is \\
\hline \multirow[t]{4}{*}{ QUESTION 18} & \multicolumn{2}{|r|}{ Do you have safety report procedures and do you use them? } \\
\hline & $\square$ & We have safety reporting procedures (for incidents and issues) and we use them \\
\hline & $\square$ & We have safety reporting procedures, but we don’t always use them \\
\hline & $\square$ & We don't have safety reporting procedures or we don't use them \\
\hline \multirow[t]{4}{*}{ QUESTION 19} & \multicolumn{2}{|r|}{ Do you report safety incidents? } \\
\hline & $\square$ & We always report safety incidents \\
\hline & $\square$ & We mostly report safety incidents \\
\hline & & We don't report safety incidents \\
\hline QUESTION 20 & \multicolumn{2}{|r|}{ Are you encouraged to report safety incidents? } \\
\hline \multirow{3}{*}{$\mid$} & $\square$ & \multirow{3}{*}{$\begin{array}{l}\text { We are always encouraged to report safety incidents } \\
\text { We are usually encouraged to report safety incidents } \\
\text { We are never encouraged to report safety incidents }\end{array}$} \\
\hline & $\square$ & \\
\hline & $\square$ & \\
\hline
\end{tabular}




\begin{tabular}{|c|c|c|}
\hline \multirow[t]{4}{*}{ QUESTION 21} & \multicolumn{2}{|r|}{ Do safety incident reports get followed up? } \\
\hline & $\square$ & Safety incident reports always get followed up \\
\hline & $\square$ & Safety incident reports sometimes get followed up \\
\hline & $\square$ & Safety incident reports don't get followed up \\
\hline \multirow[t]{4}{*}{ QUESTION 22} & \multicolumn{2}{|r|}{$\begin{array}{l}\text { Are safe work procedures are reviewed and updated if there is an incident report? Do you try to find out why } \\
\text { the incident happened and how to fix it? }\end{array}$} \\
\hline & & $\begin{array}{l}\text { Safe work procedures are reviewed and updated if there is an incident report. We try to find } \\
\text { out why an incident happened and how to fix it }\end{array}$ \\
\hline & & $\begin{array}{l}\text { Safe work procedures are sometimes reviewed and updated after an incident report } \\
\text { We usually try to find out why an incident happened and how to fix it }\end{array}$ \\
\hline & & $\begin{array}{l}\text { No one reviews safe work procedures after an incident report to try to find out why an } \\
\text { incident happened and how to fix it }\end{array}$ \\
\hline \multirow[t]{4}{*}{ QUESTION 23} & \multicolumn{2}{|r|}{ Is your safety training reviewed or updated if there is an incident? } \\
\hline & $\square$ & Our safety training is reviewed or updated if there is an incident \\
\hline & $\square$ & Our safety training is sometimes reviewed or updated after an incident \\
\hline & $\square$ & Our safety training doesn't get reviewed or updated after an incident \\
\hline \multirow[t]{4}{*}{ QUESTION 24} & \multicolumn{2}{|r|}{ How fast do they take action if you report a serious problem where someone could get hurt? } \\
\hline & $\square$ & $\begin{array}{l}\text { If we report a serious problem where someone could get hurt, they put in a solution and fix it straight } \\
\text { away }\end{array}$ \\
\hline & & $\begin{array}{l}\text { If we report a serious problem where someone could get hurt, they take action as soon as } \\
\text { they can }\end{array}$ \\
\hline & $\square$ & If we report a serious problem where someone could get hurt, they don't take action \\
\hline \multirow[t]{4}{*}{ QUESTION 25} & \multicolumn{2}{|r|}{ Do managers understand what you and they should do regarding safety? } \\
\hline & $\square$ & Managers seem to understand what we and they should do regarding safety \\
\hline & $\square$ & Managers sometimes seem to understand what we and they should do regarding safety \\
\hline & $\square$ & Managers don't know what we or they should do regarding safety \\
\hline \multirow[t]{4}{*}{ QUESTION 26} & \multicolumn{2}{|r|}{ Do you feel like you were letting the team down if you didn't follow a safety instruction? } \\
\hline & $\square$ & If I didn’t follow a safety instruction, I'd feel like I was letting the team down \\
\hline & $\square$ & If I didn't follow a safety instruction, I might get away with it with some managers/supervisors \\
\hline & $\square$ & No one would really care if I didn't follow a safety instruction \\
\hline \multirow[t]{4}{*}{ QUESTION 27} & \multicolumn{2}{|r|}{ Is there time put into safety? } \\
\hline & $\square$ & There is enough time put into safety \\
\hline & $\square$ & Time is time put into safety, but it's not quite enough \\
\hline & & There is hardly any time put into safety \\
\hline \multirow[t]{4}{*}{ QUESTION 28} & \multicolumn{2}{|r|}{ Do you feel there are enough resources/money put into safety? } \\
\hline & $\square$ & I feel that there are enough resources/money put into safety \\
\hline & $\square$ & I feel that resources/money are put into safety, but it's not quite enough \\
\hline & & I feel that there aren't enough resources/money put into safety \\
\hline \multirow[t]{4}{*}{ QUESTION 29} & \multicolumn{2}{|c|}{ Is safety a high priority for your mine? } \\
\hline & $\square$ & Safety is a high priority for our mine \\
\hline & $\square$ & Safety is sometimes a high priority for our mine \\
\hline & $\square$ & Safety is not a priority for our mine \\
\hline
\end{tabular}




\begin{tabular}{|c|c|c|}
\hline \multirow[t]{4}{*}{ QUESTION 30} & \multicolumn{2}{|r|}{ Does management get involved in safety issues? } \\
\hline & $\square$ & Management always gets involved in safety issues \\
\hline & $\square$ & Management sometimes gets involved in safety issues \\
\hline & $\square$ & Management doesn't get involved in safety issues \\
\hline \multirow[t]{4}{*}{ QUESTION 31} & \multicolumn{2}{|r|}{ Do managers/supervisors mean what they say and do what they say, in safety matters? } \\
\hline & $\square$ & Managers/Supervisors mean what they say and do what they say, in safety matters \\
\hline & $\square$ & Managers/Supervisors sometimes mean what they say and do what they say, in safety matters \\
\hline & $\square$ & Managers/Supervisors don't mean what they say or do what they say, in safety matters \\
\hline \multirow[t]{4}{*}{ QUESTION 32} & \multicolumn{2}{|r|}{ Do you feel like your health and safety matters here? } \\
\hline & $\square$ & I feel like my health and safety matters here \\
\hline & $\square$ & Mostly I feel like my health and safety matters here \\
\hline & $\square$ & I don't feel like my health and safety matters here \\
\hline \multirow[t]{4}{*}{ QUESTION 33} & \multicolumn{2}{|r|}{ Do you know who to ask about what to do, if you get injured at work? } \\
\hline & $\square$ & I know who to ask about what to do, if I get injured at work \\
\hline & $\square$ & I'm not sure who to talk to about injuries at work, but I think someone here could tell me \\
\hline & $\square$ & We don't have anyone to talk to about injuries at work \\
\hline \multirow[t]{4}{*}{ QUESTION 34} & \multicolumn{2}{|r|}{ Do you report injuries? } \\
\hline & $\square$ & We all have to report all injuries straight away \\
\hline & $\square$ & They only want us to notify serious injuries \\
\hline & $\square$ & They don't like us to report injuries \\
\hline \multirow[t]{4}{*}{ QUESTION 35} & \multicolumn{2}{|r|}{ Do you have information about injury management? } \\
\hline & $\square$ & Our notice board has a poster about injury management \\
\hline & $\square$ & I'm not sure if we have information about injury management or not \\
\hline & & There is no information about injury management on display \\
\hline \multirow[t]{4}{*}{ QUESTION 36} & \multicolumn{2}{|r|}{ Are injured workers offered suitable duties and a return to work program? } \\
\hline & $\square$ & All injured workers are offered suitable duties and a return to work plan is worked out for them \\
\hline & $\square$ & Most injured workers are helped to come back to work as soon as possible \\
\hline & $\square$ & We don't have suitable duties or a return to work program \\
\hline \multirow[t]{4}{*}{ QUESTION 37} & \multicolumn{2}{|r|}{ What do you think of your return to work program? } \\
\hline & $\square$ & Our return to work program helps get injured workers back to work whenever possible \\
\hline & $\square$ & We have a return to work program, but sometimes we don't use it or it doesn't work very well \\
\hline & $\square$ & We don't have a return to work program \\
\hline
\end{tabular}

